CLAUDIA DE QUEIROZ ACCIOLY-CONSTANTINIDES

\title{
AVALIAÇÃO DA PINEAL HUMANA IN VIVO PELA RESSONÂNCIA MAGNÉTICA FUNCIONAL
}

Tese apresentada ao Programa de Pós-Graduação em Fisiologia Humana do Instituto de Ciências Biomédicas da Universidade de São Paulo, para obtenção do Título de Doutor em Ciências. 
CLAUDIA DE QUEIROZ ACCIOLY-CONSTANTINIDES

\section{AVALIAÇÃO DA PINEAL HUMANA IN VIVO PELA RESSONÂNCIA MAGNÉTICA FUNCIONAL}

Tese apresentada ao Programa de PósGraduação em Fisiologia Humana do Instituto de Ciências Biomédicas da Universidade de São Paulo, para obtenção do Título de Doutor em Ciências.

Área de concentração: Fisiologia Humana

Orientador: Prof. Dr. José Cipolla Neto

Co-orientador: Prof. Dr. Edson Amaro Júnior

Versão original 
DADOS DE CATALOGAÇÃO NA PUBLICAÇÃO (CIP)

Serviço de Biblioteca e Informação Biomédica do Instituto de Ciências Biomédicas da Universidade de São Paulo

reprodução não autorizada pelo autor

Constantinides, Claudia de Queiroz Accioly.

Avaliação da pineal humana in vivo pela ressonância magnética funcional / Claudia de Queiroz Accioly Constantinides. -- São Paulo, 2015.

Orientador: Prof. Dr. José Cipolla Neto.

Tese (Doutorado) - Universidade de São Paulo. Instituto de Ciências Biomédicas. Departamento de Fisiologia e Biofísica. Área de concentração: Fisiologia Humana. Linha de pesquisa: Pineal humana.

Versão do título para o inglês: In vivo assessment of human pineal by functional magnetic resonance imaging.

1. Pineal humana 2. Ressonância magnética funcional 3. Ressonância magnética funcional do estado de repouso 4 . Luz azul quase monocromática 5 . Conectividade funcional 6 . Análise espectral I. Cipolla Neto, Prof. Dr. José II. Universidade de São Paulo. Instituto de Ciências Biomédicas. Programa de Pós-Graduação em Fisiologia Humana III. Título. 
Candidato(a): $\quad$ Claudia de Queiroz Accioly Constantinides.

Título da Tese: $\quad$ Avaliação da pineal humana in vivo pela ressonância magnética funcional.

Orientador(a): $\quad$ Prof. Dr. José Cipolla Neto.

A Comissão Julgadora dos trabalhos de Defesa da Tese de Doutorado, em sessão pública realizada a considerou
( ) Aprovado(a)
( ) Reprovado(a)

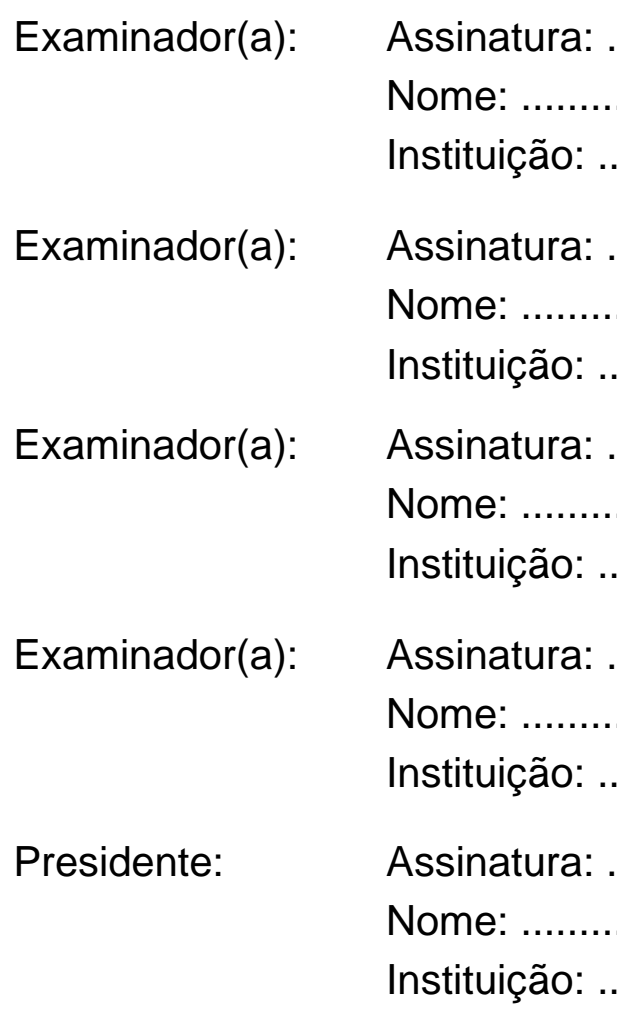




\section{PARECER 901/CEP}

Prezada Senhora,

Atendendo sua solicitação, a Comissão de Ética em Pesquisas com Seres Humanos do ICB, em sua $96^{\text {a }}$ reunião realizada em 16.06 .09 , analisou o projeto de sua responsabilidade intitulado: "Avaliação da pineal humana in vivo pela ressonância magnética funcional".

Informo a V.Sa. que, após análise e discussão, o referido projeto foi aprovado por esta Comissão.

Lembramos que cabe ao pesquisador elaborar e apresentar a este Comitê, relatórios anuais (parciais ou final), de acordo com a resolução 196/06 do Conselho Nacional da Saúde, item IX.2 letra c.

O primeiro relatório deverá ser encaminhado à Secretaria deste CEP em 16 de junho de 2010.

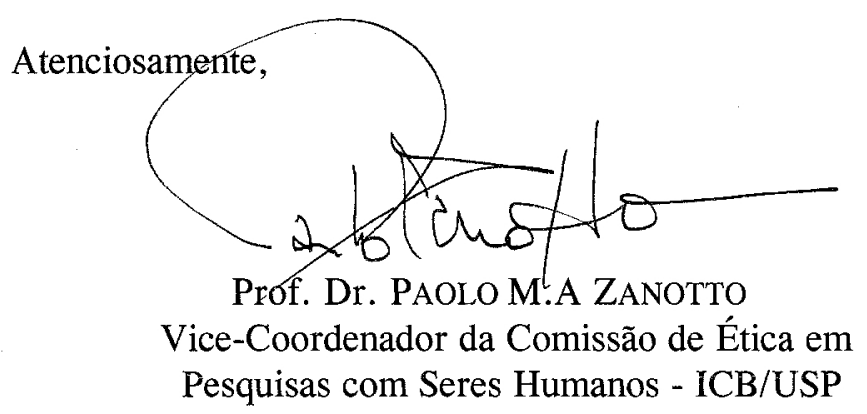

Ilma Sra.

Claudia DE QUEIROZ ACCIOLY CONSTANTINIDES

Departamento de Fisiologia e Biofisica

Instituto de Ciências Biomédicas -USP 


\section{Departamento de Radiologia}

MEDICINA

TSP
Av. Dr. Enéas de Carvalho Aguiar, $255-3^{\circ}$ andar - sala 2.11 CEP 05403-000

São Paulo - SP - Brasil

Fone/Fax: (11) 3069-7064

DR APROVAÇÃO 42/2009

\section{APROVAÇÃO}

O Conselho do Departamento de Radiologia aprovou em 14.07.2009 o projeto de pesquisa:

Título: Avaliação da pineal humana in vivo pela ressonância magnética funcional

Pesquisador responsável: Dr: José Cipolla Netto

Pesquisador executante: Claudia de Queiroz Accioly Constantinides

Responsável pelo acompanhamento InRad: Prof. Dr. Edson Amaro Júnior

São Paulo, 14 de outubro de 2009.

$$
\text { Rlheming. }
$$

Prof. Dr. Roger Chammas

Chefe do Departamento de Radiologia

FMUSP 
Dedica esta tese aa amada Nick, minha alma gêmea,

Aas meus pais e meus irmãas, cam quem aprendi sobre amar incondicional,

Aa Pedrinha e aa Dudu, minhas paixães! 


\section{AGRADECIMENTOS}

Ao Nick, marido querido, pelo suporte incondicional e amoroso, "na alegria e na tristeza", durante estes anos de muito estudo.

Aos meus pais, Marici e Paulo, e meus irmãos, Cynthia e Bibo, Thais e Jorge, Sonia e João e Adriano e Giuliana, que sempre me apoiaram e ajudaram a concretizar meus sonhos.

À minha família "adotiva”, Ellie, Paul, Lu, Felipe, Aline, Mat e Julia, meus filhos do coração, Barbara, Mary e Bruno, e sobrinhos queridos, Gabriel, Mariana, Paulinha, Pedrinho e Dudu, por serem fonte de alegria e coragem nos momentos de cansaço.

Ao meu orientador, professor José Cipolla Neto, que me ensinou e guiou meus passos de pesquisadora iniciante com muita paciência, sabedoria e carinho.

Ao meu co-orientador, professor Edson Amaro Junior, que me ensinou e guiou com paciência no aprendizado da ferramenta complexa, que é a Ressonância Magnética funcional.

A todos os amigos da clínica Nova Medicina Diagnóstica, especialmente à Cristina Rossi Longo, Claudio Rossi, Viviani Favacho Galvão, Guilherme Rossi, Letícia Borges da Silva, Joyce Bruschi Reis e Josefa L. Gonçalves, que se desdobraram em abrir caminhos para que eu pudesse conciliar este projeto com a vida profissional.

Aos amigos incansáveis, Antonio Cesário Junior, Daniel Medeiros, Fernanda G. Amaral, Ariane Turati, Marcio Andrade, Khallil T. Chaim e Bruno F. Pastorello, que perderam muitas horas de sono ao meu lado.

Ao amigo Balázs Vince Nagy, que foi "a luz no meio do túnel”.

Aos amigos Mariana P. Nucci da Silva, Paulo R. Bazán, Gilson Vieira, Raymundo M. de Azevedo Neto e João R. Sato, que muito me ajudaram e ensinaram.

À querida Lia Coelho, que, na sua generosidade, me emprestou uma centrífuga pelo "pequeno" período de 4 anos!

Aos amigos do laboratório de Neurobiologia do ICB I, Julieta H. Scialfa, Jessica A. da Silva, Caroline Mendes, Rosana Dantas, Daniella Buonfiglio, J. Sinésio da Silva Junior, que ajudaram de muitas maneiras na execução deste projeto.

Aos amigos Pedro Fernandes e Eduardo Braga, que possibilitaram e executaram as dosagens de melatonina plasmática.

À querida Maria da Graça Martin, que ajudou no desenho das máscaras da pineal. 
Aos amigos Wilson "Pavão" Ribeiro e Rodrigo Martins dos Santos, que devolveram os voluntários a seus lares, em segurança.

A todos os integrantes do LIM 44, com quem convivi e aprendi nos últimos tempos.

Ao secretário José Maria Rodrigues Junior, que é o anjo-da-guarda dos pósgraduandos do ICB I.

À Marcia M. Yamada Cunha e Adriana Bertaccini Rodrigues, pela ajuda carinhosa em todas as etapas administrativas deste projeto.

À equipe de enfermagem, que cuidou com tanto carinho e eficiência dos participantes.

A todos os voluntários que participaram da pesquisa, por amizade e por amor à ciência, doando seu tempo e "sangue" com tão boa vontade.

Às professoras e amigas queridas Maria Cristina Chammas e Claudia da Costa Leite, que me apoiaram e ajudaram a finalizar este projeto.

Ao CNPq, pela bolsa de doutorado concedida.

À FAPESP, pelo financiamento do projeto de pesquisa.

Enfim, a todos que de alguma forma participaram e ajudaram na execução deste trabalho! 
"Imagination is more important than knowledge. For knowledge is limited, whereas imagination embraces the entire world, stimulating progress, giving birth to evolution". 


\section{RESUMO}

ACCIOLY-CONSTANTINIDES, C. Q. Avaliação da pineal humana in vivo pela ressonância magnética funcional. 2015. 138 f. Tese (Doutorado em Fisiologia Humana) - Instituto de Ciências Biomédicas, Universidade de São Paulo, São Paulo, 2015.

Até o momento não há descrição de técnicas de neuroimagem capazes de mostrar a função da pineal humana in vivo e de maneira pouco invasiva. A ressonância magnética funcional (RMf) é o método mais utilizado para mapeamento cerebral humano e não envolve radiação ionizante ou uso de contrastes exógenos. Entretanto, a pineal é calcificada, relativamente pequena e próxima a vasos características que dificultam a aplicação da técnica. O presente estudo foi realizado com intuito de testar diferentes desenhos experimentais de RMf para investigar aspectos funcionais da pineal humana. Os participantes realizaram o exame de tomografia computadorizada do crânio (TC), para a avaliação qualitativa do grau de calcificação pineal. Foram coletadas imagens funcionais e amostras de sangue total antes, durante e após a apresentação de estímulo com luz azul quase monocromática em indivíduos saudáveis. Os dados da RMf foram analisados usando o pacote estatístico FMRIB Software Library (FSL - Oxford University). Os objetivos do estudo foram: 1) verificar se há modificação no sinal blood oxygenation level dependent (BOLD) da própria pineal em resposta à aplicação de estímulo luminoso; 2) verificar se a aplicação de estímulo luminoso determina alteração nas redes neurais cerebrais no estado de repouso; 3) verificar se há alteração da correlação entre o sinal BOLD proveniente da pineal e das demais regiões cerebrais antes e após a aplicação de estímulo luminoso (análise de conectividade funcional); 4) verificar se há alteração do poder na frequência do sinal BOLD na pineal em decorrência da aplicação de estímulo luminoso. Foram realizados 25 exames de RMf em 24 voluntários (9 homens) com idades variando de 22 a 50 anos. Todos os participantes que realizaram a TC $(\mathrm{N}=20)$ apresentaram calcificações pineais classificadas em pouco $(40 \%)$, moderada $(30 \%)$ e muito $(30 \%)$. A análise das imagens de RMf mostra: a) durante a aplicação do estímulo luminoso houve ativação do sistema visual cerebral, mas não foi observada resposta na pineal; b) foram observadas as seguintes redes neurais cerebrais do estado de repouso: visual medial e lateral, rede do estado padrão, sensoriomotora, auditiva, controle executivo e rede frontoparietal - entretanto, não observamos alteração nestas redes após a aplicação do estímulo luminoso; c) a pineal apresentou conectividade funcional com as áreas do tálamo bilateral, ínsula bilateral e sulco intra-parietal bilateral - porém não houve alteração na conectividade funcional da pineal após a aplicação da luz; d) a análise de poder espectral do sinal BOLD nas frequências entre 0,002 e 0,003 Hz mostrou tendência da condição luz ser maior do que a condição pré-luz na pineal, porém sem alcançar nível de significância estatística; não houve diferenças desta variável nas comparações entre as condições pré, durante e pós-aplicação da luz. Os resultados das coletas de amostras de sangue total evidenciaram redução imediata na concentração plasmática de melatonina em associação à apresentação do estímulo luminoso em $52,6 \%$ dos sujeitos, redução tardia em $15,8 \%$ dos sujeitos, redução na taxa de aumento da concentração plasmática de melatonina em 10,5\% dos sujeitos. Em $21,1 \%$ dos sujeitos não foi observada alteração evidente na curva esperada de melatonina em associação à apresentação do estímulo luminoso. As 
conclusões foram: a) a RMf não mostrou alterações no sinal BOLD da pineal em resposta à aplicação da luz; b) A RMf não mostrou diferenças nas áreas cerebrais entre as condições pré-estímulo, durante o estímulo ou pós-estímulo nas diferentes análises utilizadas, porém, observou-se tendência de maior poder espectral na pineal durante a aplicação do estímulo luminoso do que nas condições pré e pósestímulo; c) a conectividade funcional entre a pineal e áreas cerebrais. É possível que esta observação indique caminho mais promissor para estudos futuros.

Palavras-chave: Pineal humana. Ressonância magnética funcional. Ressonância magnética funcional no estado de repouso. Luz azul. FSL. Redes neurais do estado de repouso. Conectividade funcional. Análise espectral. 


\begin{abstract}
ACCIOLY-CONSTANTINIDES, C. Q. In vivo assessment of human pineal by functional magnetic resonance imaging. 2015. 138 p. Ph. D. Thesis (Human Physiology) - Instituto de Ciências Biomédicas, Universidade de São Paulo, São Paulo, 2015.
\end{abstract}

So far, there is no description of neuroimaging techniques capable of showing human pineal function in vivo, in a low invasive manner. The most used method of human brain mapping is the functional magnetic resonance imaging (fMRI), which does not involve ionizing radiation, nor the use of exogenous contrast agents. Nevertheless, the pineal is calcified, relatively small and near to blood vessels - and these characteristics make the technique application difficult. This study aimed to test different fMRI experimental designs in order to investigate the functional aspects of human pineal gland. All subjects were examined by a brain CT for the qualitative assessment of the pineal calcification level. Some functional images and total blood samples were collected before, during and after the presentation of an almost monochromatic blue light stimulation in healthy individuals. The fMRI data were analyzed with the FMRIB Software Library (FSL - Oxford University) statistical package. The purposes of the study were the following: 1) check for changes on the BOLD signal in the pineal itself, as a response to the application of luminous stimulation; 2) check if the application of luminous stimulation sets any changes to the resting-state neural networks; 3 ) check if there is any correlation between the BOLD signal in the pineal and the BOLD signal of the remaining brain areas, before and after the application of luminous stimulation (functional connectivity analysis); 4) check for changes of the power in the frequency of BOLD signal in the pineal due to the application of luminous stimulation. In total, $25 \mathrm{fMRI}$ exams were conducted with 24 volunteers ( 9 men) of 22 to 50 years of age. All subjects who were examined by a CT $(\mathrm{N}=20)$ have shown pineal calcifications classified according to the following levels: low (40\%), moderate (30\%) and high (30\%). The analysis of the fMR imaging has shown that: a) during the luminous stimulation application, the activation of the cerebral visual system was noted, but no response in the pineal could be observed; b) the following cerebral resting-state neural networks were noted: medial and lateral visual networks, default mode network, sensorimotor, auditory, executive control and frontoparietal networks - however, it was not possible to note changes on these networks after the luminous stimulation application; c) the pineal has presented functional connectivity with the bilateral thalamus, bilateral insula and bilateral intraparietal sulcus areas - nevertheless, there was no change to the pineal functional connectivity after light application; d) the spectral power analysis of the BOLD signal on the frequencies from 0.002 to $0.003 \mathrm{~Hz}$ has shown the trend of the light condition to be greater than the pre-light condition in the pineal, however, without reaching any levels of statistical significance; there were no changes of this variable on the comparisons between the pre-, during and post- conditions of light application. The results of the total blood samples collected have shown the immediate reduction of the melatonin plasmatic concentration associated to the presentation of the luminous stimulation in $52.6 \%$ of the individuals, a late reduction in $15.8 \%$ of the individuals, and a reduction of the increase rate of the melatonin plasmatic concentration in $10.5 \%$ of the individuals. No evident change related to the melatonin expected curve associated to the presentation of luminous stimulation was 
noted in $21.1 \%$ of the individuals. The conclusions were the following: a) the fMRI has not shown changes on the BOLD signal in the pineal in response to the light application; b) the fMRI has not shown differences on the cerebral changes between pre-stimulation conditions, during or after the stimulation on the multiple analysis used, however, it was possible to note the trend of greater spectral power in the pineal during the luminous stimulation application, compared to the pre- and poststimulation conditions; c) the functional connectivity between the pineal and the cerebral areas. It is possible that this observation points to the most promising way toward future studies.

Keywords: Human pineal. Functional magnetic resonance imaging. Resting-state functional magnetic resonance imaging. Blue light. FSL. Resting-state neural networks. Functional connectivity. Spectral analysis. 


\section{LISTA DE ILUSTRAÇÕES}

Figura 1 - Anatomia topográfica da pineal humana.

Figura 2 - Anatomia topográfica da pineal humana 29

Figura 3 - Estrutura química da melatonina 36

Figura 4 - Vias de síntese e degradação da melatonina 38

Figura 5 - Vias neurais hipotéticas relacionadas ao controle da síntese de melatonina pela pineal humana. 40

Figura 6 - Perfil circadiano das concentrações séricas de melatonina em humanos.

Figura 7 - Perfis circadianos das concentrações séricas de melatonina em humanos de idades variadas. 42

Figura 8 - Sensibilidade espectral dos cones, bastonetes e células ganglionares da retina intrinsecamente fotossensíveis.

Figura 9 - Resposta hemodinâmica a estímulo hipotético de curta duração 46

Figura 10 - Painel com 10 LEDs 55

Figura 11 - Painel de LEDs fixado no suporte de acrílico. .55

Figura 12 - Painel de LEDs .56

Figura 13 - Painel com 16 LEDs, sem lentes colimadoras adicionais. .57 
Figura 14 - Trigger.

Figura 15 - Sequência de apresentação do estímulo luminoso, implementada após a fase piloto. .58

Figura 16 - Distribuição do cronotipo na população estudada. .72

Figura 17 - Tomografias computadorizadas de crânio de 4 participantes 73

Figura 18 - Análise da correlação da idade dos participantes com o grau de calcificação da pineal. .75

Figura 19 - Áreas de ativação cerebral em resposta à aplicação do estímulo luminoso. .78

Figura 20 - Conectividade funcional da pineal no grupo rspre. .83

Figura 21 - Conectividade funcional da pineal no grupo rspos. .84

Figura 22 - Comparação do poder máximo do espectro do sinal BOLD na pineal, nas frequências entre 0,002 e 0,003 Hz na condição rspre>rspos. .85

Figura 23 - Comparação do poder máximo do espectro do sinal BOLD na pineal, nas frequências entre 0,002 e $0,003 \mathrm{~Hz}$ nas 3 condições (rspre, luz e rspos) .86

Figura 24 - Comparação do poder máximo do espectro do sinal BOLD na pineal, nas frequências entre 0,002 e 0,003 Hz na condição luz>rspos .86

Figura 25 - Comparação do poder máximo de oscilação do sinal BOLD na pineal, nas frequências entre 0,002 e $0,003 \mathrm{~Hz}$ na condição luz>rspre. 87

Figura 26 - Gráficos das curvas de melatonina plasmática. .89 


\section{LISTA DE TABELAS}

Tabela 1 - Resultados do questionário SRQ-20 ………...................................

Tabela 2 - Resultados do questionário sobre cronotipo....................................71

Tabela 3 - Avaliação qualitativa do grau de calcificação pineal............................74

Tabela 4 - Idade e gênero dos voluntários que foram submetidos ao exame de RMf. .75

Tabela 5 - Sujeitos incluídos e excluídos dos diferentes tipos de análise de RMf. .77

Tabela 6 - Grau de correlação dos componentes independentes da análise do grupo rspre (13 sujeitos incluídos) com as RSN do template, para $r>0,25 \ldots \ldots . . .79$

Tabela 7 - Grau de correlação dos componentes independentes da análise do grupo rspos (13 sujeitos incluídos) com as RSN do template, para $r>0,25 \ldots \ldots \ldots . .80$

Tabela 8 - Grau de correlação dos componentes independentes da análise do grupo rspre (5 sujeitos incluídos) com as RSN do template, para $r>0,25$. 81

Tabela 9 - Grau de correlação dos componentes independentes da análise do grupo rspos (5 sujeitos incluídos) com as RSN do template, para $r>0,25$. 82

Tabela 10 - Valores da dosagem de melatonina plasmática $(\mathrm{pg} / \mathrm{ml})$ nas amostras de sangue total. 


\section{LISTA DE ABREVIATURAS E SIGLAS}

BET - brain extraction tool

BOLD - sinal dependente do nível de oxigenação sanguínea, do inglês blood oxygenation level-dependent

DLMO - dim-light melatonin onset

DMN - rede neural do estado padrão, do inglês default mode network

EPI-GRE - imagem ecoplanar gradiente eco

FEAT - FMRI expert analysis tool

FLAIR - fluid attenuated inversion recovery, sequência para aquisição de imagem estrutural do encéfalo

FLIRT - FMRIB's linear registration tool

FSL - FMRIB Software Library

LED - light emitting diode

McFLIRT - motion correction using FMRIB's linear registration tool

MELODIC - multivariate exploratory linear optimized decomposition into independente components

$\mathrm{MNI}$ - Montreal Neurological Institute

MT1 - receptor 1 de membrana para melatonina

MT2 - receptor 2 de membrana para melatonina

MT3 - receptor 3 de membrana para melatonina

RM - ressonância magnética

RMf - ressonância magnética funcional

ROR/RZR - receptores nucleares órfãos relacionados ao ácido retinóico

$\mathrm{RSN}$ - redes neurais do estado de repouso, do inglês resting state networks

SRQ-20 - questionário para o rastreamento de transtornos mentais nãopsicóticos, do inglês self-reporting questionnaire

T1-3D FFE - fast field echo, sequência para aquisição de imagem estrutural do encéfalo

TC - tomografia computadorizada de crânio 
1 INTRODUÇÃO

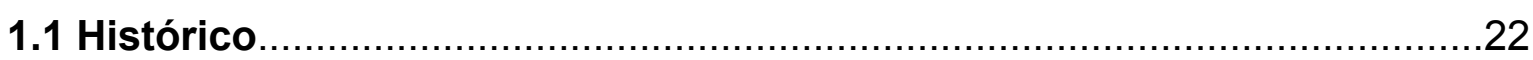

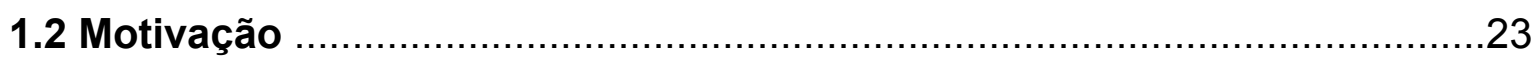

2 OBJETIVOS

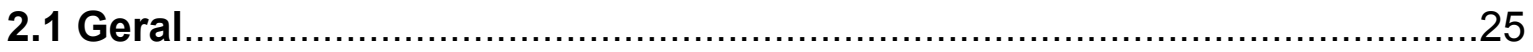

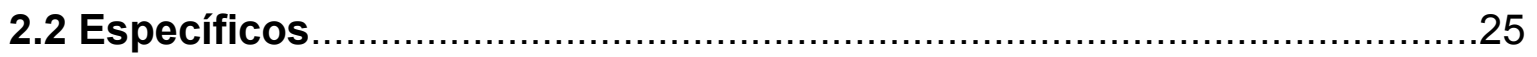

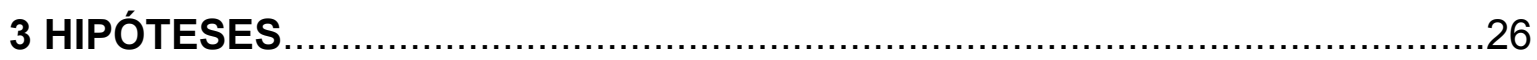

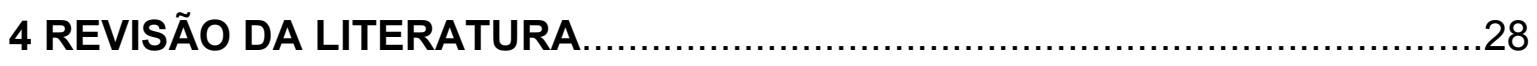

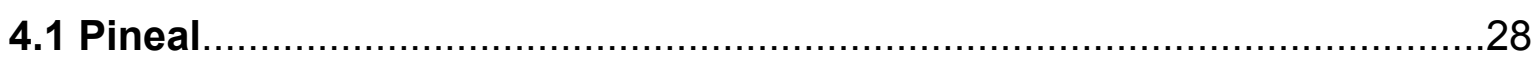

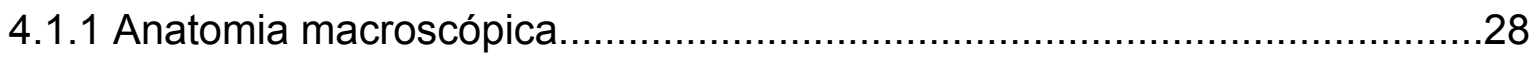

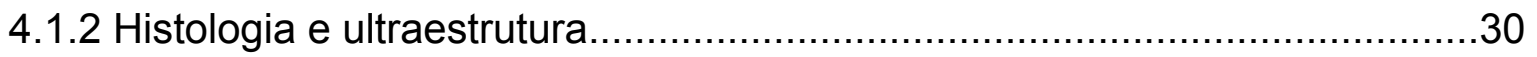

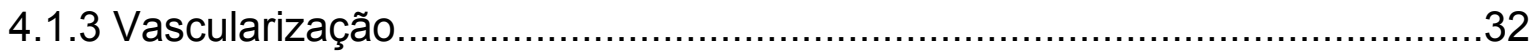

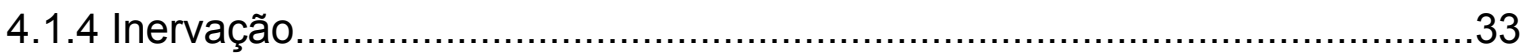

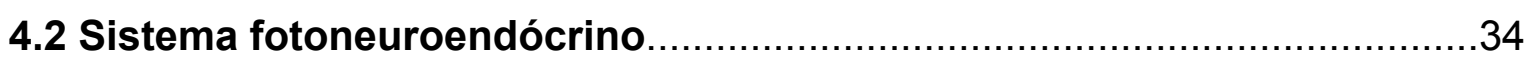

4.3 Melatonina.

4.4 Controle circadiano da síntese de melatonina ........................................

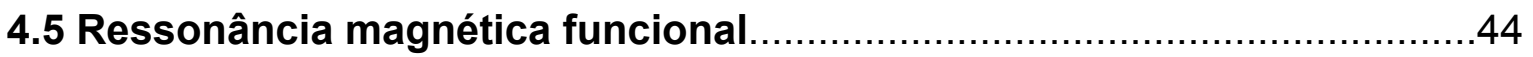

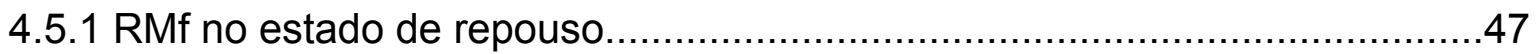

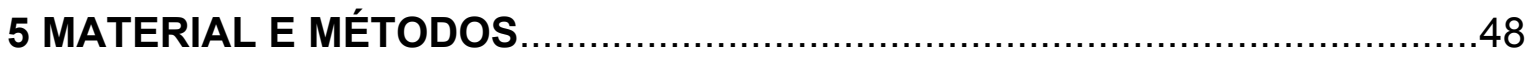

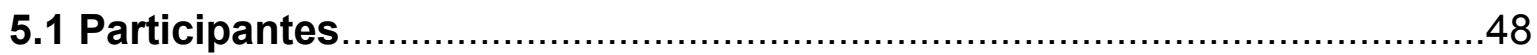

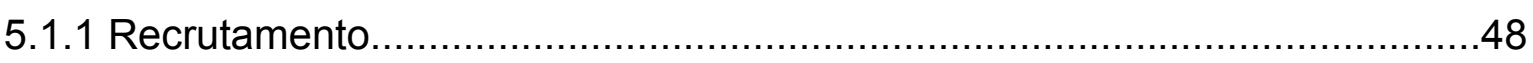

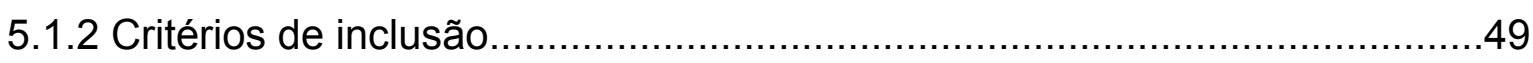

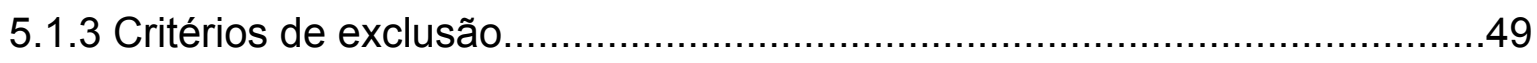

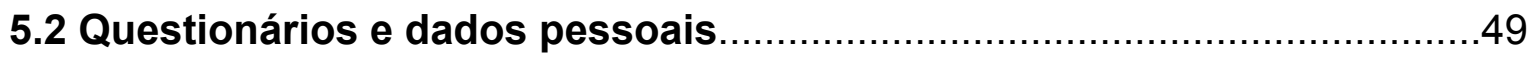

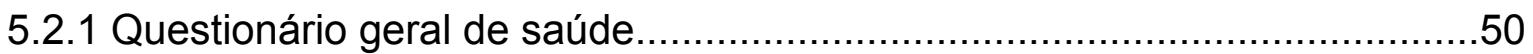

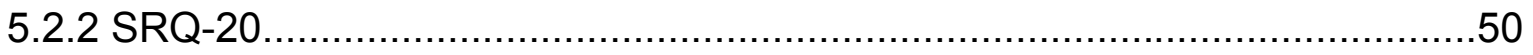

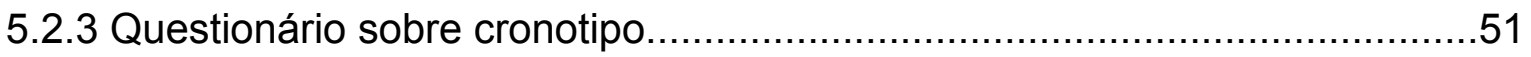

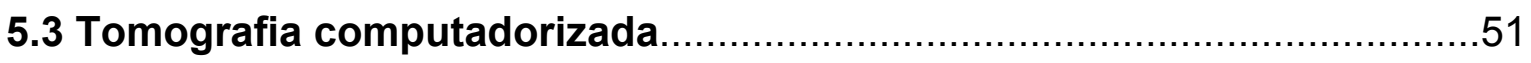

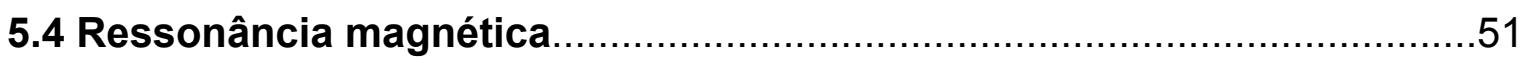

5.4.1 Sequências e parâmetros de aquisição de imagens por RM.......................52

5.4.1.1 Aquisição de imagens funcionais..........................................................52 


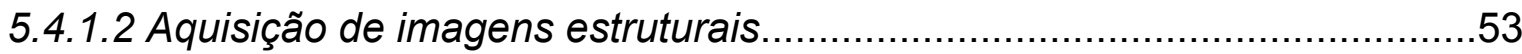

5.4.2 Estímulo e equipamentos utilizados....................................................53

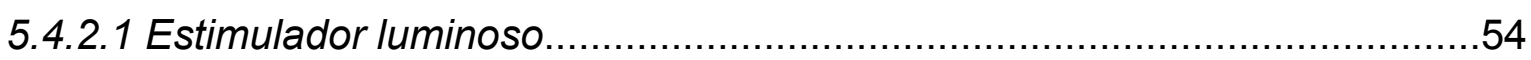

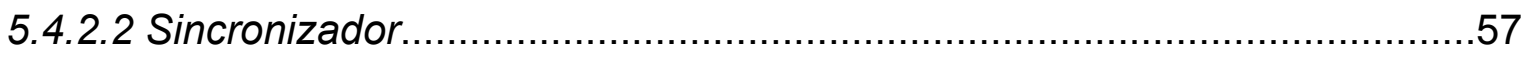

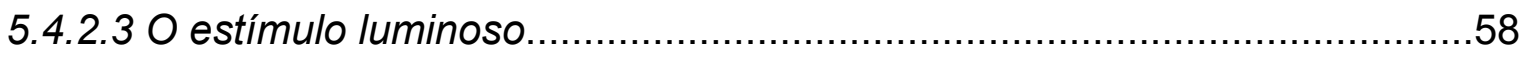

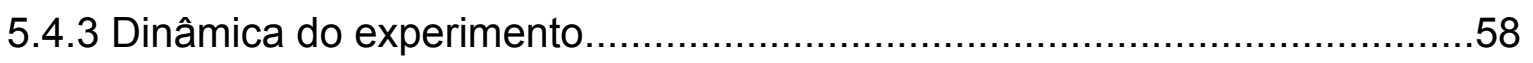

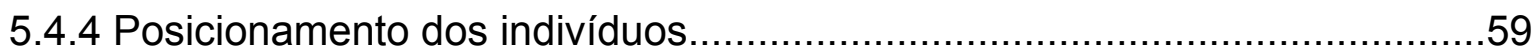

5.4.5 Realização do exame de RMf......................................................60

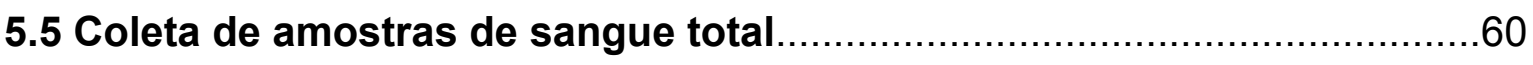

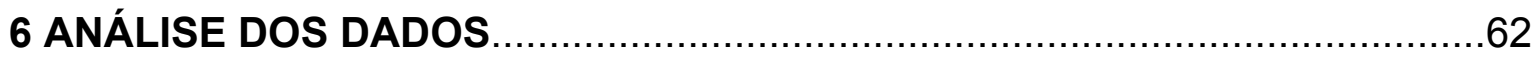

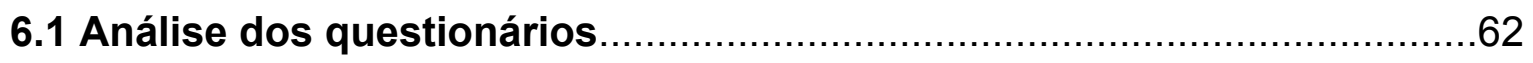

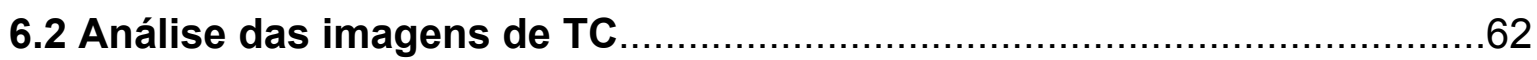

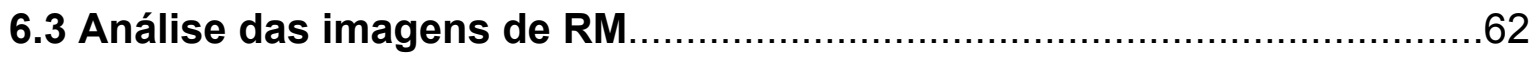

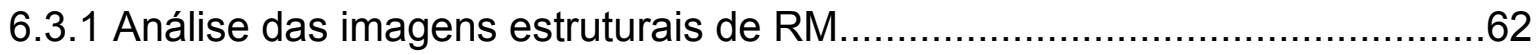

6.3.2 Análise das imagens funcionais de RM..............................................63

6.3.2.1 Análise das imagens de RMf para pesquisa de áreas de ativação...........63

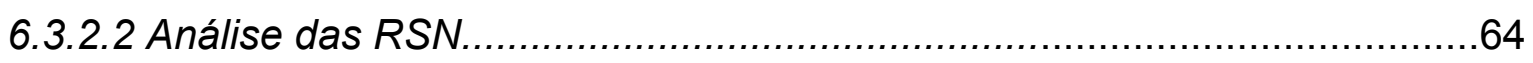

6.3.2.3 Análise da conectividade funcional da pineal......................................66

6.3.2.4 Análise espectral do sinal BOLD da pineal.......................................67

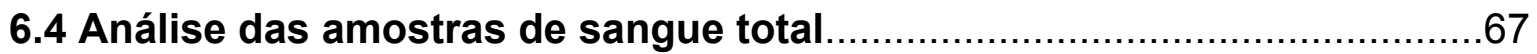

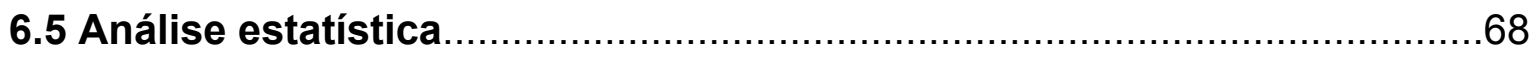

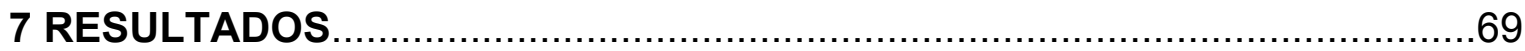

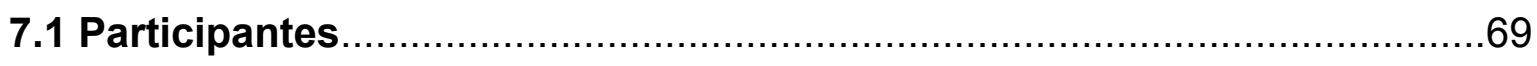

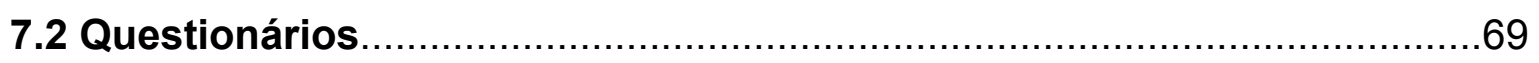

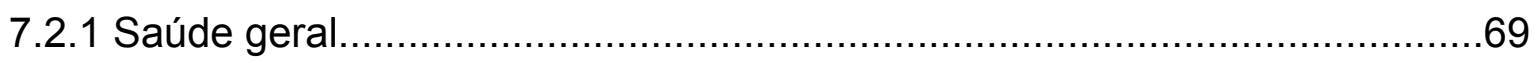

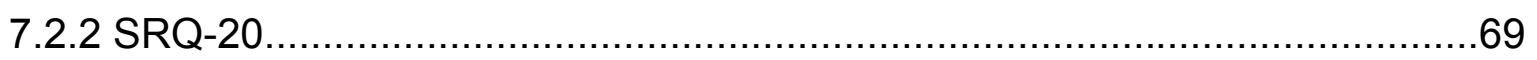

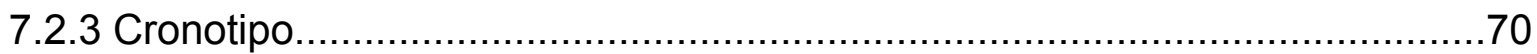

7.3 Tomografia computadorizada de crânio.......................................... 72

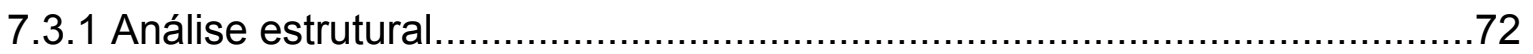

7.3.2 Análise do grau de calcificação pineal.............................................72

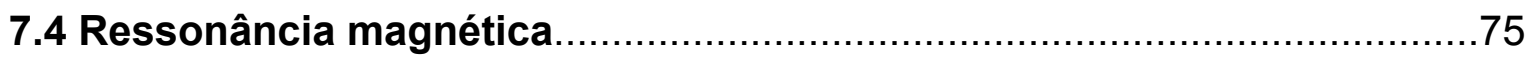

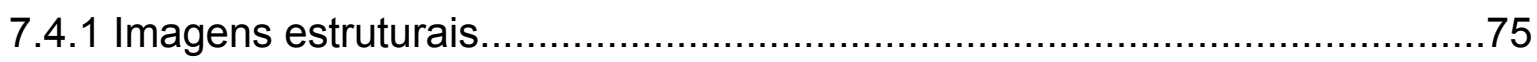

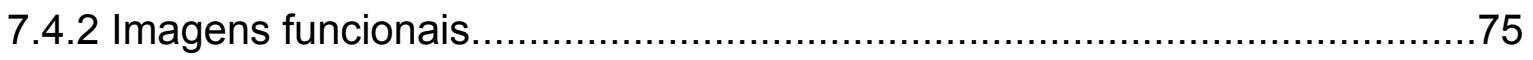


7.4.2.1 Análise da ativação de áreas encefálicas em resposta à luz. .77

7.4.2.2 Análise das RSN. 79

7.4.2.3 Análise da conectividade funcional da pineal......................................83

7.4.2.4 Análise espectral da pineal......................................................... 84

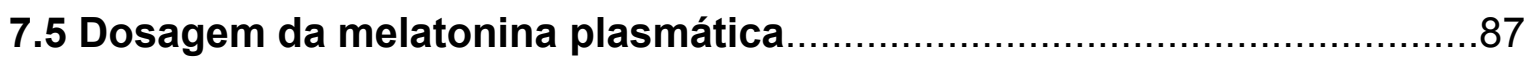

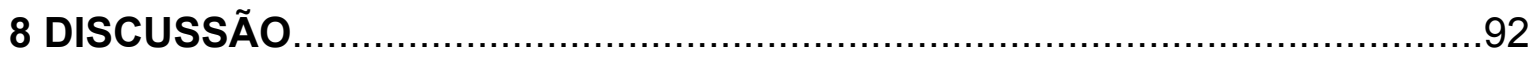

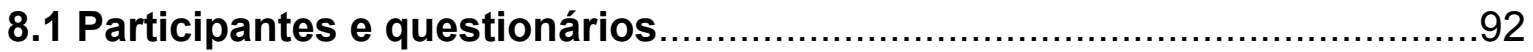

8.2 Tomografia computadorizada de crânio.................................................93

8.3 Ressonância magnética................................................................93

8.3.1 Análise da ativação de áreas encefálicas em resposta à luz......................94

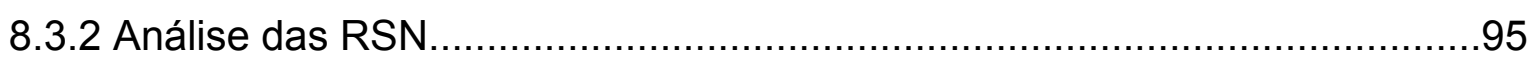

8.3.3 Análise da conectividade funcional da pineal......................................97

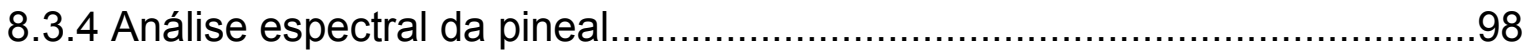

8.4 Dosagem da melatonina plasmática..................................................99

8.5 Limitações do estudo.............................................................................

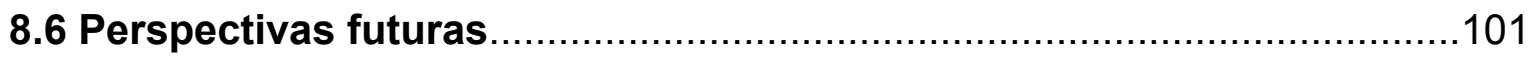

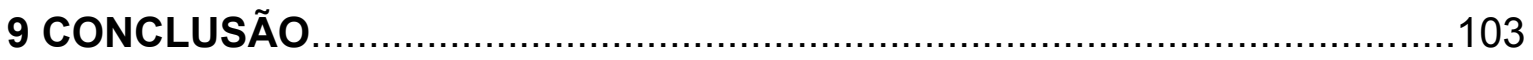

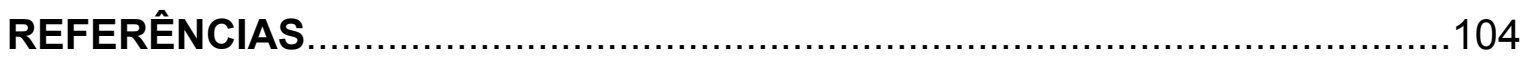

APÊNDICE A - Consentimento informado.............................................. 118

APÊNDICE B - Questionário geral de saúde...........................................122

APÊNDICE C - Exemplos de RSN da análise de grupo da condição rspre com 13 sujeitos

APÊNDICE D - Exemplos de RSN da análise de grupo da condição rspos com 13 sujeitos

APÊNDICE E - Exemplos de RSN da análise de grupo da condição rspre com 5 sujeitos

APÊNDICE F - Exemplos de RSN da análise de grupo da condição rspos com 5 sujeitos

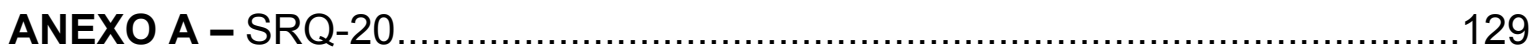

ANEXO B - Questionário sobre cronotipo............................................... 130

ANEXO C $-1^{\circ}$ Relatório sobre o estimulador luminoso....................................134

ANEXO D $-2^{\circ}$ Relatório sobre o estimulador luminoso..................................136

ANEXO E $-3^{\circ}$ Relatório sobre o estimulador luminoso................................137 
ANEXO F $-4^{\circ}$ Relatório sobre o estimulador luminoso. 


\section{INTRODUÇÃO}

\subsection{Histórico}

A pineal é conhecida como estrutura cerebral desde os séculos III e IV AC. Herophilos (325-280 AC) acreditava que a pineal funcionasse como válvula, regulando o fluxo do pneuma (spiritus, em Latim) do III para o IV ventrículo cerebral (KAPPERS, 1971, 1981). Sua localização foi descrita por Galeno (130-200 DC), que, discordando da opinião de Herophilos, acreditava tratar-se a pineal de uma glândula, apesar do desconhecimento da verdadeira função glandular na época. Galeno chamou-a de konareion (conarium, em Latim), devido ao seu formato em humanos, semelhante a pinha (conus ou pineale, em Latim). Posteriormente, o órgão foi denominado de glandula pinealis e pineal. Outros descreveram mais detalhadamente a pineal humana, como Berengario da Carpi (1470-1530) e Andreas Vesalius (1514-1564). Porém, as principais ideias sobre sua função, que perduraram por muitos séculos, foram elaboradas por René Descartes (1596-1650); segundo Descartes a alma estaria unida a todo o corpo, porém, exercendo suas funções mais particularmente na pineal do que em todas as outras partes do corpo (BINKLEY, 1988; DESCARTES, 2005; KAPPERS, 1971,1981).

Subsequentemente, o conhecimento sobre a pineal evoluiu lentamente. A pineal foi relacionada à função reprodutora em humanos no final do século XIX, quando foram descritos casos de puberdade precoce em um menino com pinealoma e de desenvolvimento prematuro da genitália externa em paciente com teratoma da região pineal. No início do século $X X$ a pineal foi reconhecida como glândula secretora e estrutura fotossensorial, sendo associada ao "terceiro olho" (órgão parietal ou frontal) dos vertebrados mais basais (BINKLEY, 1988).

$\mathrm{Na}$ década de 1950, o isolamento e a descrição da estrutura química da melatonina (substância ativa da pineal) por Lerner (1958) marcaram o início de nova fase na compreensão das funções do órgão pineal (LERNER; CASE; HEINZELMAN, 1959).

O desenvolvimento de técnicas laboratoriais permitiu a mensuração da melatonina nos fluidos e tecidos corporais, levando ao conhecimento sobre as variações circadianas dos seus níveis e sobre a redução da sua produção quando 
da exposição constante à luz (MACCHI; BRUCE, 2004; QUAY, 1964; ZEITZER et al., 2000).

Acredita-se que a principal função da pineal nos vertebrados em geral, seja a de transdutor fotoneuroendócrino (KORF; SCHOMERUS; STEHLE, 1998a). A pineal detecta direita ou indiretamente (dependendo da espécie) as condições de iluminação do ambiente, convertendo esta informação em mensagem neurohormonal, caracterizada pelo aumento da síntese noturna de melatonina (STEHLE et al., 2011). O aumento noturno da produção de melatonina persiste sob condições de escuro constante e é sincronizado ao meio ambiente pelo ciclo claro-escuro ambiental (LIU; BORJIGIN, 2005). A incidência de luz no período escuro do dia pode ter impacto significativo sobre o ritmo fisiológico da pineal, podendo ocasionar a supressão da síntese de melatonina (BORJIGIN; ZHANG; CALINESCU, 2012; LEWY et al., 1980; VOLLRATH et al., 1989).

Alterações nas concentrações noturnas de melatonina plasmática ou no ritmo circadiano têm sido encontradas em diversas doenças em humanos, como nas doenças do espectro do autismo, no diabetes, depressão e em doenças neoplásicas, entre outras (AMARAL et al., 2014; CIPOLLA-NETO et al., 2014; JASSER; BLASK; BRAINARD, 2006; KARASEK; WINCZYK, 2006; MACCHI; BRUCE, 2004; McMULLAN et al., 2013; REITER et al., 2014; TORDJMAN et al., 2013).

\subsection{Motivação}

O conhecimento do papel da pineal na fisiologia e fisiopatologia humanas é ainda limitado. Os métodos não invasivos disponíveis atualmente não permitem a análise do metabolismo da glândula, ou ainda não foram adequadamente investigados.

A pineal tem pequenas dimensões, está situada próxima a estruturas vasculares relativamente calibrosas e pode conter calcificações. Essas três características dificultam a produção de imagens de ressonância magnética (RM): a dimensão (relativamente pequena), artefato de pulsatilidade (vasos próximos) e de suscetibilidade magnética (calcificação). Outras técnicas como a tomografia por emissão de pósitrons (PET) e a tomografia computadorizada de emissão de fóton único (SPECT) podem ser utilizadas na avaliação do sistema nervoso central, porém, com menor resolução espacial e de contraste, o que as torna limitadas na 
avaliação da pineal (GHAEMI et al., 2001). Por outro lado, técnicas mais recentes (não convencionais) de RM utilizam princípios físicos que permitem a avaliação de vários parâmetros funcionais, tornando uma opção com grande flexibilidade de investigação.

Neste contexto, pretendemos analisar a capacidade da Ressonância Magnética funcional (método de imagem não invasivo) fornecer dados a respeito da avaliação funcional da pineal no ser humano vivo. 


\section{OBJETIVOS}

\subsection{Geral}

Testar técnicas de ressonância magnética funcional (RMf) para investigar aspectos funcionais da pineal.

\subsection{Específicos}

1) Verificar se há modificação no sinal relacionado ao nível de oxigenação sanguínea (blood oxygenation level-dependent, BOLD) da pineal em resposta à aplicação de estímulo luminoso.

2) Verificar se a aplicação de estímulo luminoso determina alteração nas redes neurais do estado de repouso.

3) Verificar se há alteração na correlação do sinal BOLD da pineal com as demais regiões cerebrais antes e após a aplicação de estímulo luminoso (análise de conectividade funcional).

4) Verificar se há alteração no poder máximo do espectro de frequência do sinal BOLD na pineal, na frequência do estímulo luminoso aplicado. 


\section{HIPÓTESES}

1) Acreditamos que haverá modificação no sinal BOLD da pineal em resposta à aplicação do estímulo luminoso. O sinal BOLD é baseado nas modificações na oxigenação, fluxo e volume sanguíneos decorrentes da ativação de área cerebral (HUETTEL; SONG; McCARTHY, 2008b). A pineal é estrutura neuroendócrina, composta predominantemente por pinealócitos, que são células da linhagem neuronal, consideradas como neurônios especializados (KORF; SCHOMERUS; STEHLE, 1998c). Baseado nestas informações, acreditamos que a pineal responderá de forma semelhante ao tecido neural em resposta à aplicação de estímulo adequado, apresentando ativação associada ao estímulo luminoso.

2) Acreditamos que haverá alteração nas redes neurais do estado de repouso em decorrência da aplicação do estímulo luminoso. Quando secretada, a melatonina é liberada na circulação sanguínea e no líquor, atingindo órgãos-alvo em todo o organismo, onde age por ação direta da molécula (função antioxidante) ou pela ligação a proteínas intracelulares, receptores de membrana plasmática ou receptores nucleares (ALLEGRA et al., 2003; BENITEZ-KING, 2006; HARDELAND et al., 2011; SMIRNOV, 2001; TRICOIRE et al., 2002; WITT-ENDERBY et al., 2003). Os receptores de melatonina já foram demonstrados em algumas áreas cerebrais de humanos (SMIRNOV, 2001; WITT-ENDERBY et al., 2003). Baseado nestas observações, acreditamos que a melatonina possa participar da modulação da atividade cerebral em humanos. Esperamos observar redução na concentração plasmática de melatonina associada à apresentação da luz (MACCHI; BRUCE, 2004; ZEITZER et al., 2000) e acreditamos que a variação na concentração de melatonina poderá modular a função cerebral no estado de repouso.

3) Acreditamos que haverá alteração na conectividade funcional da pineal com áreas cerebrais, em decorrência da aplicação do estímulo luminoso. A conectividade funcional pode ser definida como a sincronia de atividade neural entre áreas distintas. Acredita-se que áreas que exibem flutuações do sinal BOLD correlacionadas no tempo, sejam funcionalmente conectadas (ROSAZZA; MINATI, 2011). Sendo a pineal constituída predominantemente por pinealócitos, que são considerados neurônios modificados, acreditamos que este órgão apresente conectividade funcional com áreas cerebrais. 
4) Esperamos encontrar variações no poder máximo do espectro de frequência do sinal BOLD na pineal na frequência do estímulo luminoso, entre as condições pré-estímulo luminoso, durante o estímulo luminoso e pós-estímulo luminoso. $\mathrm{O}$ aumento no valor do poder máximo do espectro da região de interesse na frequência do estímulo apresentado, indica a ativação dessa região de interesse (MARCHINI; RIPLEY, 2000). Acreditamos que o poder máximo do espectro da pineal durante a aplicação do estímulo luminoso será maior do que antes ou após o mesmo, refletindo a ativação do órgão pineal naquele momento. Esperamos encontrar maior valor do poder máximo do espectro de força na fase pré-estímulo luminoso que na fase pós-estímulo, refletindo a menor ativação da pineal após cessado o estímulo luminoso. 


\section{REVISÃO DA LITERATURA}

\subsection{Pineal}

\subsubsection{Anatomia macroscópica}

O órgão ou complexo pineal ${ }^{1}$ está presente em todos os vertebrados já investigados, com poucas exceções, como alguns crocodilos (MANO; FUKADA, 2007; OKSCHE, 1965). Esse órgão, que tem origem embrionária a partir de evaginação no teto do diencéfalo, semelhante ao que ocorre com as vesículas ópticas, é componente do sistema fotoneuroendócrino e é responsável pela produção rítmica de melatonina em todos os vertebrados estudados (KORF, 1994; KORF; SCHOMERUS; STEHLE, 1998a).

Há grande variabilidade na forma e tamanho da pineal de mamíferos entre as diferentes espécies. Em humanos, a pineal é um pequeno órgão em forma de pinha, cujas dimensões médias, no adulto, variam de 5 a $9 \mathrm{~mm}$ de comprimento, 1 a $5 \mathrm{~mm}$ de largura e 3 a $5 \mathrm{~mm}$ de espessura, com peso médio de 100 a $180 \mathrm{mg}$ e pouca variabilidade relacionada ao gênero ou idade (ARENDT, 1995b).

A pineal situa-se junto ao limite posterior do terceiro ventrículo, ocupando a depressão entre os colículos superiores e o mesencéfalo (VOLLRATH, 1984). Em outras espécies de mamíferos, como em alguns roedores, a pineal pode apresentar aspecto alongado, contendo a parte superficial, localizada na superfície dorsal do cérebro e a parte profunda, situada junto ao tronco cerebral; as duas partes estão conectadas pela haste pineal, que, na maioria das espécies, contém pinealócitos (MOLLER; BAERES, 2002).

A pineal está relacionada anteriormente ao terceiro ventrículo, que se insinua na porção anterior da glândula formando o recesso pineal.

A pineal encontra-se imersa no espaço subaracnoide e está conectada ao cérebro através de pedúnculo que se divide anteriormente em duas lâminas, a superior e a inferior, correspondendo às comissuras habenular e posterior, respectivamente; essas lâminas estão separadas entre si pelo recesso pineal (VOLLRATH; OKSCHE, 1981a) (figuras 1 e 2).

1 Glândula pineal associada a um órgão acessório, como o órgão parapineal em lampreias e peixes, o órgão frontal em anfíbios e o olho parietal em répteis lacertílios. 
Figura 1 - Anatomia topográfica da pineal humana

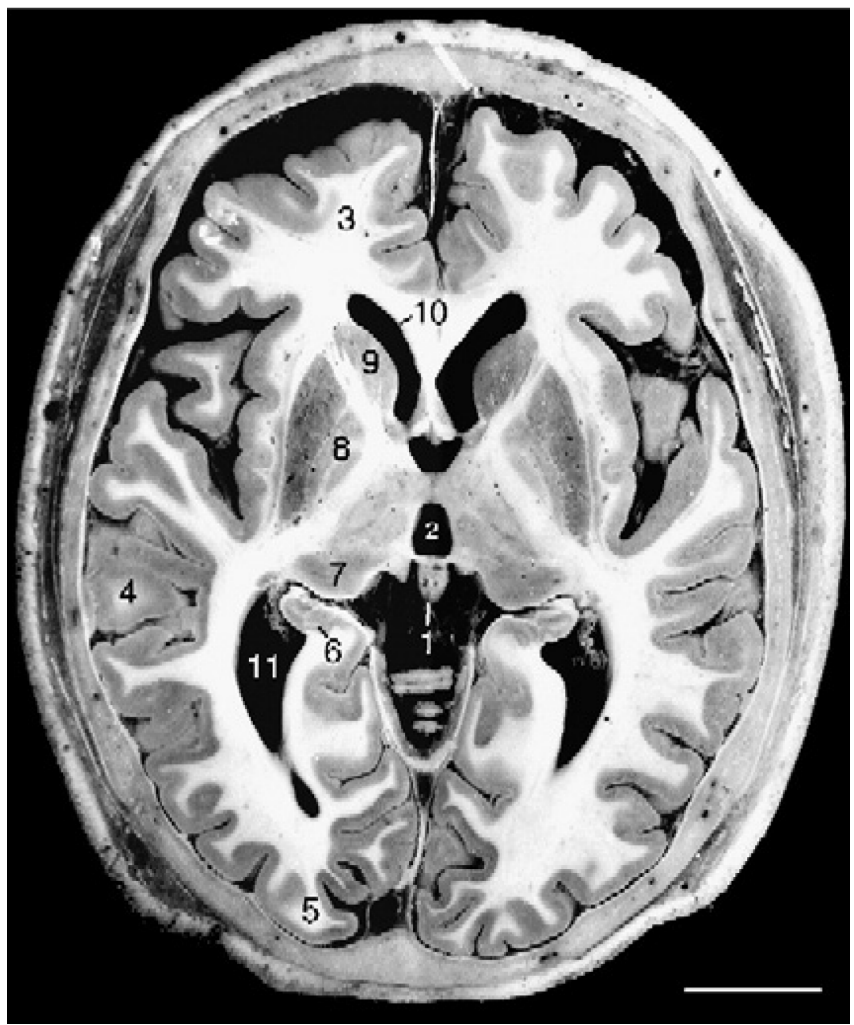

Corte axial (horizontal) da cabeça humana. 1 - pineal; 2 - III ventrículo; 3 - lobo frontal; 4 - lobo temporal; 5 lobo occipital; 6 - hipocampo; 7 - tálamo; 8 - núcleo lentiforme; 9 - núcleo caudado; 10 - corno anterior do ventrículo lateral; 11 - corno temporal do ventrículo lateral. (Barra no canto inferior direito $=2,3 \mathrm{~cm}$ ).

Fonte: Duvernoy e Risold (2007)

Figura 2 - Anatomia topográfica da pineal humana

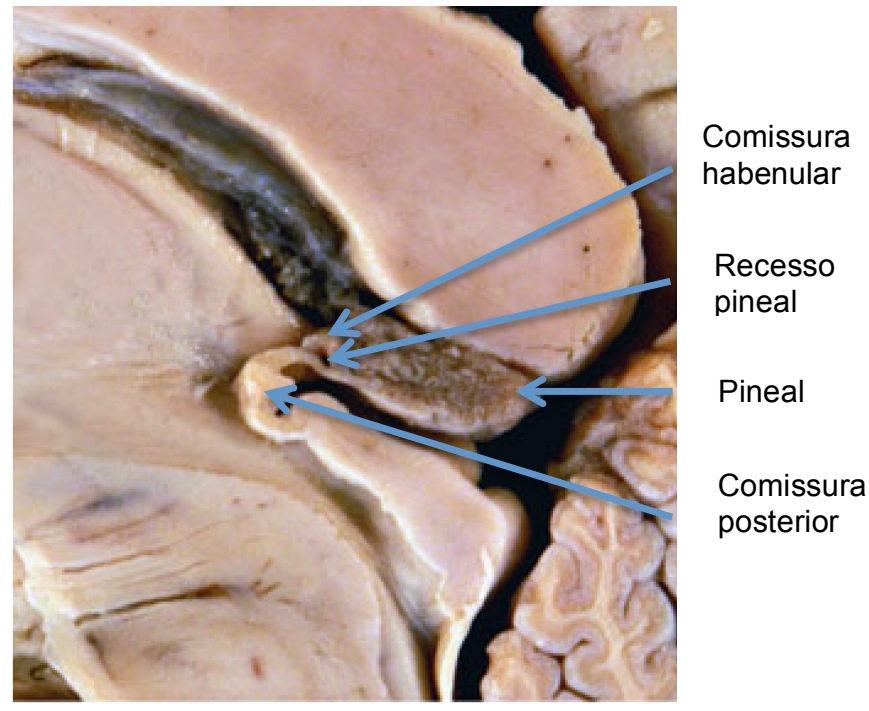

Corte sagital do cérebro humano não fixado, mostrando a localização topográfica da pineal. Fonte: Modificado de Stehle et al. (2011) 
A pineal, os núcleos habenulares e as comissuras posterior e habenular compõe o epitálamo, que, por sua vez, é parte do diencéfalo (VOLLRATH, 1984).

A presença de concreções calcáreas é característica da pineal do mamífero; as concreções calcáreas são compostas por material orgânico e inorgânico (VÍGH, 1998). Em humanos, o número de concreções aumenta com a idade, o que, no passado, foi considerado sinal da inativação gradual da pineal. Porém, a ocorrência das calcificações pineais não segue paralela com a redução da atividade metabólica ou da quantidade de células da pineal, podendo estar relacionada ao processo secretório do órgão (TAPP; HUXLEY, 1972; VÍGH, 1998; WURTMAN; AXELROD; BARCHAS, 1964).

\subsubsection{Histologia e ultraestrutura}

O parênquima da pineal é formado predominantemente por pinealócitos, que podem ser classificados em três tipos, de acordo com suas características estruturais e ultraestruturais: fotorreceptor pineal verdadeiro, fotorreceptor pineal modificado e pinealócito sensu stricto (KORF, 1994). Os três tipos de pinealócitos pertencem à linhagem das células neuronais e expressam vários marcadores típicos de neurônios e das células neuroendócrinas, como neurofilamentos, sinaptofisina e sinaptobrevina II, entre outros (KORF; SCHOMERUS; STEHLE, 1998c). Os três tipos de pinealócitos parecem ser relacionados, uma vez que pinealócitos de mamíferos, incluindo humanos, podem apresentar imunorreatividade para proteínas específicas de células fotorreceptoras e relacionadas à fotorrecepção, como opsina, antígeno $S$ e recoverina (FOSTER et al., 1989; KORF et al., 1985a, 1985b, 1992; KORF; SATO; OKSCHE, 1990; KORF; SCHOMERUS; STEHLE, 1998c; VÍGH; VÍGH-TEICHMANN, 1981). O significado funcional dessas proteínas nos pinealócitos sensu stricto ainda é desconhecido, pois essas células não contêm os grupos complementares 11-cis e todo-trans, envolvidos na fotorrecepção e fototransdução que ocorre nas células fotorreceptoras (SCHOMERUS; RUTH; KORF, 1994). Outra característica comum aos três tipos de pinealócitos é a presença de fitas sinápticas, que são estruturas especializadas, provavelmente relacionadas à liberação rápida e contínua de neurotransmissor; são encontradas em abundância em determinados órgãos sensoriais (especificamente nas células fotorreceptoras da retina e da pineal e nas células ciliadas da cóclea) e nos 
pinealócitos sensu stricto (GERSDORFF, 2001; KURUMADO; MORI, 1976; McNULTY; FOX, 1992; VOLLRATH, 1984).

Os fotorreceptores pineais verdadeiros e modificados estão presentes em vertebrados não-mamíferos e são diretamente fotossensíveis (KORF, 1994). Os pinealócitos fotorreceptores verdadeiros, que se assemelham morfologicamente aos fotorreceptores da retina, contêm segmentos interno e externo, o último apresentado numerosos discos formados pelas invaginações do plasmalema. O segmento externo está conectado ao interno por cílio do tipo $9 \times 2+0$ (KORF, 1994). Os processos basais dos pinealócitos fotorreceptores formam sinapses com neurônios intrapineais de $2^{\mathrm{a}}$ ordem, que, em conjunto com alguns processos longos desses fotorreceptores, semelhantes a axônios, projetam-se para áreas-alvo no sistema nervoso central, como formação reticular do tronco cerebral, área pré-tectal, núcleos habenulares, vários núcleos talâmicos e hipotalâmicos e região pré-óptica (EKSTRÖM, 1984, 1987; KORF, 1994; KORF; SCHOMERUS; STEHLE, 1998c). Os pinealócitos fotorreceptores modificados, também presentes em vertebrados nãomamíferos, podem apresentar o segmento externo em forma de cílio bulboso, sem as invaginações do plasmalema (KORF; SCHOMERUS; STEHLE, 1998c).

A pineal do mamífero é estrutura sólida formada predominantemente por pinealócitos, que são do tipo sensu stricto (não fotossensíveis), distribuídos em forma de cordões separados por capilares (VOLLRATH, 1984); esses pinealócitos produzem melatonina no período escuro do dia, independentemente do hábito noturno ou diurno de cada espécie (ACKERMANN et al., 2006; FALCÓN et al., 2009). Existem relatos na literatura sobre dois ou mais tipos de pinealócitos sensu stricto (CALVO; BOYA, 1984; ERLICH; APUZZO, 1985). Em algumas espécies de mamíferos, a distribuição celular não é homogênea, podendo-se observar regiões distintas, cortical e medular (ERLICH; APUZZO, 1985). Em algumas espécies de mamíferos não-primatas, certos pinealócitos estão diretamente expostos ao líquor (HEWING, 1978). O pinealócito do mamífero, em geral, não contém segmentos interno e externo, mas, pode apresentar cílio do tipo $9+0$, que se assemelha a um polo receptor (KORF, 1994). Há relatos escassos na literatura sobre pinealócitos de mamíferos com estruturas semelhantes a discos lamelares, sugestivos de segmentos externos, observados em algumas espécies (NADAKAVUKAREN; BUCANA, 1980; VÍGH; VÍGH-TEICHMANN, 1993). O parênquima pineal em mamíferos contém neurônios e células gliais, principalmente astrócitos, e está 
separado da camada de tecido conjuntivo adjacente (cápsula) e dos capilares pela lâmina basal (KORF; SCHOMERUS; STEHLE, 1998c; VOLLRATH; OKSCHE, 1981b). Alguns pinealócitos de mamíferos imunorreagentes ao antígeno $S$ podem enviar processos semelhantes a axônios para certas áreas cerebrais, como a região da comissura posterior, núcleos habenulares e área pré-tectal (KORF et al., 1986; KORF; SATO; OKSCHE, 1990). Pinealócitos de mamíferos podem apresentar prolongamentos semelhantes a terminações axônicas, que formam sinapses com neurônios intrapineais (VÍGH; VÍGH-TEICHMANN, 1988; VÍGH-TEICHMANN et al., 1991); em alguns mamíferos, os axônios destes neurônios unem-se às fibras das comissuras habenular e posterior (VÍGH; VÍGH-TEICHMANN, 1992).

A pineal humana é estrutura sólida, como nos demais mamíferos, porém muitas vezes apresenta cistos de tamanhos variados, que podem ser evidenciados em até $41 \%$ das autópsias (AL-HOLOU et al., 2011; HASEGAWA; OHTSUBO; MORI, 1987; TAPP; HUXLEY, 1972). Na pineal humana, o pinealócito sensu stricto encontra-se distribuído de maneira organizada, formando lóbulos que, muitas vezes, assemelham-se a folículos (KORF; SCHOMERUS; STEHLE, 1998b; MOLLER; BAERES, 2002; VOLLRATH; OKSCHE, 1981c). Os astrócitos, numerosos na pineal humana, formam extensa rede de fibras que, no adulto, envolvem quase todos os pinealócitos (ERLICH; APUZZO, 1985). As características estruturais dos pinealócitos em humanos são semelhantes às dos demais mamíferos, acima descritas, incluindo a presença eventual de cílios contendo estruturas semelhantes a discos lamelares, sugestivos de segmentos externos, observados por Hasegawa, A. et al., (1990). As fitas sinápticas são encontradas em abundância nos pinealócitos em humanos, porém suas funções em pinealócitos sensu stricto ainda requerem investigações (JOUVET et al., 1994; REUSS, 2010).

\subsubsection{Vascularização}

A pineal do mamífero apresenta acentuada vascularização. Segundo Goldman e Wurtman (1964), o fluxo sanguíneo na pineal do rato é de $4 \mathrm{ml} / \mathrm{min}$ por grama de tecido, igualando-se ao fluxo sanguíneo da neuro-hipófise e sendo superado, apenas, pelo fluxo sanguíneo do rim; não se sabe mais detalhes em humanos.

O suprimento sanguíneo principal da pineal humana é provido pela artéria pineal lateral, geralmente originada da artéria coroidea posteromedial, que é ramo da 
artéria cerebral posterior (KAHILOGULLARI et al., 2013; VOLLRATH; OKSCHE, 1981e). Outras artérias que podem irrigar a pineal, porém, encontradas mais raramente, são a artéria pineal medial, geralmente ramo da artéria coroidea posteromedial e a artéria pineal rostral, que se origina com mais frequência da circulação cerebral anterior do que da posterior (KAHILOGULLARI et al., 2013).

A drenagem venosa da pineal ocorre através da veia cerebral magna, que drena na porção anterior do seio reto (VOLLRATH; OKSCHE, 1981e).

\subsubsection{Inervação}

Dois sistemas têm sido considerados principais na inervação da pineal do mamífero: a inervação simpática e a inervação central.

A inervação simpática da pineal tem grande importância na regulação da biossíntese de melatonina. O neurotransmissor noradrenalina estimula a biossíntese de melatonina em todas as espécies estudadas de mamíferos (KORF; SCHOMERUS; STEHLE, 1998c).

Fibras simpáticas periféricas originadas nos gânglios cervicais superiores do sistema nervoso autônomo simpático, apresentam papel fundamental no controle da função da pineal (VOLLRATH; OKSCHE, 1981d). Essas fibras simpáticas formam os nervos conários direito e esquerdo, que correm junto ao contorno inferior da veia cerebral magna em direção ao polo posterior da pineal. Cada nervo conário faz parte de um feixe neurovascular em seu curso; porém, as fibras de cada nervo atingem e penetram na pineal independentemente dos vasos (VOLLRATH; OKSCHE, 1981d).

Em ratos, as fibras nervosas originadas nas células intrinsecamente fotossensíveis da retina dirigem-se para os núcleos supraquiasmáticos hipotalâmicos, que têm importante papel como marcapassos circadianos centrais (TSANG; BARCLAY; OSTER, 2014). Esses núcleos projetam-se para os núcleos paraventriculares hipotalâmicos e, então, para a coluna intermediolateral da medula torácica superior, onde têm origem as fibras simpáticas pré-ganglionares rumo aos gânglios cervicais superiores (MOLLER; BAERES, 2002; VOLLRATH, 1984).

Quanto à inervação central pinealopetal, as fibras nervosas que inervam a pineal de roedores têm origem nos núcleos habenulares mediais e laterais, núcleos paraventriculares hipotalâmicos, folheto intergeniculado do corpo geniculado lateral, 
área pré-tectal e núcleos da comissura posterior (KORF; SCHOMERUS; STEHLE, 1998c; MOLLER; BAERES, 2002).

Além destes sistemas citados, existem evidências que sugerem a inervação parassimpática na pineal de mamíferos, tais como, a presença de acetilcolinesterase e acetilcolinatransferase na pineal de várias espécies, além da demonstração de terminais nervosos com aspecto morfológico semelhante ao das terminações colinérgicas, que permanecem intactos após a lesão dos gânglios cervicais superiores (PHANSUWAN-PUJITO; MOLLER; GOVITRAPONG, 1999).

Em humanos, as vias neurais que ligam as fibras nervosas simpáticas com 0 sistema óptico ainda não foram totalmente esclarecidas. Porém, a necessidade da comunicação intacta entre a retina e o sistema nervoso central para a sincronização do ritmo circadiano com o ambiente, foi evidenciada por Lockley et al. (1997) e Skene et al. (1999) que, estudando indivíduos que apresentavam visão presente, indivíduos cegos e indivíduos que haviam sido submetidos à enucleação ocular bilateral, observaram que a maioria (77\%) dos sujeitos com visão presente apresentavam ritmos circadianos sincronizados ao meio ambiente, que a maioria (76\%) dos sujeitos cegos apresentavam ritmos circadianos anormais e que todos os indivíduos com enucleação bilateral apresentavam ritmo circadiano em livre-curso ${ }^{2}$ (SKENE; ARENDT, 2007).

A inervação central e parassimpática da pineal humana também não foram totalmente esclarecidas.

\subsection{Sistema fotoneuroendócrino}

O sistema fotoneuroendócrino, presente em vertebrados, é fundamental para a sincronização dos ritmos endógenos do organismo com os eventos rítmicos ambientais (KORF, 1994). Para que ocorra a sincronização o organismo deve ser capaz de detectar os sinalizadores ambientais (zeitgebers; por exemplo, a luz ambiental) através de estruturas receptoras, enviar estas informações ao oscilador endógeno e transmiti-las aos demais órgãos e estruturas corporais, por meio de efetores neuroendócrinos/neuronais. A melatonina é produzida ritmicamente pelo

\footnotetext{
2 Na ausência de ciclos ambientais, o ser vivo passa a expressar o ritmo de atividade com seu período natural, endógeno, diferente do período de 24 horas.
} 
órgão pineal durante a noite em todos os vertebrados estudados, exercendo o papel da mensagem neuroendócrina que sinaliza a parte escura do dia a todo o organismo (KORF, 1994; KORF; SCHOMERUS; STEHLE, 1998b, 1998c).

O sistema fotoneuroendócrino sofreu alterações durante a evolução filogenética (KORF, 1994; KORF; SCHOMERUS; STEHLE, 1998a, 1998c). Nos ciclostomados, répteis, anfíbios e alguns tipos de aves, os fotorreceptores que participam da regulação da biossíntese de melatonina localizam-se no próprio complexo pineal; nos mamíferos, esse controle é efetuado por fotorreceptores situados na retina, acreditando-se, atualmente, que a pineal desses vertebrados não seja capaz de detectar diretamente o estímulo luminoso. Quanto ao oscilador endógeno principal, há evidências de que esse elemento localiza-se no próprio complexo pineal em certos vertebrados não-mamíferos; nos mamíferos o oscilador endógeno localiza-se nos núcleos supraquiasmáticos hipotalâmicos (KORF, 1994; KORF; SCHOMERUS; STEHLE, 1998a, 1998c; TSANG; BARCLAY; OSTER, 2014).

Em humanos, como nos demais mamíferos, a pineal não é diretamente fotorreceptora; as células fotossensíveis que detectam a irradiância do ambiente localizam-se na retina (BERSON; DUNN; TAKAO, 2002) e o oscilador endógeno localiza-se nos núcleos supraquiasmáticos hipotalâmicos (HARPER et al., 2008).

\subsection{Melatonina}

A melatonina (N-acetil-5-metoxitriptamina) é uma indolamina ${ }^{3}$ (UCKO, 1992) que contém dois grupos funcionais, o metoxi, no carbono 5 e o acetil, ligado ao nitrogênio do grupo amina, que conferem propriedade anfifílica à molécula. Os carbonos 2 e 3 do anel pirrólico apresentam capacidade redutora, o que faz da melatonina um potente antioxidante (CIPOLLA-NETO; AFECHE, 2008) (figura 3).

${ }^{3}$ Amina heterocíclica com um anel benzeno fundido a um pirrol, o último, um heterociclo nitrogenado. 
Figura 3 - Estrutura química da melatonina

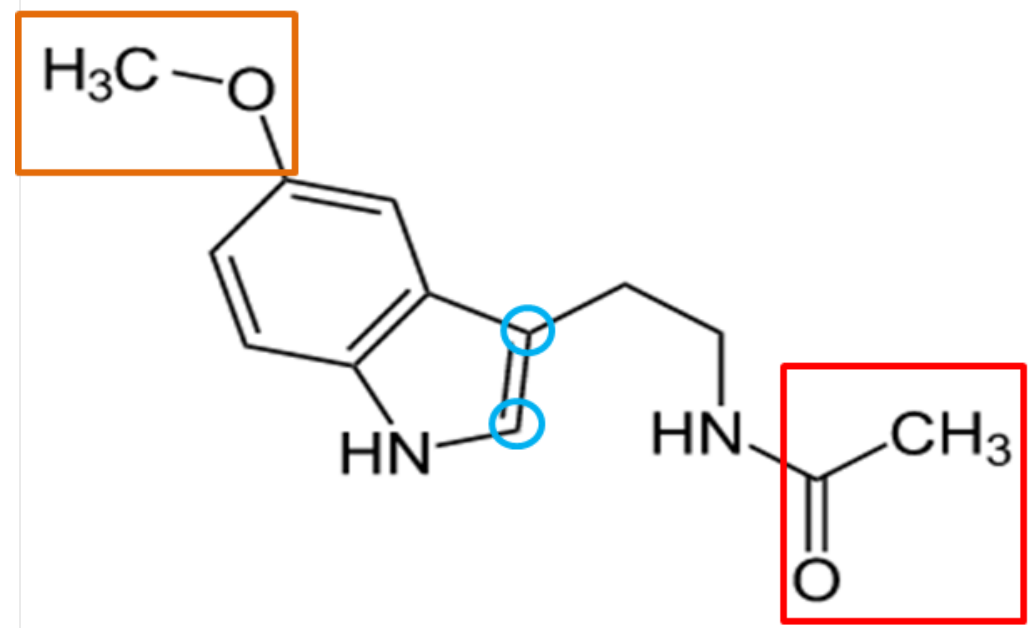

No quadrado laranja à esquerda está destacado o grupamento metoxi e em vermelho, à direita, o grupamento acetil. Os círculos azuis indicam os carbonos 2 e 3, constituintes do anel pirrólico da melatonina, que apresentam alto poder redutor.

Fonte: Turati (2013)

A melatonina é uma molécula que surgiu precocemente na cadeia evolutiva, sendo encontrada universalmente em organismos unicelulares, plantas, fungos e animais (HARDELAND; PANDI-PERUMAL; CARDINALI, 2006; PANDI-PERUMAL et al., 2006); é produzida a partir do triptofano, inclusive em organismos basais, como cianobactérias, algas e tripanossomos. A estrutura molecular da melatonina permaneceu inalterada em todos os seres vivos (ACUÑA-CASTROVIEJO et al., 2014).

A propriedade anfifílica permite que a melatonina possa se difundir tanto em meios hidrofóbicos como em meios hidrofílicos, sendo capaz de penetrar e ser encontrada em qualquer compartimento fluido do corpo, inclusive nos diferentes compartimentos e organelas intracelulares (COSTA; LOPES; LAMY-FREUND, 1995; SHIDA; CASTRUCCI; LAMY-FREUND, 1994).

A melatonina é produzida à noite pela pineal nos mamíferos, apesar de ser, também, sintetizada por outros órgãos e tecidos corporais, como a retina, células do trato gastrointestinal, plaquetas e células do sistema imunológico, entre outros exemplos (ACUÑA-CASTROVIEJO et al., 2014).

O ritmo de síntese de melatonina é gerado pelo marcapasso circadiano localizado nos núcleos supraquiasmáticos do hipotálamo (KLEIN; MOORE, 1979). A síntese de melatonina em alguns dos outros órgãos e tecidos que não a pineal, 
ocorre durante todo o período de 24 horas do dia, sem as flutuações rítmicas dia/noite; neste caso, a melatonina provavelmente exerce funções parácrinas e autócrinas (ACUÑA-CASTROVIEJO et al., 2014). É desconhecido o impacto da melatonina de origem extrapineal na concentração plasmática de melatonina; porém, em geral, a pinealectomia em mamíferos resulta na eliminação da detecção de melatonina no plasma (CARDINALI; PÉVET, 1998).

Os passos para a síntese de melatonina no pinealócito são os seguintes: captação do aminoácido essencial L-triptofano do sangue pela pineal, que, sob ação da triptofano-5-hidroxilase, gera 5-hidroxitriptofano; esse, pela ação de uma descarboxilase de aminoácidos aromáticos inespecífica, é convertido em serotonina, que é $\mathrm{N}$-acetilada pela $\mathrm{N}$-acetiltransferase, produzindo a $\mathrm{N}$-acetilserotonina; essa sofre ação da hidróxi-indol-O-metiltransferase, sendo convertida em melatonina (CARDINALI; PÉVET, 1998).

A melatonina não é armazenada na célula, portanto, uma vez sintetizada, é rapidamente liberada na corrente sanguínea por difusão passiva, devido à sua alta lipossolubilidade, podendo ser encontrada também em outros fluidos corporais, como o líquor e a saliva (CARDINALI; PÉVET, 1998; TRICOIRE et al., 2002; VÍGH; VÍGH-TEICHMANN, 1992).

A melatonina é metabolizada principalmente no fígado e, secundariamente, nos rins, sendo excretada na urina predominantemente na forma do metabólito 6sulfatoximelatonia (CARDINALI; PÉVET, 1998; KOPIN et al., 1960) (figura 4). 
Figura 4 - Vias de síntese e degradação da melatonina

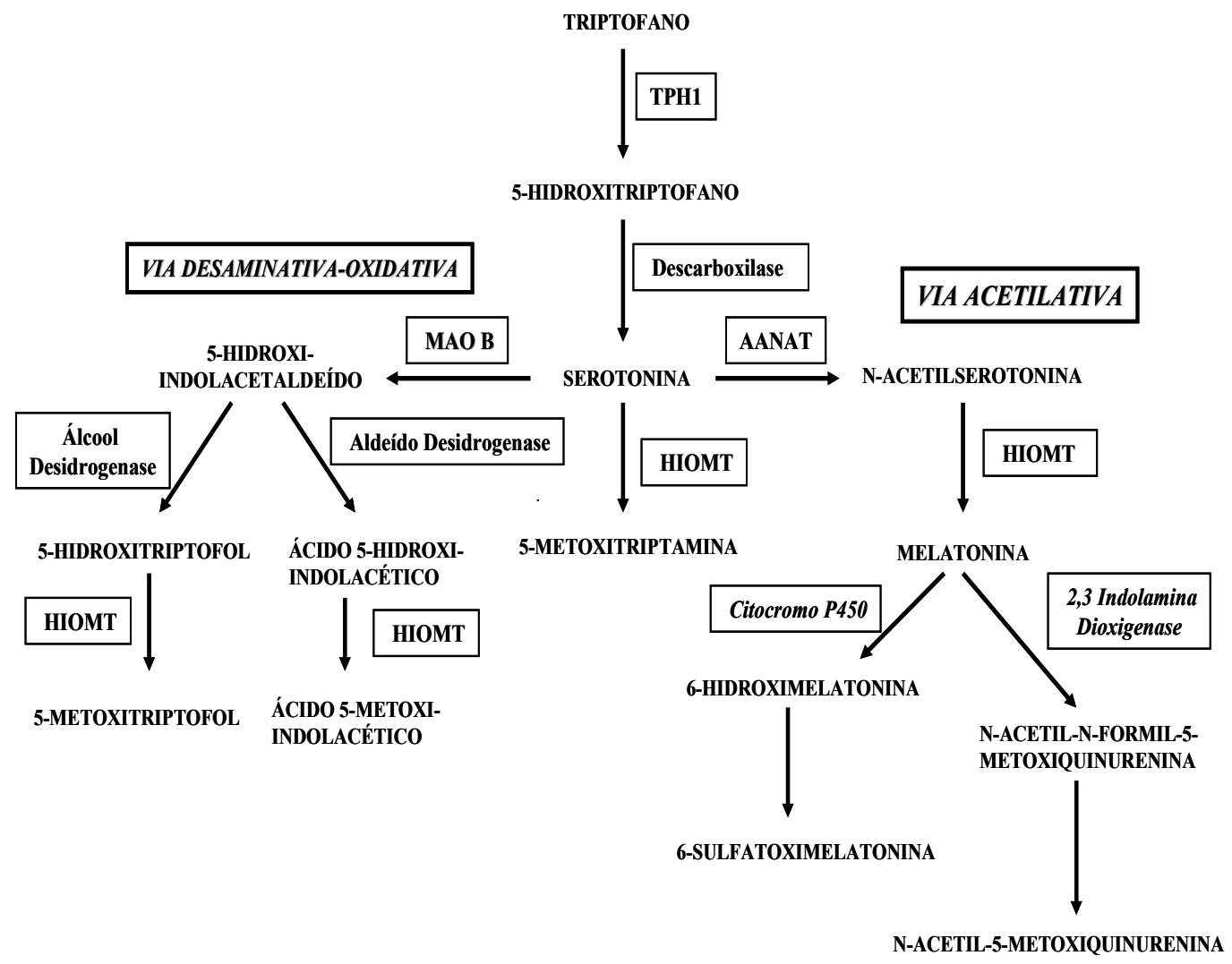

A figura representa as vias metabólicas de síntese e degradação da melatonina no órgão pineal. AANAT arilalquilamina $\mathrm{N}$-acetiltransferase; HIOMT - hidroxindol-oxi-metiltransferase; MAO B - monoamina oxidase; TPH1 - triptofano hidroxilase.

Fonte: Modificado de Cipolla-Neto e Afeche (2008)

Algumas ações da melatonina são bem estabelecidas, dentre as quais podemos destacar a cronobiótica, que, através da sua síntese rítmica pela pineal, auxilia na manutenção da ordenação temporal interna dos fenômenos fisiológicos e comportamentais, e a antioxidante, pela ação direta da molécula, neutralizando os radicais livres (ACUÑA-CASTROVIEJO et al., 2014; HARDELAND; PANDIPERUMAL; CARDINALI, 2006).

Existem evidências de que a melatonina participa de muitas funções bioquímicas e fisiológicas, como controle da temperatura corporal, da pressão sanguínea e da frequência cardíaca, sono, reprodução e modulação do sistema imunológico, entre outras (MACCHI; BRUCE, 2004).

As ações da melatonina provavelmente ocorrem através de quatro mecanismos principais, que foram descritos em diferentes espécies de mamíferos: 
a) ligação da melatonina a proteínas intracelulares, como a calmodulina (BENITEZ-KING; ANTON-TAY, 1993; BENITEZ-KING, 2006); é possível que uma das ações da melatonina, o efeito antiproliferativo em células do câncer de mama, seja parcialmente mediada pela sua ligação com a calmodulina (SANCHEZ-BARCELO et al., 2005);

b) efeitos antioxidantes (ALLEGRA et al., 2003); os efeitos antioxidantes da melatonina têm sidos observados em diversas condições mórbidas associadas às espécies reativas, como, por exemplo, situações de isquemia/reperfusão, inflamação, radiação ionizante e toxinas mitocondriais (BONNEFONT-ROUSSELOT; COLLIN, 2010);

C) ligação a receptores nucleares (SMIRNOV, 2001); os efeitos imunomodulatórios são, em parte, mediados por este mecanismo (CALVO; GONZÁLEZ-YANES; MALDONADO, 2013);

d) ligação a receptores da membrana plasmática (WITT-ENDERBY et al., 2003).

Os receptores nucleares da melatonina pertencem à subfamília de receptores órfãos ROR/RZR e têm expressão em vários órgãos e tecidos de mamíferos, como o cérebro, a retina e células do sistema imunológico (SMIRNOV, 2001).

Os receptores de membrana plasmática, $\mathrm{MT}_{1}$ e $\mathrm{MT}_{2}$, são receptores de alta afinidade da melatonina, ligados à proteína $G$ (DUBOCOVICH, 1995) e podem ser encontrados em diferentes órgãos e tecidos em mamíferos, incluindo o encéfalo (EKMEKCIOGLU, 2006). Além dos receptores de alta afinidade, há o $\mathrm{MT}_{3}$, pertencente à família das quinona-redutases, que possui menor afinidade pela melatonina que os receptores $\mathrm{MT}_{1}$ e $\mathrm{MT}_{2}$; o $\mathrm{MT}_{3}$ é encontrado no cérebro e tecidos periféricos do hamster (PAUL et al., 1999).

Entre os receptores de melatonina citados, $\mathrm{MT}_{1}$ e $\mathrm{MT}_{2}$ foram os mais estudados em humanos até o momento. Uz et al. (2005) demonstraram a presença de receptores $\mathrm{MT}_{1}$ no sistema nervoso central humano em populações celulares distintas do córtex cerebelar e em estruturas que fazem parte do sistema dopaminérgico (área 10 de Brodmann, putamen, núcleo caudado, núcleo accumbens, substância negra, amígdala e hipocampo). Al-Ghoul, Herman e Dubocovich (1998) e Savaskan et al. (2005) evidenciaram a presença do receptor $\mathrm{MT}_{2}$ no hipocampo e córtex cerebelar humanos. Weaver e Reppert (1996) demonstraram a expressão gênica do receptor $\mathrm{MT}_{1}$ no núcleo supraquiasmático 
humano. Wu et al. (2006) demonstraram a presença de receptores $M_{1}$ no hipotálamo e hipófise humanos.

\subsection{Controle circadiano da síntese de melatonina}

A síntese de melatonina é controlada indiretamente pelas condições de iluminação do ambiente. Em mamíferos não-humanos, informações fotossensoriais chegam até a pineal por via que tem início nas células ganglionares intrinsecamente fotossensíveis da retina, atingindo os núcleos supraquiasmáticos hipotalâmicos através dos tratos retino-hipotalâmicos; esses enviam projeções para os núcleos paraventriculares hipotalâmicos, coluna intermediolateral da medula espinal torácica, gânglios cervicais superiores do sistema nervoso simpático, nervos carotídeos internos e, finalmente, nervos conários, que se estendem até a pineal (MOORE, 1996) (figura 5). Essas vias não foram totalmente esclarecidas em humanos, conforme relatado anteriormente.

Figura 5 - Vias neurais hipotéticas relacionadas ao controle da síntese de melatonina pela pineal humana

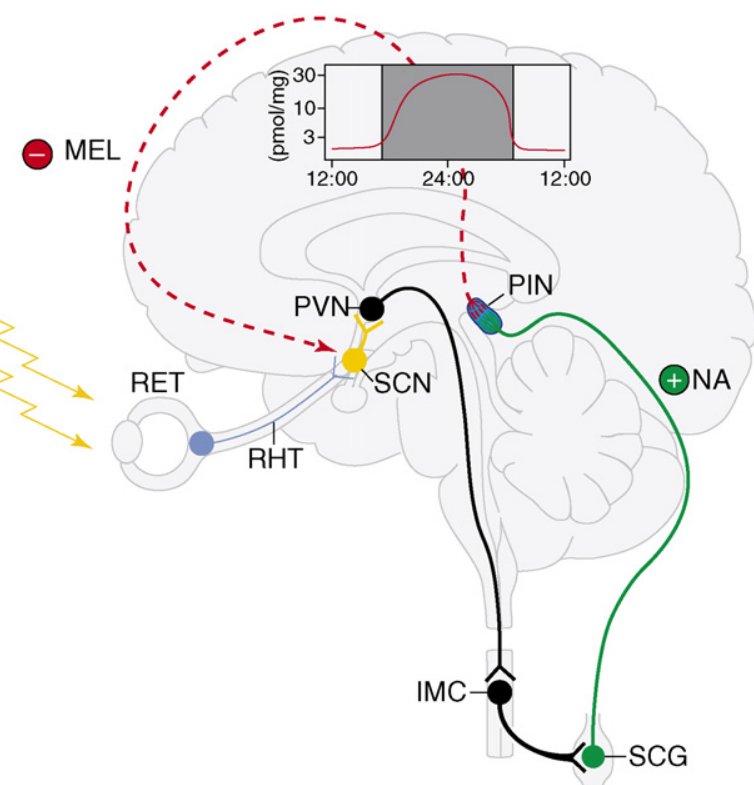

O gráfico mostra a oscilação dos níveis de melatonina na pineal humana (pmol por mg de proteína) em relação ao horário do dia (área cinza, noite; 12:00, meio-dia; 24:00, meia-noite). Abreviações: IMC, coluna intermediolateral da medula espinal; MEL, melatonina; NA, noradrenalina; PIN, pineal; PVN, núcleo paraventricular hipotalâmico; RET, retina; RHT trato retino-hipotalâmico; SCG, gânglio cervical superior; NSQ, núcleo supraquiasmático.

Fonte: Maronde e Stehle (2007) 
As fibras simpáticas noradrenérgicas dos nervos conários que atingem a pineal têm papel fundamental no controle da síntese de melatonina. A noradrenalina estimula a síntese noturna de melatonina pela ação nos receptores $\beta$-adrenérgicos no pinealócito, potencializada pela ação nos receptores $\alpha$-adrenérgicos, ativando a adenilatociclase, com aumento dos níveis de AMPc, que estimula a atividade da Nacetiltransferase e a síntese de melatonina (ARENDT, 1995a; KARASEK; WINCZYK, 2006).

Durante o dia as concentrações de melatonina no plasma humano são baixas, ocorrendo aumento significativo à noite. A concentração plasmática de melatonina começa a aumentar entre $21 \mathrm{~h}$ e $22 \mathrm{~h}$, atinge o máximo entre $2 \mathrm{~h}$ e $4 \mathrm{~h}$ e retorna aos níveis basais entre $6 \mathrm{~h}$ e $7 \mathrm{~h}$ (KARASEK; WINCZYK, 2006) (figura 6).

Figura 6 - Perfil circadiano das concentrações séricas de melatonina em humanos

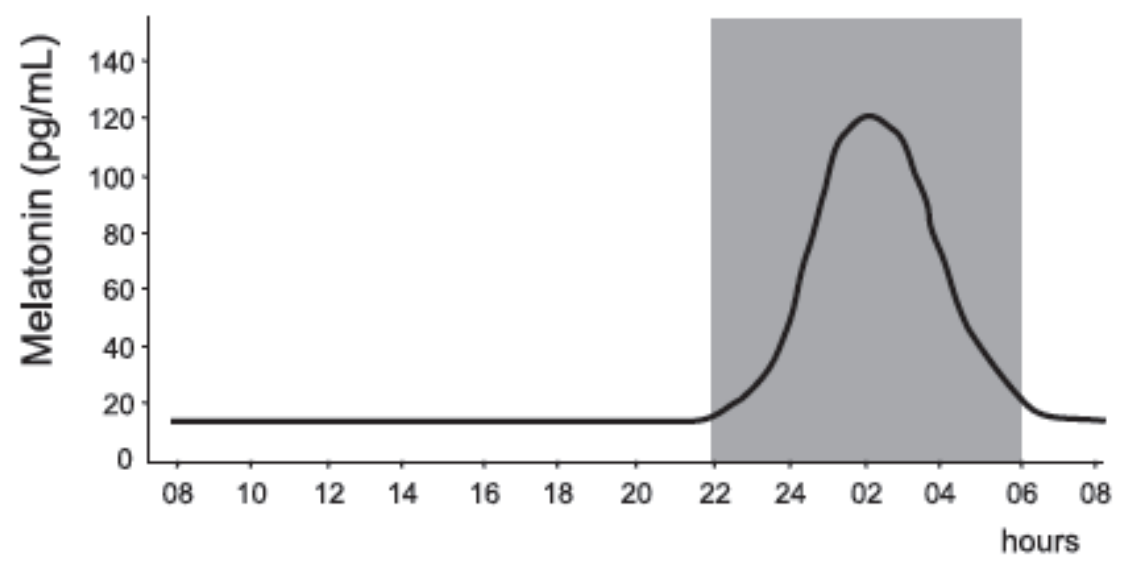

Área cinza: período escuro do dia hours = horário do dia

Fonte: Karasek e Winczyk (2006)

A amplitude da secreção noturna de melatonina é, provavelmente, geneticamente determinada e apresenta grande variabilidade interindividual (BERGIANNAKI, et al., 1995). Entretanto, Selmaoui e Touitou (2003) demonstraram que o perfil circadiano de melatonina é fortemente reprodutível no mesmo indivíduo, através de estudo que avaliou esse perfil durante período de 6 semanas.

A secreção rítmica de melatonina tem início no ser humano entre a $6^{\mathrm{a}}$ e $8^{\mathrm{a}}$ semanas de vida após o nascimento, estando bem estabelecida entre 21 e 24 semanas de vida. A amplitude do pico noturno de melatonina atinge os maiores níveis entre $\circ 4^{\circ}$ e $7^{\circ}$ anos de vida. No adulto jovem ocorre a redução da 
concentração noturna máxima de melatonina, que permanece estável até 35-40 anos de idade; após este período, há a redução gradual e progressiva dos níveis plasmáticos noturnos de melatonina (KARASEK; WINCZYK, 2006) (figura 7).

Figura 7 - Perfis circadianos das concentrações séricas de melatonina em humanos de idades variadas

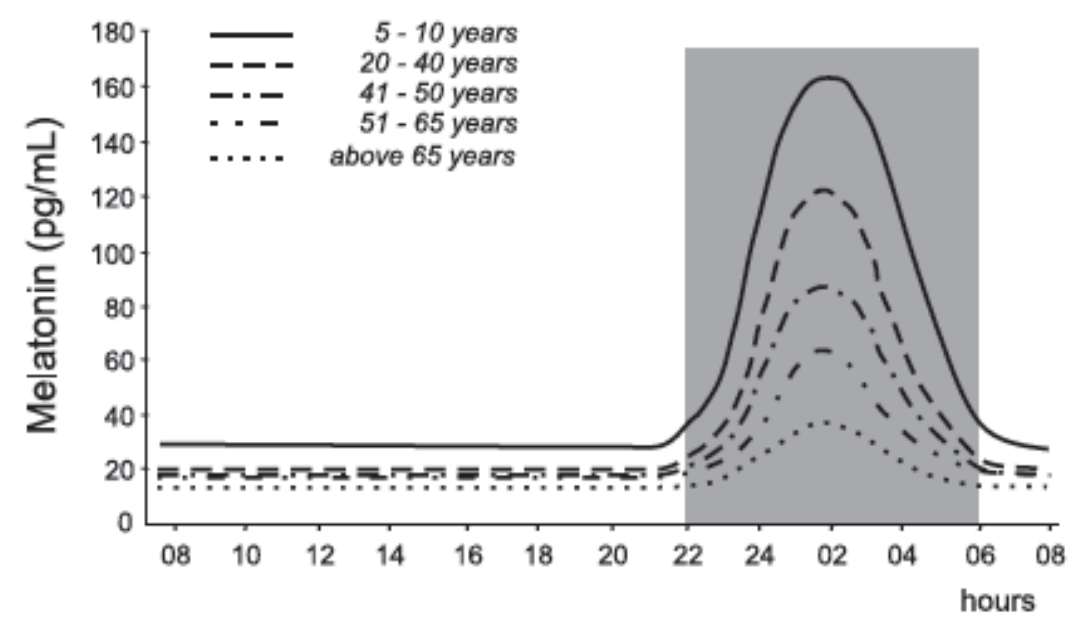

Área cinza = período escuro do dia

hours = horário do dia

Fonte: Karasek e Winczyk (2006)

A síntese de melatonina é rapidamente suprimida no período escuro do dia pela exposição aguda à luz de intensidade e duração suficientes (LEWY et al., 1980; McINTYRE et al., 1989; VOLLRATH et al., 1989), apesar da grande variabilidade na sensibilidade humana à luz entre os indivíduos, que pode ser determinada por fatores diversos, como fatores genéticos, fatores ligados ao envelhecimento ocular geneticamente ou fatores ambiente (CHELLAPPA et al., 2014; HIGUCHI et al., 2005; TURNER; MAINSTER, 2008). No passado, acreditava-se que somente intensidades relativamente altas de luz seriam determinantes da supressão da síntese de melatonina; porém, níveis baixos de iluminação, tais como aqueles encontrados em residências, também podem suprimir a produção noturna de melatonina pela pineal (MACCHI; BRUCE, 2004).

A supressão da síntese de melatonina pela exposição à luz varia de acordo com as características espectrais do estímulo luminoso (LOCKLEY; BRAINARD; CZEISLER, 2003; THAPAN; ARENDT; SKENE, 2001). O pico de sensibilidade do sistema de controle da síntese de melatonina pela pineal em humanos coincide com 
o das células ganglionares da retina intrinsecamente fotossensíveis (correspondem a $0,2 \%$ do total de células ganglionares da retina), que contêm o pigmento melanopsina (BERSON, 2003; DACEY et al., 2005; THAPAN; ARENDT; SKENE, 2001). A sensibilidade da melanopsina em humanos é máxima ao comprimento de onda $(\lambda)$ de $482 \mathrm{~nm}$, que corresponde à luz azul (GAMLIN et al., 2007) (figura 8).

Figura 8 - Sensibilidade espectral dos cones, bastonetes e células ganglionares da retina intrinsecamente fotossensíveis

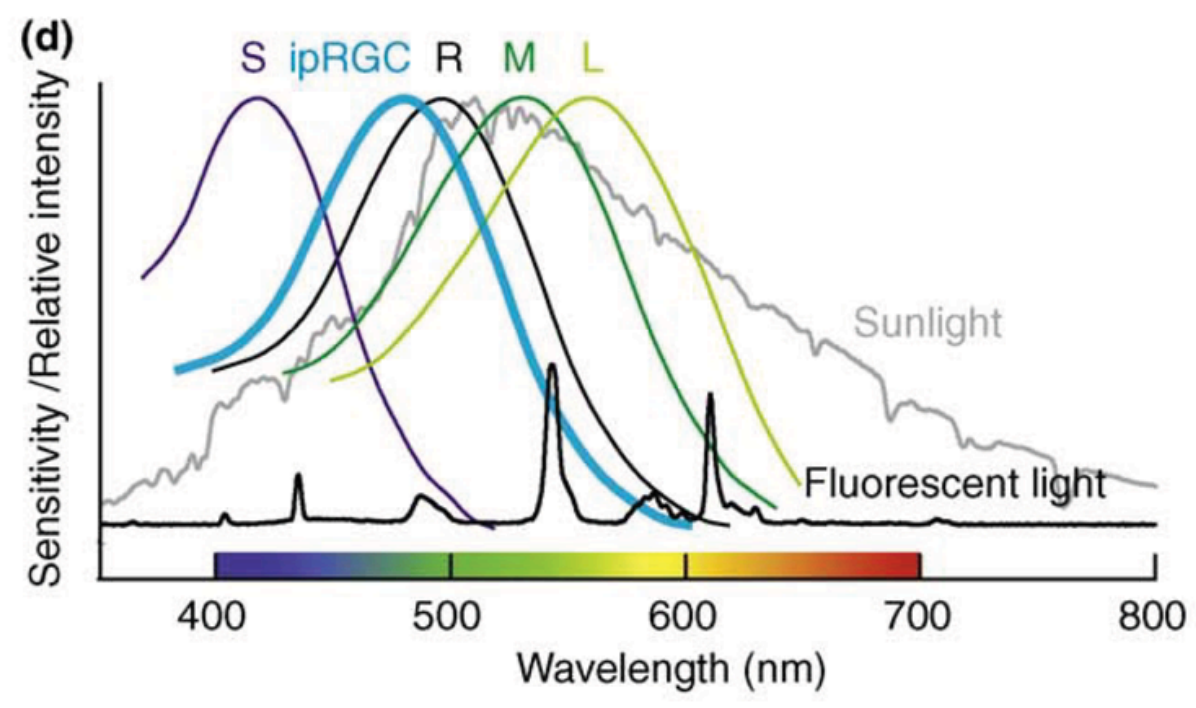

$L=$ cones $L$

$M=$ cones $M$

$\mathrm{R}=$ bastonetes

$\mathrm{S}=$ cones $\mathrm{S}$

ipRGC = células ganglionares da retina intrinsecamente fotossensíveis

Fonte: Megumi e Panda (2010)

A melanopsina é fotopigmento que se assemelha às opsinas de invertebrados em vários aspectos, incluindo a sequência de aminoácidos e a cascata de sinalização através da proteína $G_{q / 11}$ e fosfolipase $C$, resultando na abertura de canais de cátions e despolarização celular (DAVIES; FOSTER; HANKINS, 2012; SEXTON; BUHR; GELDER, 2012). A resposta à luz das células ganglionares da retina intrinsecamente fotossensíveis, em comparação com os cones e bastonetes, tem início lento (a latência da resposta pode atingir vários segundos), baixa sensibilidade ao estímulo e inativação lenta após cessado o estímulo (a latência da resposta ao término do estímulo pode corresponder a dezenas de segundos) (TU et al., 2005); a 
latência na resposta dessas células está relacionada à intensidade da luz (quanto maior a intensidade luminosa, menor a latência à resposta) e reforça o conceito de que as células ganglionares da retina intrinsecamente fotossensíveis correspondem a detectores de irradiância (SEXTON; BUHR; GELDER, 2012).

É provável que as células ganglionares da retina intrinsecamente fotossensíveis recebam informações dos fotorreceptores clássicos da retina, os cones e bastonetes, uma vez que as funções visuais não formadoras de imagem (sincronização dos ritmos circadianos com o ambiente, reflexo pupilar e supressão de melatonina induzida pela luz) estão prejudicadas, porém, não totalmente abolidas em mamíferos que não possuem melanopsina (BERSON, 2003; SEXTON; BUHR; GELDER, 2012).

Em humanos, a maioria dos indivíduos cegos apresenta ritmos circadianos anormais ou em livre-curso, como referido anteriormente, porém, alguns indivíduos cegos em relação à visão consciente, apresentam a fotorrecepção pelas células ganglionares da retina intrinsecamente fotossensíveis, mantendo ritmos circadianos sincronizados com o ambiente (CZEISLER et al., 1995; LOCKLEY et al., 1997; SKENE et al., 1999).

A cor dos olhos em humanos não têm efeitos significativos na resposta noturna da pineal à luz (JASSER; BLASK; BRAINARD, 2006; REITER et al., 2011).

\subsection{Ressonância magnética funcional}

As imagens por RM baseiam-se na utilização de forte campo magnético e ondas de radiofrequência. Determinados núcleos atômicos apresentam a característica intrínseca chamada spin ${ }^{4}$ (WESTBROOK; KAUT, 2000). Quando colocados sob forte campo magnético estático, esses núcleos passam realizar precessão ao redor de eixo que é paralelo (estado de baixa energia) ou antiparalelo (estado de alta energia) ao campo magnético externo (HUETTEL; SONG; McCARTHY, 2008a). Geralmente, a maior parte dos núcleos assume o estado de menor energia. Se for aplicada energia aos núcleos exatamente na frequência de precessão, alguns núcleos com baixa energia irão absorver a energia do sistema (fenômeno de ressonância:

4 Devido às leis de indução magnética, núcleos que têm carga efetiva (núcleos com número de massa ímpar) e estão em rotação adquirem momento magnético e são capazes de alinhar-se a um campo magnético externo. $O$ processo dessa interação é o momento angular ou rotação (spin). 
transferência de energia entre dois sistemas na mesma frequência). Estes spins passam ao estado de alta energia, o que é conhecido como excitação. Uma vez removida a fonte de radiofrequência externa (energia), alguns núcleos retornarão ao estado de baixa energia, liberando a energia absorvida. Esta energia liberada é convertida no sinal da ressonância magnética, que podemos observar nos exames (HUETTEL; SONG; McCARTHY, 2008a).

O estudo de RMf usando o sinal relacionado ao nível de oxigenação sanguínea (BOLD) como contraste é método bem estabelecido para a avaliação da função cerebral (BOHNING et al., 2003). Esse método é sensível às alterações na oxigenação sanguínea que acompanham a resposta vascular (aumento de volume e fluxo sanguíneos) secundárias à atividade neuronal, permitindo imagens com resolução espacial da ordem de poucos milímetros, ou submilimétricas. As imagens são adquiridas pela técnica de eco-planar que permite resolução temporal da ordem de segundos, podendo atingir a ordem de milessegundos (AMARO Jr.; BARKER, 2006; MATTHEWS; JEZZARD, 2004).

Os mecanismos da relação entre a resposta BOLD e a atividade neuronal não são totalmente conhecidos (LOGOTHETIS et al., 2001). A energia usada na atividade neuronal é relacionada principalmente com a despolarização neuronal póssináptica e, em menor extensão, com a geração de potenciais de ação (ATTWELL; LAUGHLIN, 2001). O aporte de substrato para o metabolismo energético aumenta com o aumento do fluxo sanguíneo local, sendo o último, provavelmente, consequência direta da ação do neurotransmissor, refletindo, assim, a sinalização local. Quando há aumento da atividade neural, ocorre aumento da taxa local do consumo do oxigênio e aumento reflexo do volume sanguíneo cerebral regional e do fluxo sanguíneo cerebral regional, com consequente redução relativa na quantidade de desoxi-hemoglobina presente no tecido (NORRIS, 2006). A hemoglobina apresenta comportamento diamagnético quando saturada com o oxigênio, com efeito neutro no campo magnético; quando sem o oxigênio, apresenta comportamento paramagnético (PAULING; CORYELL, 1936), ocasionando distúrbios no campo magnético e consequente redução da intensidade do sinal na RM. Essas diferenças nas propriedades magnéticas da hemoglobina determinam pequenas mudanças de sinal nas sequências BOLD, que possibilitam a geração de mapas de ativação cerebral (AMARO Jr; YAMASHITA, 2001; NORRIS, 2006; WEISSKOFF, 2000). No ser humano saudável, o aumento do fluxo sanguíneo 
regional é dominante sobre as outras alterações, com o consequente aumento da intensidade do sinal em aquisições T2, o chamado efeito BOLD. Estes eventos são a base para o estudo da função cerebral com RM usando o contraste BOLD (RAICHLE, 2008; RAICHLE; MINTUN, 2006; RAMSEY; HOOGDUIN; JANSMA, 2002; VILLRINGER, 2000).

A resposta BOLD aos estímulos de curta duração apresenta três fases (figura 9). Após o estímulo pode haver pequena resposta inicial negativa (initial dip), que dura de 2 a 3 segundos e corresponde ao aumento transitório da concentração relativa de desoxi-hemoglobina; esta é seguida pela resposta principal, que atinge o máximo em aproximadamente 5 segundos e que corresponde à redução da concentração relativa de desoxi-hemoglobina pelo grande influxo de oxigênio, secundário ao aumento do fluxo sanguíneo; finalmente, alguns segundos após cessar a atividade neural, esta fase é seguida pela resposta negativa, ou efeito rebote pós-estímulo (undershoot), que pode levar até um minuto para retornar à linha de base (NORRIS, 2006) e corresponde ao acúmulo global da desoxi-hemoglobina no leito venular, que requer maior tempo para ser eliminado. Esta 'lavagem' é em parte explicada pelo modelo ‘balão’ (FRISTON et al., 2000).

Figura 9 - Resposta hemodinâmica a estímulo hipotético de curta duração.

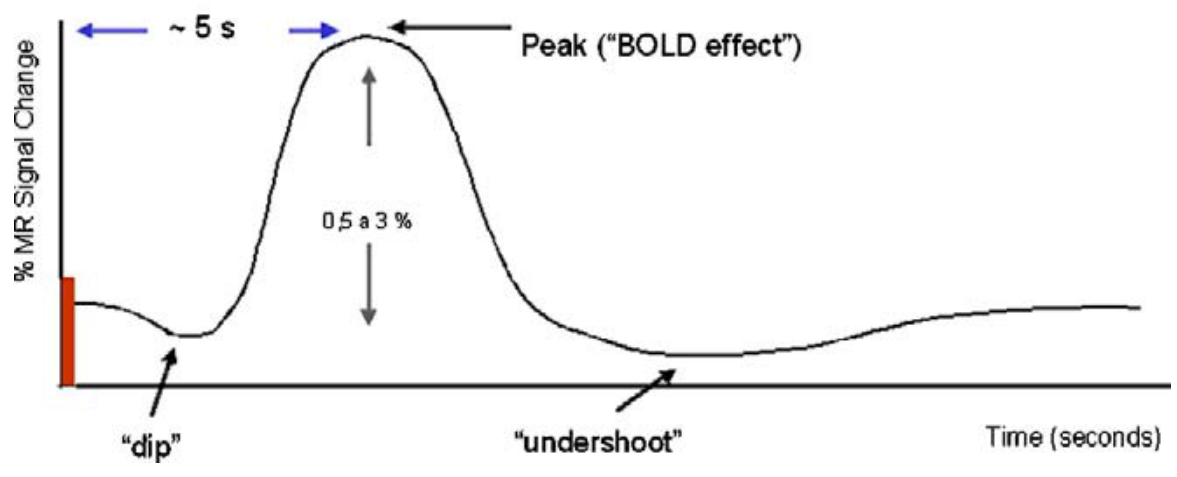

O efeito BOLD atinge o pico cerca de $5 \mathrm{~s}$ após o início da apresentação do estímulo (barra vermelha). Fonte: Amaro Jr e Barker (2006)

\subsubsection{RMf no estado de repouso}

O estudo da conectividade cerebral representa nova abordagem da RMf que permite investigar a atividade neural em regiões que são funcionalmente 
conectadas, porém, anatomicamente distantes (BISWAL et al., 1995; FRISTON et al., 1993; ROSAZZA, 2011). A conectividade funcional pode ser definida como a sincronia da atividade neural entre regiões cerebrais. Acredita-se que áreas do cérebro que exibem flutuações do sinal BOLD correlacionadas no tempo pertençam à mesma rede funcional (BISWAL et al., 1995).

O estudo da conectividade funcional pode ser realizado durante a execução de tarefa ativa ou durante o estado de repouso (resting state, RS).

$\mathrm{Na}$ RMf é possível caracterizar a atividade neural coerente em frequências muito baixas, menores que $0,1 \mathrm{~Hz}$; essa atividade neural não está diretamente associada com a atividade coerente detectada no eletroencefalograma (EEG), o último com resolução temporal da ordem de milessegundos (RAICHLE, 2010). Não se conhece a exata origem das flutuações de baixa frequência do sinal BOLD, mas, acredita-se que sejam decorrentes da associação da atividade neural espontânea com fatores de confusão de natureza não-fisiológica e fisiológica não-neuronal (AUER, 2008). Os mapas de conectividade funcional gerados a partir da atividade cerebral espontânea não controlada são referidos como redes do estado de repouso (resting state networks, RSN) (AUER, 2008).

As RSN são reprodutíveis, tanto em análises intra quanto interindividuais (BISWAL et al., 2010; CHEN et al., 2008; DAMOISEAUX et al., 2006; SHEHZAD et al., 2009). 


\section{MATERIAL E MÉTODOS}

Este é um estudo prospectivo, unicêntrico, de observação em humanos. O projeto de pesquisa foi aprovado pela Comissão de Ética em Pesquisas com Seres Humanos do Instituto de Ciências Biomédicas (ICB) da Universidade de São Paulo, em sessão realizada em 16/06/2009, sob o Parecer número 901 e aprovado pelo Conselho do Departamento de Radiologia do Hospital das Clínicas da Faculdade de Medicina da Universidade de São Paulo (HC FMUSP), em sessão realizada em 14/07/2009, sob o Parecer de Aprovação número 42/2009. A coleta de dados estendeu-se de março de 2012 a abril de 2014.

\subsection{Participantes}

Neste estudo foram avaliados voluntários saudáveis recrutados entre alunos de pós-graduação do ICB, alunos de pós-graduação e médicos residentes do Departamento de Radiologia do HC FMUSP e entre familiares e conhecidos do pesquisador principal. Todos os voluntários tiveram pleno conhecimento dos objetivos e métodos do experimento e deram o seu consentimento por escrito (termo de consentimento informado, apêndice A).

\subsubsection{Recrutamento}

Os voluntários responderam aos questionários geral de saúde (apêndice B), para a identificação de eventuais doenças crônicas descompensadas, uso de medicamentos de ação no sistema nervoso central ou que pudessem interferir com os níveis plasmáticos de melatonina, e de saúde mental (Self-Reporting Questionnaire, SRQ-20) (anexo A), para o rastreamento de transtornos mentais nãopsicóticos.

Os voluntários responderam ao questionário para avaliação do cronotipo (anexo B) (HORNE; OSTBERG, 1976).

Os voluntários recrutados foram devidamente avisados de que todas as informações fornecidas são estritamente sigilosas. 
5.1.2 Critérios de inclusão

- Homens ou mulheres não portadores de doenças crônicas descompensadas;

- com idades variando de 18 a 50 anos;

- sem antecedentes de doença neurológica que tenha evoluído com sequelas ou doença neurológica atual ou recente;

- consentimento por escrito para a participação do estudo.

\subsubsection{Critérios de exclusão}

- Indivíduos que apresentassem contraindicação ao exame de RM (marcapasso, clipe intracraniano, implante coclear, claustrofobia, etc.);

- indivíduos portadores de aparelhos ortodônticos ou implantes dentários, pela possibilidade de causarem distúrbios no campo magnético;

- indivíduos em tratamento de doenças neurológicas ou com antecedentes de neurocirurgia ou trauma craniano que tenha evoluído com sequela;

- indivíduos portadores de doenças crônicas descompensadas ou doenças graves que pudessem interferir na condução do estudo, como neoplasias, cardiopatias descompensadas, diabetes mellitus tipo I ou II, depressão grave, etc..

\subsection{Questionários e dados pessoais}

Todos os participantes responderam aos questionários de saúde geral e SRQ-20

e leram e assinaram ao termo de consentimento livre e esclarecido antes da realização do exame de RMf.

Todos os participantes, exceto 2, que não foram encontrados, responderam ao questionário sobre cronotipo.

Foram calculados, retrospectivamente, os horários do nascer e pôr-do-sol dos dias em que foram realizados os exames de RMf, com base nos dados do sítio sobre geociência Geoscience Australia (Australian Government, www.ga.gov.au), para determinar em qual momento da curva de concentração plasmática de 
melatonina ( $1^{\mathrm{a}}$ metade ou $2^{\mathrm{a}}$ metade da curva) foi aplicado o estímulo luminoso. Os cálculos foram corrigidos para o horário de verão quando necessário.

Foram coletados os seguintes dados pessoais: nome, número do RG, data de nascimento, idade, nome da mãe, endereço, telefone, estado civil, peso, altura, presença de próteses e clipes metálicos, fragmentos de metal no corpo, implantes dentários ou outros fatores que impossibilitassem a realização do exame de RMf. Alguns dados pessoais acima relatados eram necessários para que fosse gerado o registro temporário do voluntário no HC FMUSP, para a realização do exame de tomografia computadorizada de crânio (TC), que será explicado na seção 5.3.

\subsubsection{Questionário geral de saúde}

O questionário geral de saúde foi elaborado pelo pesquisador principal e serviu como instrumento de anamnese resumida, para a identificação de doenças enquadradas nos critérios de exclusão. Este questionário incluiu algumas perguntas relacionadas aos impedimentos para a realização do exame de RM.

\subsubsection{SRQ-20}

O SRQ-20 é instrumento de autoavalição recomendado pela Organização Mundial de Saúde (OMS) para o rastreamento de transtornos mentais não-psicóticos (HARDING et al, 1980; WORLD HEALTH ORGANIZATION, 2001). O SRQ-20 é composto por 20 questões sobre sintomas psicossomáticos (GONÇALVES; STEIN; KAPCZINSKI, 2008). As respostas são do tipo sim/não e cada resposta afirmativa pontua com o valor 1 . O escore final é formado pela somatória dos pontos, variando de 0 (nenhuma probabilidade) a 20 (extrema probabilidade). $O$ ponto de corte do SRQ-20 pode variar dependendo do contexto cultural em que é aplicado. Gonçalves, Stein e Kapczinski (2008) validaram o SRQ-20 para uso no Brasil, encontrando o valor de corte de 7/8 (igual ou menor que 7, caso negativo; igual ou maior que 8, caso positivo) como mais adequado, independente do gênero, com sensibilidade de $86,33 \%$ e especificidade de $89,31 \%$. Este valor de corte foi adotado no presente estudo.

O questionário SRQ-20 foi utilizado neste estudo para o rastreamento de doenças enquadradas nos critérios de exclusão. 


\subsubsection{Questionário sobre cronotipo}

Foi utilizada a versão em português (BENEDITO-SILVA et al., 1990) do questionário sobre cronotipo desenvolvido por Horne e Ostberg (1976), para classificar a população estudada. Este é um questionário de autoavalição composto por 19 perguntas de múltipla escolha, que se referem a diferentes situações cotidianas e os indivíduos declaram sua preferência de horário na realização das atividades propostas. Cada questão tem uma pontuação e a somatória resulta em valor que é classificado como matutino extremo (de 70 a 86 pontos), matutino (de 59 a 69 pontos), intermediário (de 42 a 58 pontos), vespertino (de 31 a 41 pontos) e vespertino extremo (de 16 a 30 pontos).

\subsection{Tomografia computadorizada}

Os participantes foram submetidos à realização de TC sem o uso do contraste endovenoso, para observarmos qual a influência da calcificação na capacidade da RM em medir o sinal da pineal. Esse exame foi realizado antes ou após o exame de $\mathrm{RM}$, em dia diferente do exame de RM.

Todos os exames de TC foram realizados no Instituto de Radiologia (InRad) do HC FMUSP, em tomógrafos multislice, com aquisição volumétrica da imagem, utilizando $120 \mathrm{kV}$ e $220 \mathrm{mAs}$. Os participantes que realizaram a TC receberam o laudo escrito e as imagens do exame.

\subsection{Ressonância Magnética}

Todos os exames foram realizados no InRad do HC FMUSP em sistema de RM com campo de 3,0 T, com gradientes operando em $80 \mathrm{mT} / \mathrm{m}$ e razão de subida em 100-200 mT/s (Achieva, X series, Philips, Holanda). As imagens foram adquiridas com bobina de crânio de 8 canais.

Foi realizado o registro dos dados fisiológicos (movimentos respiratórios e eletrocardiograma) de todos os participantes durante os exames de RM, com os equipamentos periféricos do aparelho de RM e taxa de amostragem de $500 \mathrm{~Hz}$, para utilização desses dados como fatores de confusão durante a análise dos dados. 
Os primeiros 5 exames realizados constituíram a fase piloto, a partir da qual foi estabelecido o desenho definitivo do experimento.

\subsubsection{Sequências e parâmetros de aquisição de imagens por RM}

No exame de RMf eram adquiridas imagens estruturais (FLAIR, Fluid Attenuated Inversion Recovery, e T1-3D FFE, Fast Field Echo) e imagens funcionais (RMf).

A duração total de exame de RMf era de, aproximadamente, 50 minutos.

Após a fase piloto, decidimos realizar as seguintes sequências de imagens, em todos os participantes: imagens funcionais (sequência eco-planar gradiente eco, EPI-GRE) no estado de repouso (Resting State, RS) antes da apresentação de estímulo luminoso (sequência doravante denominada rspre), imagens funcionais durante a apresentação de estímulo luminoso (sequência doravante denominada luz) e RS após a apresentação de estímulo luminoso (sequência doravante denominada rspos), e imagens estruturais ponderadas em T1-3D e FLAIR, para a sobreposição com os mapas resultantes da análise dos dados da RMf e para a pesquisa de eventuais lesões encefálicas.

\subsubsection{Aquisição de imagens funcionais}

- Aquisição paralela SENSE (SENSitivity Encoding), fator de aceleração de 2,5, com cortes intercalados;

- orientação: axial;

- FOV (field of view): $240 \times 240 \mathrm{~mm}$;

- matriz: 120 x 120;

- espessura do corte: $2 \mathrm{~mm}$;

- voxel: $2 \times 2 \times 2 \mathrm{~mm}$;

- voxel REC: $1,5 \times 1,5 \times 2$ mm;

- matriz de reconstrução: 160;

- intervalo: 0;

- TE (tempo de eco): $30 \mathrm{~ms}$;

- TR (tempo de repetição): 3.000 ms;

- ângulo de inclinação: $90^{\circ}$. 
As aquisições rspre e rspos tinham duração de 7,5 min, contendo 150 volumes e 42 fatias cada uma.

A aquisição luz tinha duração de $17 \mathrm{~min}$, contendo 340 volumes e 42 fatias.

\subsubsection{Aquisição de imagens estruturais}

\section{FLAIR:}

- Aquisição: cortes intercalados;

- orientação: axial;

- FOV: 230 x $180 \mathrm{~mm}$;

- matriz: $350 \times 210$;

- voxel: $0,45 \times 0,45 \times 5,00 \mathrm{~mm}$;

- intervalo: 0,5 mm;

- TE: $130 \mathrm{~ms}$;

- TR: $11.000 \mathrm{~ms}$;

- $\mathrm{TI}$ (tempo de inversão): $2.800 \mathrm{~ms}$.

\section{T1-3D FFE:}

- Aquisição paralela SENSE, fator de aceleração de 1,5 na direção do corte;

- pré-pulso de inversão: 900 ms;

- orientação: sagital;

- FOV: $240 \times 240$;

- matriz: $240 \times 240$;

- espessura do corte: $1 \mathrm{~mm}$;

- voxel: $1 \times 1 \times 1 \mathrm{~mm}$;

- TE: 3,2 ms;

- TR: $7 \mathrm{~ms}$;

- ângulo de inclinação: $8^{\circ}$.

\subsubsection{Estímulo e equipamentos utilizados}

Foram projetados e construídos especialmente para este projeto um estimulador luminoso (Zurc \& Zurc, São Paulo, SP) e um equipamento sincronizador (trigger) 
(Zurc \& Zurc, São Paulo, SP), para que a aplicação do estímulo estivesse precisamente sincronizada com a aquisição de imagens de RMf.

O estimulador luminoso foi desenhado por engenheiro mecânico (BVN) especialista em iluminação e pós-doutorando pelo Instituto de Psicologia da USP, Departamento de Psicologia Experimental e construído sob a orientação do mesmo. Foi realizada a modificação do estimulador luminoso, conforme explicado na seção 5.4.2.1, sob a supervisão do mesmo engenheiro. Os relatórios sobre a aferição do estimulador, elaborados pelo referido engenheiro, encontram-se nos anexos $\mathrm{C}$ a $\mathrm{F}$.

Os instrumentos foram construídos com material compatível com ambiente de RM, para evitar que a) fossem afetados pelo campo magnético e ondas de radiofrequência, ou que $b$ ) interferissem na qualidade das imagens de RM.

\subsubsection{Estimulador luminoso}

A intensidade do estímulo luminoso, o tempo de exposição a esse estímulo e sua composição espectral em relação ao comprimento de onda são determinantes na redução da secreção noturna de melatonina (BERSON; DUNN; TAKAO, 2002; BRAINARD et al., 2001; REA et al., 2005; THAPAN; ARENDT; SKENE, 2001). Optamos pela utilização de luz quase monocromática (composta por faixa estreita de comprimentos de onda) com pico de $\lambda$ semelhante ao $\lambda$ de sensibilidade máxima do sistema circadiano, possibilitando estimulação mais eficiente (GAMLIN et al., 2007).

O primeiro protótipo do estimulador luminoso foi inicialmente constituído por painel contendo 10 LEDs com $\lambda_{\max }$ de $475 \mathrm{~nm}$, distribuídos em duas colunas de 5 peças em placa eletrônica, utilizando-se lentes colimadoras sobre cada um dos LEDs (figura 10); esse painel permanecia preso a suporte de acrílico e era colocado dentro do magneto do equipamento de RM, do lado de fora da bobina de crânio (figura 11). Entre o painel de LEDs e os olhos do voluntário eram colocadas 2 folhas de material difusor (poliéster), para homogeneizar a distribuição da emissão, uma delas próxima ao painel ( $1^{\circ}$ difusor) e a outra fixada na bobina de crânio $\left(2^{\circ}\right.$ difusor $)$ (figura 12). 
Figura 10 - Painel com 10 LEDs

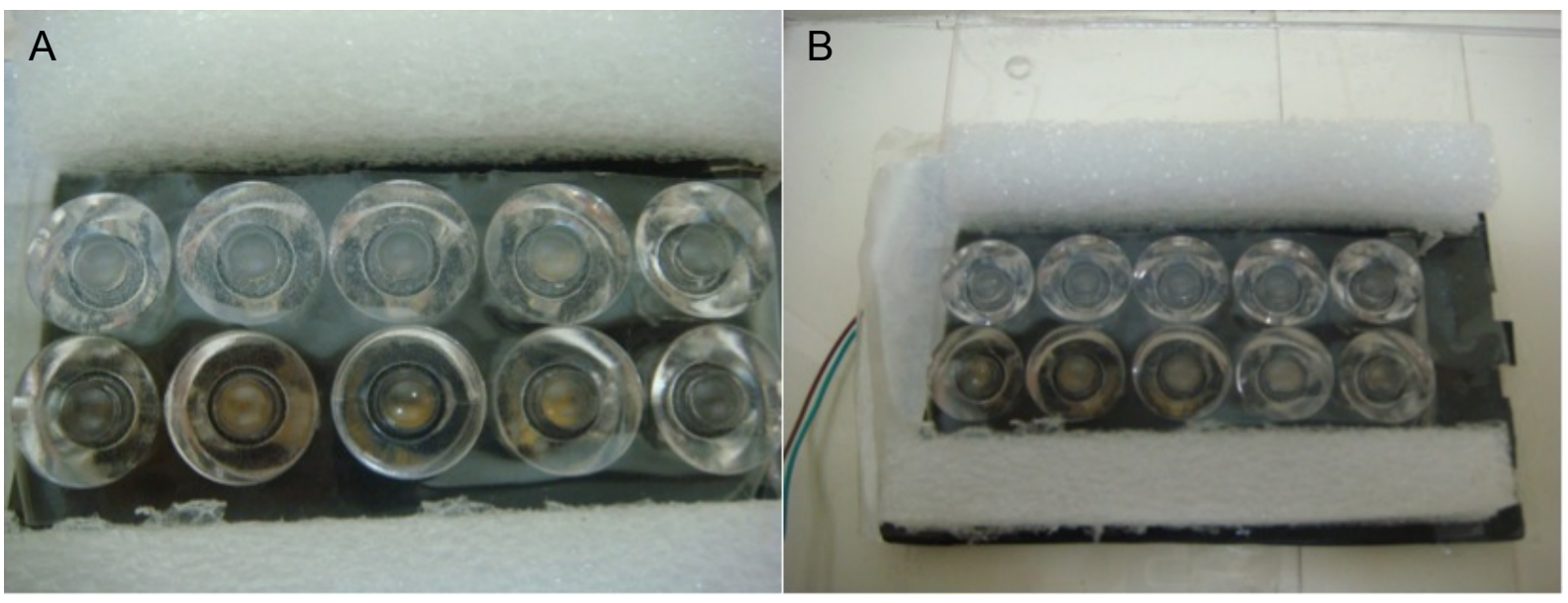

A e B) Painel com 10 LEDs contendo lentes colimadoras, visto de frente, sem a folha de material difusor.

Figuras 11 - Painel de LEDs fixado no suporte de acrílico

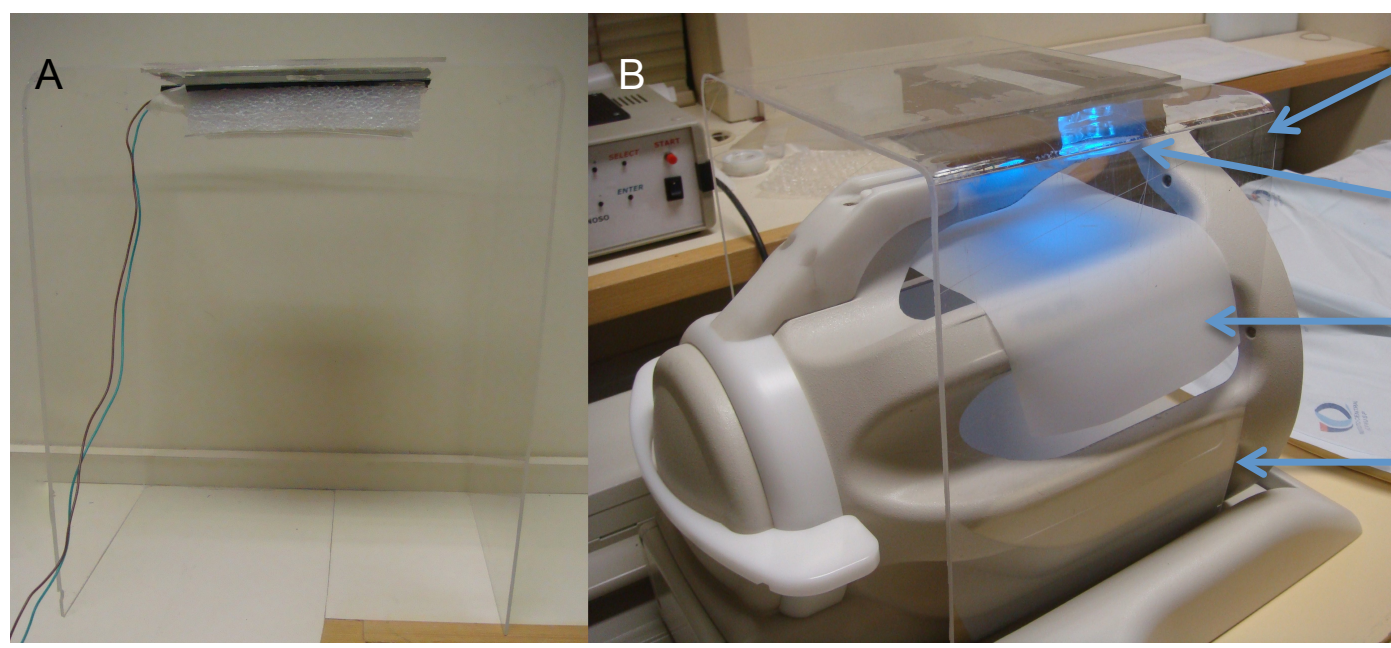

Acrílico

Painel de LEDs

$2^{\circ}$ difusor

Bobina de crânio

A) Painel de LEDs fixado na parte superior do suporte de acrílico, vista lateral. B) O suporte de acrílico foi colocado na posição que permanece durante a realização do exame (por fora da bobina de crânio utilizada no exame de ressonância magnética do encéfalo) e com as luzes acesas. 
Figuras 12 - Painel de LEDs

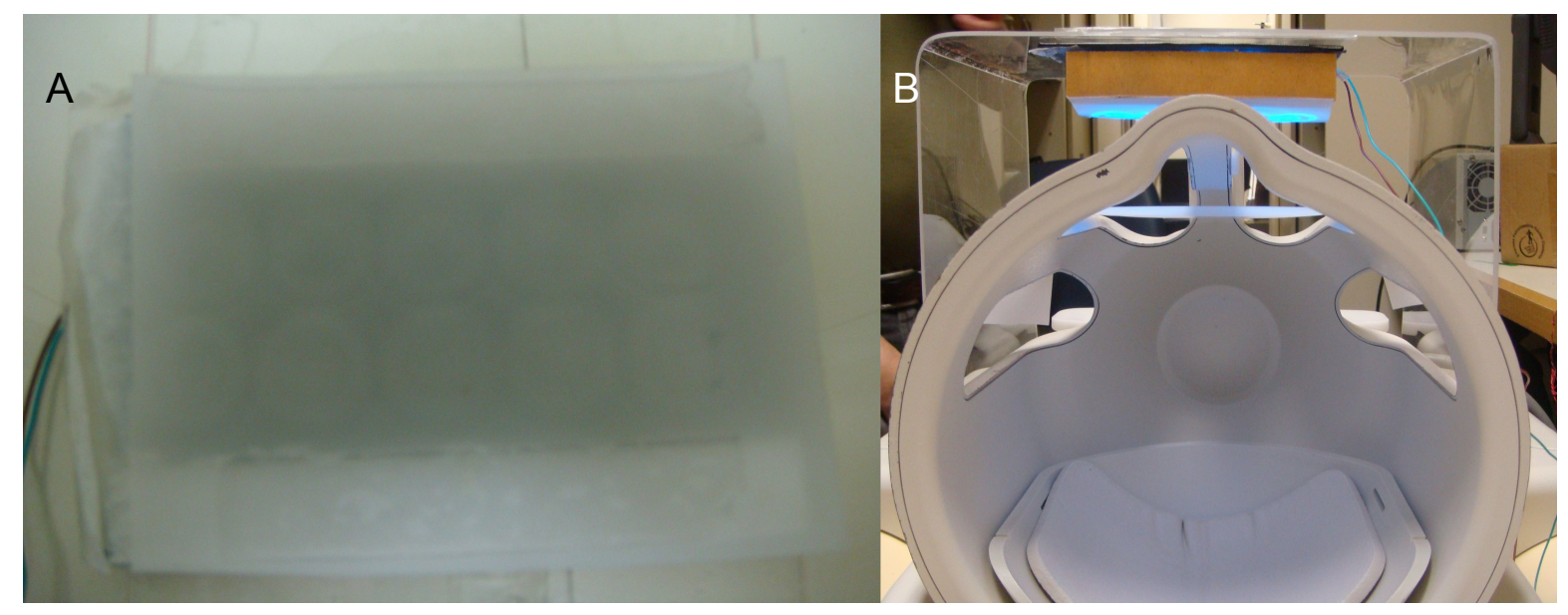

A) Painel de LEDs coberto pelo $1^{\circ}$ difusor, visto de frente. B) Painel de LEDs fixado ao suporte de acrílico e com as luzes acessas, colocado na posição que permanece durante a realização do exame (por fora da bobina de crânio).

Foi avaliado o efeito do campo magnético sobre o estimulador luminoso, constatando-se ausência de modificação da luminância aferida dentro e fora do campo magnético. Os valores da luminância foram aferidos mais de uma vez, em momentos diferentes, devido à necessidade de substituição de LEDs; o valor máximo medido foi de $494,3 \pm 99,8 \mathrm{~cd} / \mathrm{m}^{2}$.

O estimulador apresentou falha no seu funcionamento (LEDs queimados) e optamos por modificar o painel de LEDs, que passou a conter 16 LEDs com $\lambda_{\max }$ de $465 \mathrm{~nm}$, distribuídos em duas colunas de oito peças em placa eletrônica, sem a necessidade do uso de lentes colimadoras adicionais (devido ao tipo de LED utilizado), sendo as duas folhas de material difusor (poliéster) fixadas no próprio painel; os demais parâmetros do estimulador permaneceram inalterados. $O$ valor máximo da luminância aferida foi de $332 \mathrm{~cd} / \mathrm{m}^{2}$. Após a fase piloto, todos os dados de RMf foram obtidos com a utilização deste estimulador (figura 13). 
Figura 13 - Painel com 16 LEDs, sem lentes colimadoras adicionais

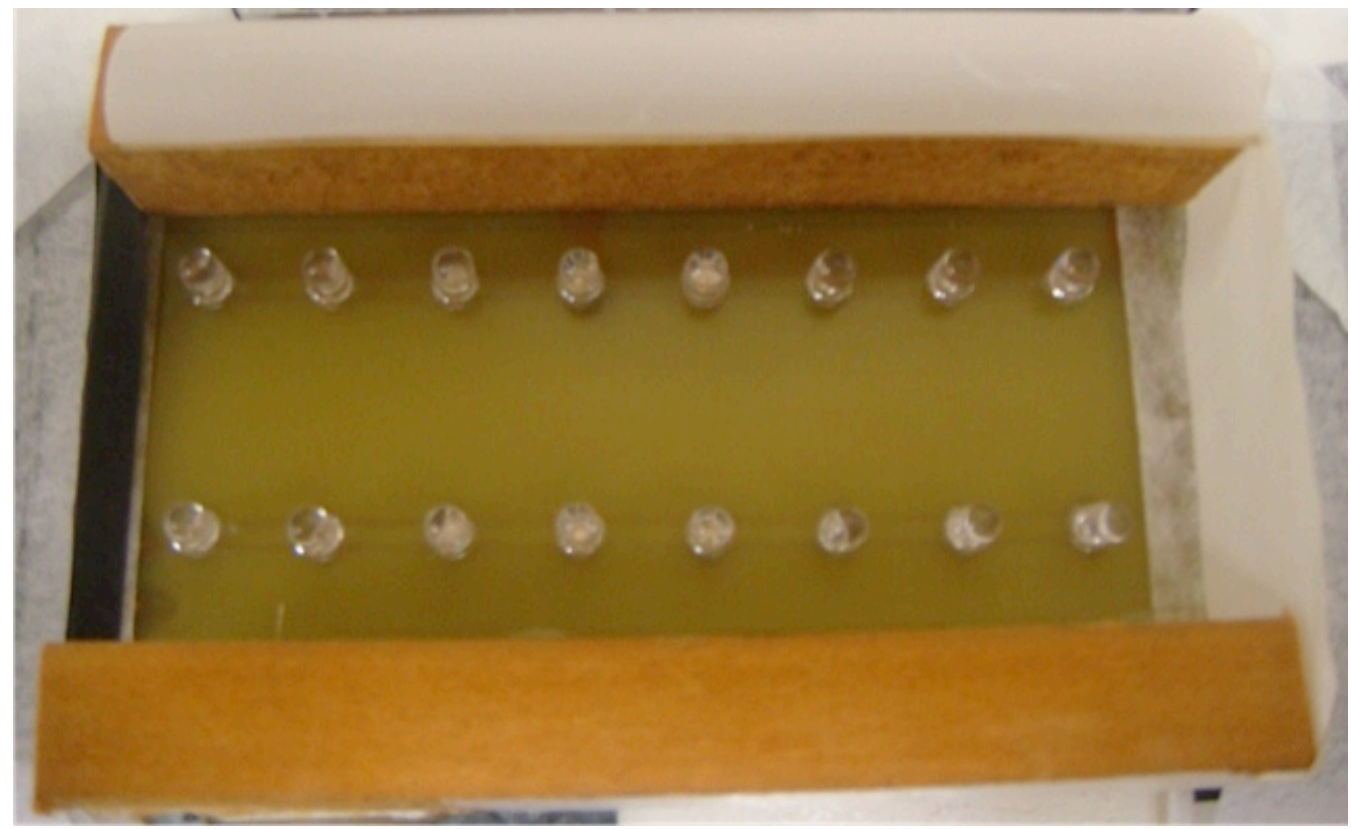

Painel com 16 LEDs, visto de frente, sem as folhas difusoras.

\subsubsection{Sincronizador}

Foi desenvolvido aparelho (trigger) que possibilitou realizar a estimulação luminosa dentro do magneto, sincronizando a aquisição das imagens de RMf com a apresentação do estímulo luminoso (figura 14).

Figura 14 - Trigger

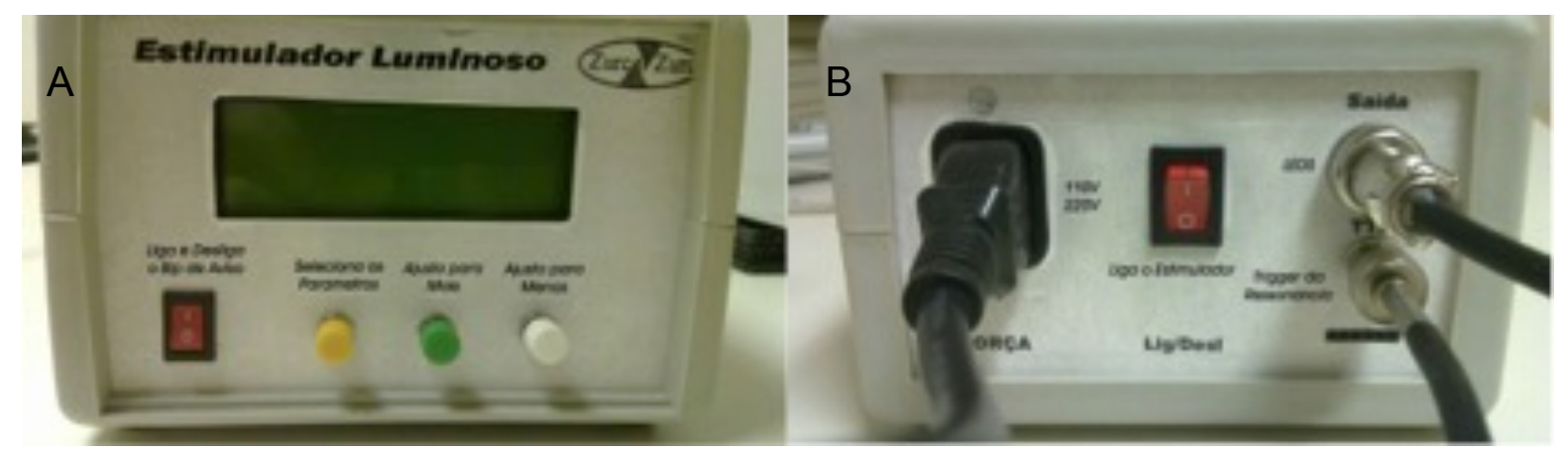

A e B) Aparelho eletrônico que sincroniza a aquisição das imagens de RMf com a apresentação do estímulo luminoso. 


\subsubsection{O estímulo luminoso}

Após a fase piloto, o estímulo luminoso foi apresentado em blocos da seguinte maneira (figura 15):

Figura 15 - Sequência de apresentação do estímulo luminoso, implementada após a fase piloto

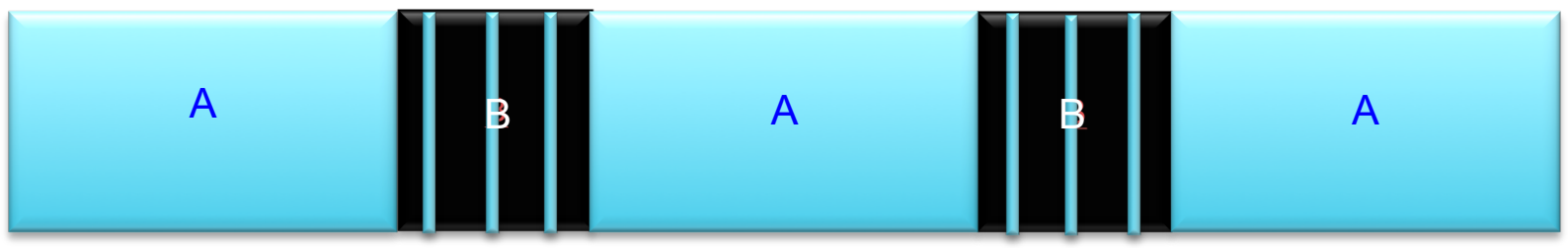

Apresentação do estímulo luminoso em blocos de $300 \mathrm{~s}(\mathrm{~A})$, intercalados com períodos de escuro de $60 \mathrm{~s}$ e flashes de $1 \mathrm{~s}(\mathrm{~B})$ (série iniciada e finalizada em períodos de exposição luminosa).

Em cada um dos períodos de escuro eram aplicados três flashes de luz azul, com duração de $1 \mathrm{~s}$ cada um e intervalos de $12 \mathrm{~s}$ entre os flashes, para minimizar a possibilidade de movimentação do participante ao início do próximo bloco de luz.

A utilização da luz azul para o estímulo visual foi realizada com base nas normas de segurança ocular preconizadas pela International Electrotechnical Commission (INTERNATIONAL ELECTROTECHNICAL COMMISSION, 2006).

\subsubsection{Dinâmica do experimento}

Os participantes eram orientados a não fumar e não ingerir substâncias que poderiam interferir com a produção de melatonina pela pineal (por exemplo, café, chá, bebidas alcoólicas) após as $15 \mathrm{~h}$ no dia do exame de RMf e a ingerir refeição leve por volta das $20 \mathrm{~h}$.

Os voluntários chegavam ao setor de RM do InRad do HC FMUSP entre $21 \mathrm{~h}$ e $21 \mathrm{~h} 30 \mathrm{~min}$. Eram solicitados a colocar a roupa do hospital para evitar metais dentro da sala do exame de RM e passavam por entrevista com funcionário(a) da enfermagem, que averiguava os requerimentos de segurança para a realização do exame de RM. Era colocado o acesso venoso por funcionário(a) da enfermagem, com jelco número 20 ou 22, que permanecia durante todo o experimento, exceto nos 
casos de perda do acesso venoso. Após a entrevista com a enfermagem e com o acesso venoso colocado, o participante era levado para sala no próprio setor de RM, onde permanecia deitado em maca, com os olhos vendados por duas máscaras sobrepostas, em ambiente com iluminação de até 10 lux, aferida com luxímetro digital (Minipa, modelo MLM-1011, Texas, USA).

O exame de RMf tinha início entre 23 h 30 min e 24 h, mantendo-se o ambiente com iluminação reduzida e o voluntário com os olhos vendados até o momento do exame.

As máscaras para vendar os olhos eram retiradas imediatamente antes do início do exame de RM, estando o participante dentro da sala do magneto e deitado na maca do aparelho de RM; as máscaras eram recolocadas imediatamente após o término do exame de RM, antes do participante levantar da maca do aparelho, ainda dentro da sala do magneto.

As luzes da sala do magneto eram mantidas apagadas durante a permanência do voluntário; era necessário acender a luz em sala ao lado, durante as coletas das amostras de sangue, para possibilitar o procedimento. O voluntário permanecia dentro do magneto quando a coleta de sangue era realizada durante o exame de RM e era orientado a manter os olhos fechados. Durante a aplicação do estímulo luminoso o participante era orientado a manter os olhos abertos. Após o término da aplicação do estímulo luminoso, o participante era orientado a manter os olhos fechados até o final do experimento. Após o término do exame de RM, o voluntário tinha os olhos vendados novamente e assim permanecia até o final do experimento, fora da sala do magneto e em ambiente com iluminação de até 10 lux. Após o término do exame de RM e com o participante fora da sala do magneto, eram colhidas duas amostras de sangue total com intervalo de 15 min entre cada uma, retirado o acesso venoso e finalizado o experimento.

\subsubsection{Posicionamento dos indivíduos}

Todos os indivíduos foram posicionados em decúbito dorsal na maca do aparelho de RM, com a cabeça em posição neutra na bobina. Foi colocada fita adesiva na fronte de cada participante, prendendo-a nas regiões laterais da bobina, para manter o alinhamento da cabeça do participante. Foram colocadas almofadas de espuma nas laterais, entre a cabeça do sujeito e a bobina, para limitar a movimentação da 
cabeça. Foram colocados protetores auriculares em todos os sujeitos, para a redução da intensidade do som gerado pelo aparelho de RM em funcionamento.

\subsubsection{Realização do exame de RMf}

As sequências de imagens eram adquiridas na seguinte ordem: imagens funcionais no estado de repouso antes da aplicação do estímulo luminoso, imagens funcionais durante a aplicação do estímulo luminoso, imagens funcionais no estado de repouso após a aplicação do estímulo luminoso, imagens estruturais (T1-3D FFE e FLAIR).

Durante as aquisições no estado de repouso, o participante era orientado a permanecer acordado com os olhos fechados.

Antes de cada sequência de aquisição, o participante era relembrado sobre como deveria permanecer.

\subsection{Coleta de amostras de sangue total}

Foram coletadas amostras de sangue total para a posterior dosagem de melatonina plasmática, antes, durante (em alguns casos) e após o exame de RM.

No início deste estudo, havia sido determinado que seriam dosados no sangue os níveis de hematócrito, que podem estar relacionados à intensidade do sinal BOLD (LEVIN et al., 2001), cortisol (FERREIRA et al., 2005) e enzimas hepáticas (TGO, TGP, FA e Y-GT) (ARENDT, 1995a), que podem estar relacionados com os níveis plasmáticos de melatonina; porém, devido a dificuldades técnicas, optamos pela não execução desses exames de sangue; esta decisão foi informada a todos os participantes.

As amostras de sangue total foram, inicialmente, coletadas como indicado a seguir, exceto nos casos de perda do acesso venoso, quando ocorreram atrasos na coleta ou nos casos de amostra com hemólise, quando optamos, em alguns casos, pela coleta de amostra(s) adicional(is):

- $1^{\text {a }}$ coleta: entre 22 h e 22 h 30 min;

- $2^{\mathrm{a}}$ coleta: $23 \mathrm{~h}$; 
- $3^{a}$ coleta: entre 23 h 30 min e 24 h ou imediatamente antes de transferir o voluntário para a sala do magneto;

- $4^{\mathrm{a}}$ coleta: após a realização de todo o exame de RM, com o voluntário fora da sala do magneto;

- $5^{a}$ coleta: 15 min após a $4^{a}$ coleta;

- $6^{a}$ coleta: 15 min após a $5^{\mathrm{a}}$ coleta.

Do $11^{\circ}$ sujeito em diante, decidimos coletar amostras logo após o rspre, com o sujeito dentro do magneto, para aumentar o número de pontos da curva de melatonina. Os momentos das coletas passaram a ser os seguintes:

- $1^{\text {a }}$ coleta: entre 22 h e 22 h 30 min;

- $2^{\mathrm{a}}$ coleta: $23 \mathrm{~h}$;

- $3^{a}$ coleta: entre 23 h 30 min e 24 h ou imediatamente antes de transferir o voluntário para a sala do magneto;

- $4^{a}$ coleta: imediatamente após a realização do rspre, com o voluntário dentro do magneto;

- $5^{\mathrm{a}}$ coleta: imediatamente após o término de todo o exame de RM, com o voluntário fora da sala do magneto;

- $6^{a}$ coleta: 15 min após a $6^{a}$ coleta.

Em alguns casos, foi realizada a coleta de sangue logo após o rspos, além das demais, com o sujeito dentro do magneto; nesses casos, foram coletas 7 amostras de sangue total.

As amostras de sangue total foram coletadas em tubos plásticos contendo heparina sódica (do $1^{\circ}$ ao $5^{\circ}$ casos, fase piloto) ou EDTA (do $6^{\circ}$ voluntário ao $25^{\circ}$ casos), centrifugadas imediatamente após a sua coleta para a separação do plasma, que era temporariamente armazenado no gelo seco ou no freezer a $-20{ }^{\circ} \mathrm{C}$ e transferido, em até $72 \mathrm{~h}$, para o congelamento $\mathrm{a}-80^{\circ} \mathrm{C}$ até o ensaio para a dosagem da melatonina. 


\section{ANÁLISE DOS DADOS}

\subsection{Análise dos questionários}

Os dados do questionário geral de saúde foram avaliados e usados para a pesquisa de doenças que fossem classificadas como fatores de exclusão.

Os dados do questionário SRQ-20 de cada indivíduo foram avaliados através dos escores encontrados, para o rastreamento de doenças que fossem classificadas como fatores de exclusão.

Os dados sobre cronotipo foram utilizados para classificar a população estudada. Vinte e dois sujeitos responderam ao questionário (não foi possível contatar dois participantes, que não responderam a esse questionário).

\subsection{Análise das imagens de TC}

As imagens de TC foram analisadas pela equipe de Neurorradiologia do InRad do HC FMUSP e foram gerados laudos escritos. Cada participante que realizou a TC recebeu o laudo escrito e as imagens do exame, conforme já referido.

Foi realizada a avaliação qualitativa do grau de calcificação da pineal de cada exame de TC por inspeção visual, com o uso do programa OsiriX, versão 5.5.2 64bit (Pixmeo SARL, Suíça, www.osirix-viewer.com). O grau de calcificação pineal foi classificado de 0 a 3 ( 0 = calcificações ausentes; 1 = pineal pouco calcificada; 2 = pineal moderadamente calcificada; $3=$ pineal muito calcificada). A pineal foi considerada pouco calcificada quando as calcificações ocupavam menos do que a metade do tecido pineal, a pineal foi considerada moderadamente calcificada quando as calcificações ocupam cerca de metade do tecido pineal e foi considerada muito calcificada quando as calcificações ocupavam mais do que a metade do tecido pineal.

\subsection{Análise das imagens de RM}

6.3.1 Análise das imagens estruturais de RM 
As imagens estruturais FLAIR e T1-3D FFE foram analisadas por inspeção visual de neurorradiologista (EAJr) com 20 anos de experiência na análise de imagens clínicas de RM. As imagens foram observadas utilizando-se o programa OsiriX, versão 5.5.2 64-bit (Pixmeo SARL, Suíça, www.osirix-viewer.com).

\subsubsection{Análise das imagens funcionais de RM}

As imagens de RMf foram analisadas usando o pacote estatístico FMRIB Software Library (FSL), versão 5.0.6 (Centre for Functional MRI of Brain - FMRIB, Analysis Group, Oxford, UK, www.fmrib.ox.ac.uk/fsl/ ) (JENKINSON et al., 2012; SMITH et al., 2004; WOOLRICH et al., 2009).

\subsubsection{Análise das imagens de RMf para pesquisa de áreas de ativação}

Foi usada a ferramenta FEAT (FMRI Expert Analysis Tool), versão 6.00, do programa estatístico $\mathrm{FSL}$, que contém instrumentos de análise para experimentos de imagem cerebral, para a análise das imagens funcionais coletadas durante a aplicação do estímulo luminoso. A análise com o FEAT é baseada em um modelo linear generalizado (General Linear Model, GLM) e produz mapas probabilísticos de ativação cerebral através da regressão linear múltipla.

As imagens funcionais individuais foram submetidas à análise de primeiro nível (First Level Analysis) e pré-processadas nas seguintes etapas: reorientação das imagens funcionais para que apresentassem a mesma orientação das imagens de referência (Montreal Neurological Institute, MNI152) utilizadas, usando a ferramenta fslreorient2std do FSL; remoção de vóxeis em estruturas extraencefálicas com a ferramenta BET (Brain Extration Tool); filtro temporal passa-alto para a remoção de artefatos de baixa frequência com tempo máximo de passagem de $300 \mathrm{~s}$ e controle dos limites do sinal BOLD associados à estimulação; correção de movimento utilizando a ferramenta McFLIRT (Motion correction using FMRIB's Linear Registration Tool), correção do tempo de aquisição dos cortes, que tiveram aquisição intercalada, de baixo para cima, no plano anteroposterior; suavização espacial com filtro Gaussiano de $4 \mathrm{~mm}$, para o aumento da razão sinal/ruído das imagens. O mapa de ativação foi obtido pelo GLM. As respostas obtidas pela aplicação do estímulo luminoso foram detectadas pela análise da série temporal de 
cada voxel, que, por hipótese, é a convolução da função estímulo com a função da resposta hemodinâmica canônica dada pela função Gamma (tempo para o pico de 6 $\mathrm{s}$, desvio padrão de $3 \mathrm{~s}$ ). Os parâmetros de movimentação da cabeça (Standard Motion Parameters) foram utilizados como cofatores para auxiliar na remoção de efeitos residuais que tenham permanecido nos dados, mesmo após a correção de movimentos. Foram acrescentadas as séries temporais do sinal BOLD do líquor e da região da veia cerebral magna como fatores de confusão adicionais. Para a extração das séries temporais do líquor, foram desenhadas máscaras em cada um dos ventrículos laterais e na cisterna quadrigêmina usando a imagem funcional-exemplo (example_func, é a imagem usada para fazer a correção de movimento pelo programa FSL) de cada sujeito após a correção de movimento, com o total de 12 vóxeis em cada ventrículo lateral e 6 vóxeis na cisterna quadrigêmina em cada caso. Para a extração das séries temporais das veias cerebrais magnas foram desenhadas máscaras com número de vóxeis variando de 32 a 34, usando a imagem funcional-exemplo de cada sujeito após a correção de movimento. $O$ desenho das máscaras do líquor e da região da veia cerebral magna foi realizado com a ferramenta FSLview do programa FSL. A extração da série temporal do sinal BOLD do líquor e da região da veia cerebral magna foi realizada utilizando a ferramenta fs/maths do programa FSL. Para controle dos resultados falso-positivos foi considerado significativo o conjunto de vóxeis (clusters) sobreviventes ao limiar de Z-score > 2,3 corrigido para comparações múltiplas, com o limiar para voxel no nível de significância de $p<0,05$.

A análise de grupo entre sujeitos (High Level Analysis) foi realizada com 0 resultado das imagens individuais submetidas ao processamento de primeiro nível e registradas no espaço padrão $\mathrm{MNI152}$, utilizando a ferramenta de registro linear FLIRT (FMRIB's Linear Image Registration Tool). Na comparação dos casos foi utilizada a opção mixed effects, considerando a variabilidade entre os sujeitos. Para controle dos resultados falso-positivos, foi considerado significativo o conjunto de vóxeis (clusters) sobreviventes ao limiar de Z-score > 2,3 corrigidos para comparações múltiplas, com o limiar para voxel no nível de significância de $p<0,05$.

\subsubsection{Análise das RSN}


Esta análise foi realizada com a utilização da ferramenta MELODIC (Multivariate Exploratory Linear Optimized Decomposition into Independent Components) do FSL, versão 3.1.4, que decompõe os dados de RMf em diferentes componentes independentes temporais e espaciais (BECKMANN et al., 2005). Foi realizada a análise de grupo com o algoritmo dual regression, incluindo as imagens funcionais nas condições rspre e rspos, selecionando a opção Multi-session temporal concatenation, que deve ser utilizada quando há interesse em avaliar os padrões espaciais, em protocolos que apresentam o padrão temporal da resposta variável nos diferentes sujeitos. Com o algoritmo dual regression o conjunto de mapas espaciais da análise de grupo foi usado para gerar versões dos mapas espaciais e séries temporais específicas de cada sujeito (BECKMANN et al., 2009; FILIPPINI et al., 2009); nesse algoritmo, para cada sujeito, o conjunto de mapas espaciais da análise de grupo é submetido à regressão no conjunto de dados do próprio sujeito, resultando no conjunto de séries temporais sujeito-específico, um para cada mapa espacial da análise de grupo; subsequentemente, é realizada a regressão dessas séries temporais no mesmo conjunto de dados de cada sujeito, resultando no conjunto de mapas espaciais específicos de cada indivíduo, um para cada mapa espacial da análise de grupo. O número de componentes independentes foi definido em 20, permitindo a comparação dos resultados encontrados por Smith et al., 2009. As imagens funcionais individuais foram pré-processadas nas seguintes etapas: reorientação das imagens funcionais para que apresentassem a mesma orientação das imagens de referência (Montreal Neurological Institute, MNI152), usando a ferramenta fs/reorient2std do FSL; remoção de vóxeis em estruturas extraencefálicas com a ferramenta BET (Brain Extration Tool); filtro temporal passa-alto para a remoção de artefatos de baixa frequência com tempo máximo de passagem de 100 $\mathrm{s}$; correção de movimento utilizando a ferramenta McFLIRT (Motion correction using FMRIB's Linear Registration Tool), correção do tempo de aquisição dos cortes, que tiveram aquisição intercalada de baixo para cima, no plano anteroposterior; suavização espacial com filtro Gaussiano de $4 \mathrm{~mm}$, para o aumento da razão sinal/ruído das imagens. As diferenças entre as condições rspre e rspos foram testadas usando a ferramenta randomise do FSL, que efetua a comparação pareada por teste de permutação, com 10.000 permutações. A análise dual regression foi realizada duas vezes, com duas subseleções de sujeitos, incluindo 13 e incluindo 5 
sujeitos, devido às diferenças encontradas nas dosagens de melatonina, conforme explicado na seção 7.5 .

Foi realizada a análise de grupo das condições rspre e rspos isoladamente. As RSN encontradas nessas duas condições foram comparadas a um padrão (template) descrito por Smith et al. (2009), contendo 10 redes neurais. A comparação foi feita usando a ferramenta fslcc do FSL, que efetua a correlação cruzada entre todos os componentes resultantes da análise de grupo com o conjunto de redes neurais de referência. $O$ valor mínimo de $r$ foi estabelecido em 0,25 . A comparação com o fs/cc foi realizada duas vezes, com duas subseleções de sujeitos, incluindo 13 sujeitos e incluindo 5 sujeitos, devido às diferenças encontradas nas dosagens de melatonina, conforme explicado na seção 7.5.

\subsubsection{Análise da conectividade funcional da pineal}

A conectividade funcional da pineal foi avaliada pela análise de correlação do sinal BOLD na pineal (Region of Interest, $R O I$ ) com o sinal BOLD nos demais vóxeis cerebrais estudados (seed-based analysis).

Foram realizadas as análises de primeiro nível para o rspre e rspos de cada sujeito, a análise de grupo da condição rspre, a análise de grupo da condição rspos e a análise de grupo comparando as duas condições. Para a extração da série temporal do sinal BOLD da pineal, foi desenhada a máscara da pineal de cada sujeito com o uso da ferramenta FSLview, utilizado a imagem funcional-exemplo gerada no pré-processamento do MELODIC, com número de vóxeis que variaram de 4 a 6 por sujeito. A seleção dos vóxeis das pineais foi feito tentando-se excluir, sempre que possível, as áreas de ausência de sinal nas pineais, provavelmente ocasionadas pela presença de calcificações. A extração da série temporal do sinal BOLD da pineal foi realizada utilizando o arquivo de imagens filtered_func_data, que corresponde aos dados em quatro dimensões (4 D) pré-processados no MELODIC para correção de movimento, e a ferramenta fslmaths do programa FSL. Foi aplicado filtro temporal passa-baixo de $6 \mathrm{~s}$ nas séries temporais da pineal de cada caso utilizando a ferramenta fs/maths do programa FSL, para remoção de artefatos de alta frequência. Foi realizada a correção do tempo de aquisição dos cortes de cada caso, usando a ferramenta slicetimer do programa FSL. Na análise, foram acrescentadas as séries temporais do sinal BOLD do líquor e da região da veia 
cerebral magna e os dados fisiológicos respiratórios como fatores de confusão adicionais. Foi utilizada a ferramenta Physiological Noise Modelling (PNM) do programa FSL para gerar os fatores de confusão a partir dos dados fisiológicos respiratórios de cada sujeito. Não foi possível incluir os dados fisiológicos de frequência cardíaca dos participantes como fatores de confusão, por se apresentarem com muito ruído.

\subsubsection{Análise espectral do sinal BOLD da pineal}

Foi extraída a série temporal da pineal de cada sujeito a partir das imagens funcionais originais, nas condições rspre, luz e rspos, usando as máscaras das pineais de cada sujeito, previamente desenhadas, e a ferramenta fs/maths do programa FSL.

Foi calculado o periodograma da série temporal da pineal de cada sujeito e em cada condição com a transformada discreta de Fourier, após a normalização do sinal para média 0 e variância 1 , possibilitando medir a contribuição da oscilação em cada frequência na variância do sinal.

Foi comparado o poder máximo da frequência de oscilação do sinal BOLD na pineal nas frequências entre 0,002 e $0,003 \mathrm{~Hz}$, que incluíam a frequência do estímulo luminoso aplicado (frequência do estímulo luminoso $=1 / 360 \mathrm{~Hz}=0,00277$ ), nas condições rspre, luz e rspos. Esta análise foi feita duas vezes, incluindo 15 sujeitos e incluindo 10 sujeitos. Optamos por fazer a análise com 15 sujeitos sem incluir a condição luz, para comparar as condições rspre e rspos. Decidimos realizar a comparação da condição luz com as demais condições e para isto foi necessário fazer a subseleção de 10 sujeitos (dentre os 15 previamente incluídos) em que a sequência luz não apresentou artefatos na região da pineal, conforme explicado na seção 7.4.2.

\subsection{Análise das amostras de sangue total}

A dosagem da melatonina plasmática foi realizada utilizando o kit Melatonin ELISA (imunoensaio enzimático para a determinação quantitativa em diagnóstico in vitro) para soro e plasma humanos (IBL International, Hamburg, Germany), seguindo as instruções fornecidas no kit. As análises dos resultados foram realizadas com o 
programa Prism, versão 6.0f (GraphPad Software, La Jolla, CA, USA).

\subsection{Análise estatística}

As comparações entre médias foram realizadas com o teste $\mathrm{T}$ de Wilcoxon ou com o teste de Friedman.

A análise de correlação foi feita pela determinação do coeficiente de correlação de Spearman.

O nível de significância considerado em todos os testes estatísticos foi de $p<0,05$. Nos testes de Wilcoxon foi realizada a correção do valor de $\mathrm{p}$ para comparações múltiplas pelo método de Bonferroni.

Os testes estatísticos foram realizados com o programa Prism, versão 6.0f (GraphPad Software, La Jolla, CA, USA). 


\section{RESULTADOS}

\subsection{Participantes}

Foram recrutados 24 sujeitos (9 homens), com faixa etária variando de 22 a 50 anos, média de 32,7 anos.

\subsection{Questionários}

\subsubsection{Saúde geral}

Nenhum participante foi excluído das análises dos dados em decorrência dos resultados do questionário geral de saúde. Alguns indivíduos apresentaram antecedentes de cirurgias e doenças crônicas (correção de persistência do canal arterial, colecistectomia, cirurgia por doença de Crohn, tireoidectomia total por bócio multinodular, doença de Crohn em remissão, pielonefrites de repetição, nefrolitíase, hipotireoidismo), porém, não enquadradas nos critérios de exclusão. Um participante apresentou antecedente de doença neurológica (meningite meningocócica) em 1991, tendo evoluído sem sequelas, não sendo enquadrado nos critérios de exclusão. Um participante apresentou antecedente de internação por traumatismo cranioencefálico em 1993, não sendo submetido a neurocirurgia na ocasião, evoluindo sem sequelas e, por isso, não excluído do estudo. Alguns participantes faziam uso de medicamentos (anticoncepcional oral, finasterida e levotiroxina). Um participante era fumante (sujeito 6) e foi orientado a não fumar no dia do exame de RMf.

\subsubsection{SRQ-20}

Nenhum participante foi excluído das análises dos dados devido aos resultados do questionário de saúde mental. Todos os participantes apresentaram escores menores ou iguais a 7 , sendo considerados casos negativos para o rastreamento de transtornos mentais não-psicóticos. Os resultados do questionário SRQ-20 estão listados na tabela 1. 
Tabela 1 - Resultados do questionário SRQ-20

\begin{tabular}{|c|c|c|c|}
\hline SUJEITO & GÊNERO & IDADE & ESCORE \\
\hline 1 & $M$ & 50 & 0 \\
\hline 2 & $F$ & 25 & 2 \\
\hline 3 & $F$ & 24 & 0 \\
\hline 4 & $F$ & 23 & 7 \\
\hline 5 & $F$ & 22 & 3 \\
\hline 6 & $F$ & 30 & 0 \\
\hline 8 & $M$ & 33 & 2 \\
\hline $7=9$ & $M$ & 27 & 2 \\
\hline 10 & $M$ & 26 & 1 \\
\hline 11 & $\mathrm{~F}$ & 31 & 0 \\
\hline 12 & $M$ & 38 & 1 \\
\hline 13 & $F$ & 29 & 1 \\
\hline 14 & $F$ & 29 & 1 \\
\hline 15 & $\mathrm{~F}$ & 43 & 4 \\
\hline 16 & $\mathrm{~F}$ & 43 & 0 \\
\hline 17 & $\mathrm{~F}$ & 32 & 2 \\
\hline 18 & $\mathrm{~F}$ & 34 & 0 \\
\hline 19 & $M$ & 30 & 0 \\
\hline 20 & $F$ & 36 & 7 \\
\hline 21 & M & 33 & 1 \\
\hline 22 & M & 25 & 1 \\
\hline 23 & $\mathrm{~F}$ & 35 & 3 \\
\hline 24 & $M$ & 39 & 3 \\
\hline 25 & $\mathrm{~F}$ & 48 & 2 \\
\hline
\end{tabular}

\subsubsection{Cronotipo}

Vinte e dois voluntários responderam ao questionário sobre cronotipo. $\mathrm{Na}$ população estudada $4,2 \%$ eram matutinos extremos, $25 \%$ eram matutinos, $50 \%$ eram intermediários, $8,3 \%$ eram vespertinos, $4,2 \%$ eram vespertinos extremos. Os resultados do questionário sobre cronotipo encontram-se na tabela 2 e figura 16. 
Tabela 2 - Resultados do questionário sobre cronotipo

\begin{tabular}{|c|c|}
\hline SUJEITO & CRONOTIPO \\
\hline 1 & Matutino \\
\hline 2 & Intermediário \\
\hline 3 & Intermediário \\
\hline 4 & Intermediário \\
\hline 5 & Matutino extremo \\
\hline 6 & Intermediário \\
\hline 7 e 9 & Matutino \\
\hline 8 & Intermediário \\
\hline 10 & Matutino \\
\hline 11 & Intermediário \\
\hline 12 & --- \\
\hline 13 & Intermediário \\
\hline 14 & Intermediário \\
\hline 15 & Intermediário \\
\hline 16 & Vespertino \\
\hline 17 & Matutino \\
\hline 18 & Vespertino \\
\hline 19 & Vespertino extremo \\
\hline 20 & Matutino \\
\hline 21 & --- \\
\hline 22 & Intermediário \\
\hline 23 & Intermediário \\
\hline 24 & Intermediário \\
\hline 25 & Matutino \\
\hline
\end{tabular}

--- = dado não disponível 
Figura 16 - Distribuição do cronotipo na população estudada

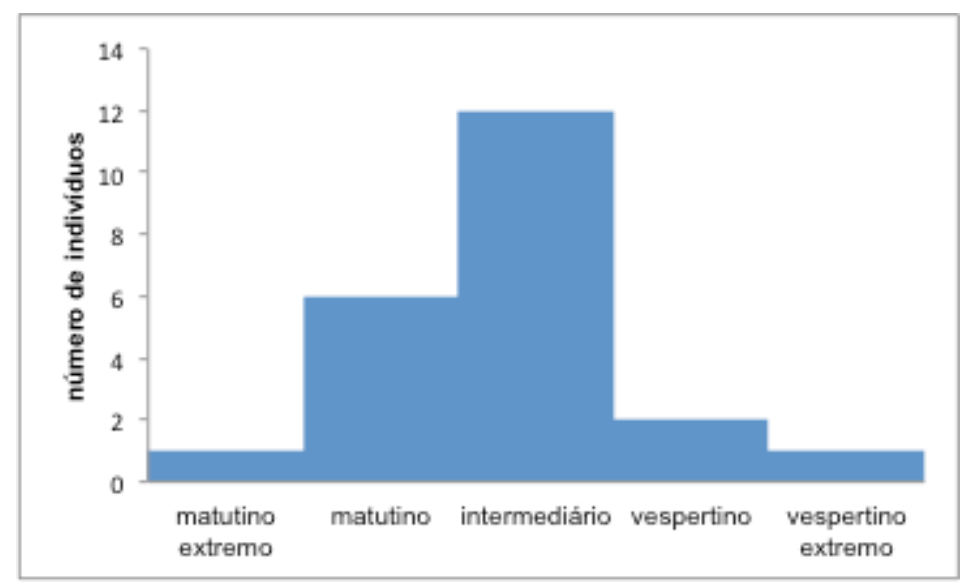

No eixo vertical está o número de indivíduos da população estudada.

\subsection{Tomografia computadorizada do crânio}

Vinte participantes foram submetidos ao exame de TC. Três voluntários optaram por não realizar o exame de TC por vontade própria (sujeitos 12, 20 e 21), devido à inconveniência de retornar ao Hospital em dia diferente do dia do exame de RMf. Um voluntário (sujeito 24) foi excluído da análise dos dados, conforme explicado na seção 7.4.2., e, por este motivo, não foi submetido a todas as avaliações previstas neste estudo, incluindo a TC.

\subsubsection{Análise estrutural}

Os exames de TC foram avaliados por neurorradiologistas experientes, seguindo a rotina clínica de laudos do InRad. Não foram encontradas alterações encefálicas significativas.

\subsubsection{Análise do grau de calcificação pineal}

Todos os participantes que realizaram a TC apresentaram calcificações pineais. $40 \%$ dos participantes apresentaram pineais pouco calcificadas, $30 \%$ apresentaram pineais moderadamente calcificadas e $30 \%$ apresentaram pineais muito calcificadas 
(figura 17). Os resultados da avaliação qualitativa do grau de calcificação pineal encontram-se na tabela 3.

Figura 17 - Tomografias computadorizadas de crânio de 4 participantes

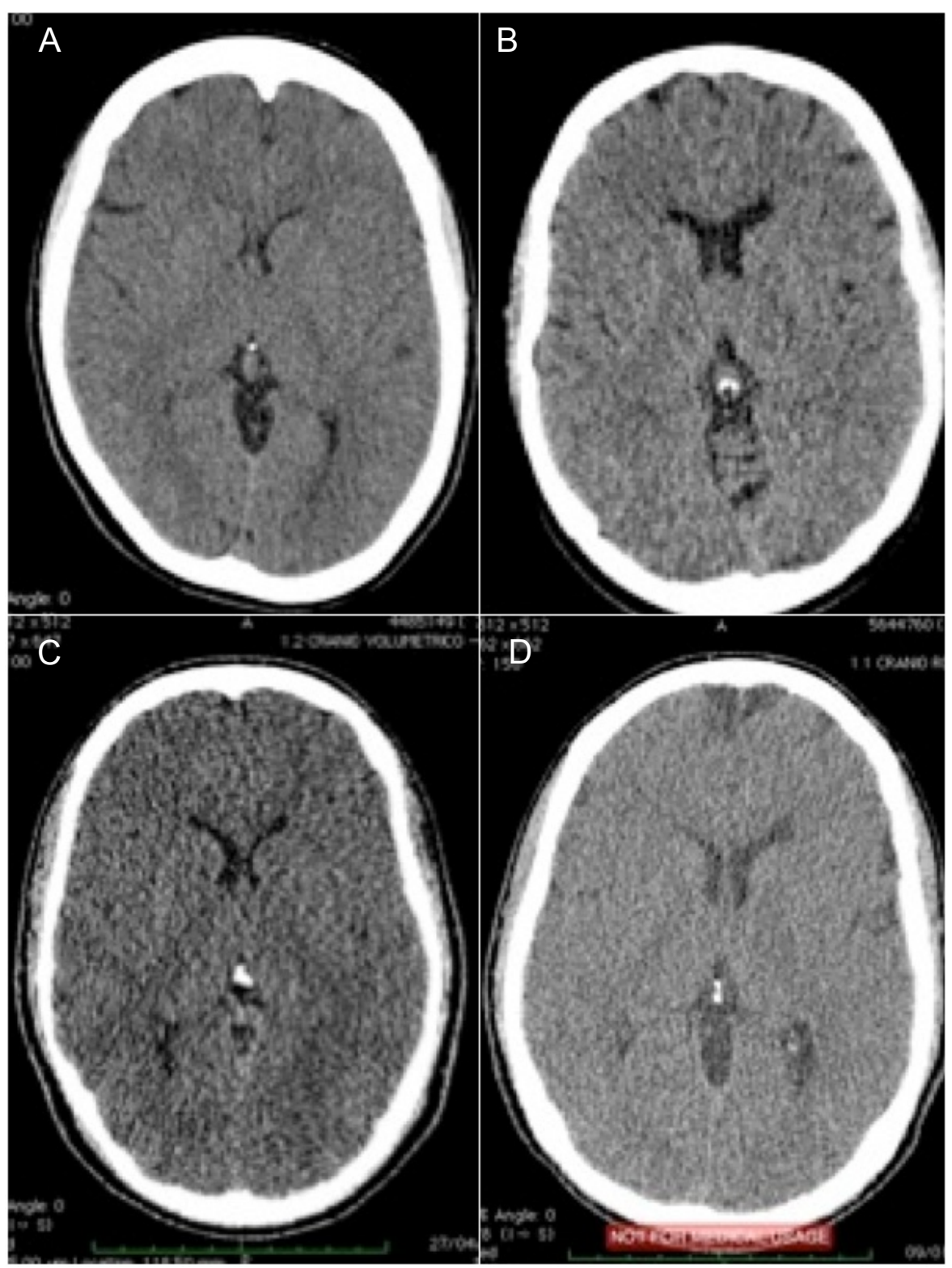

A a D) Cortes axiais das tomografias de voluntários diferentes, em plano que inclui as pineais. A) Pineal pouco calcificada; B) pineal moderadamente calcificada; C e D) pineais muito calcificadas. 
Tabela 3 - Avaliação qualitativa do grau de calcificação pineal

\begin{tabular}{|c|c|c|c|c|c|c|}
\hline \multirow[b]{2}{*}{ SUJEITO } & \multirow[b]{2}{*}{ IDADE } & \multicolumn{5}{|c|}{ GRAU DE CALCIFICAÇAO } \\
\hline & & 0 & 1 & & 2 & 3 \\
\hline 1 & 50 & & & & & $\bar{x}$ \\
\hline 2 & 25 & & $\mathrm{X}$ & & & \\
\hline 3 & 24 & & $\mathrm{X}$ & & & \\
\hline 4 & 23 & & $x$ & & & \\
\hline 5 & 22 & & $\mathrm{X}$ & & & \\
\hline 6 & 30 & & & & $X$ & \\
\hline $7=9$ & 27 & & & & & $X$ \\
\hline 8 & 33 & & & & & $\mathrm{X}$ \\
\hline 10 & 26 & & & & & $X$ \\
\hline 11 & 31 & & $\mathrm{X}$ & & & \\
\hline 12 & 38 & & & --- & & \\
\hline 13 & 29 & & & & $X$ & \\
\hline 14 & 29 & & & & & $X$ \\
\hline 15 & 43 & & & & $X$ & \\
\hline 16 & 43 & & $\mathrm{X}$ & & & \\
\hline 17 & 32 & & & & & $\mathrm{X}$ \\
\hline 18 & 34 & & $\mathrm{X}$ & & & \\
\hline 19 & 30 & & & & $X$ & \\
\hline 20 & 36 & & & --- & & \\
\hline 21 & 33 & & & --- & & \\
\hline 22 & 25 & & $X$ & & & \\
\hline 23 & 35 & & & & $X$ & \\
\hline 24 & 39 & & & --- & & \\
\hline 25 & 48 & & & & $X$ & \\
\hline
\end{tabular}

--- = não foi submetido ao exame de TC

$0=$ ausência de calcificações pineais

$1=$ pineal pouco calcificada

$2=$ pineal moderadamente calcificada

$3=$ pineal muito calcificada

Não houve correlação entre a idade do participante e o grau de calcificação da pineal (figura 18). 
Figura 18 - Análise da correlação da idade dos participantes com o grau de calcificação da pineal

A

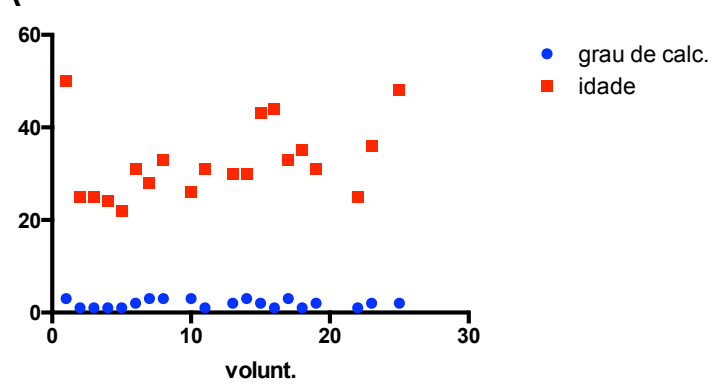

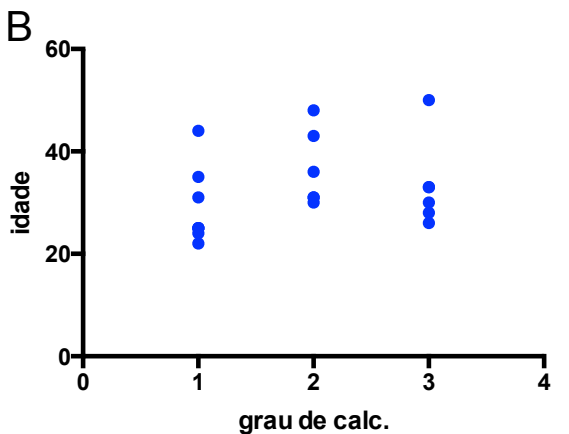

A) Distribuição do grau de calcificação pineal e idade dos participantes. B) Não houve correlação entre o grau de calcificação pineal e a idade dos voluntários (teste de correlação de Spearman, $r=0,3339, p=0,075$ ).

\subsection{Ressonância Magnética}

\subsubsection{Imagens estruturais}

Foi encontrada alteração encefálica relevante (lesões perivenulares em FLAIR agrupadas em região subependimária temporal direita e outras áreas) em um participante (sujeito 24), sendo necessária a sua exclusão das análises dos dados. Este voluntário foi submetido ao exame diagnóstico de RM do encéfalo e encaminhado para a avaliação e acompanhamento por neurologista do ambulatório de Neurologia do HC FMUSP. Não foram encontradas alterações encefálicas significativas nos demais casos.

\subsubsection{Imagens funcionais}

Foram realizados 25 exames de RM em 24 participantes (tabela 4).

Tabela 4 - Idade e gênero dos voluntários que foram submetidos ao exame de RMf

(continua)

\begin{tabular}{ccc}
\hline SUJEITO & IDADE (ANOS) & GÊNERO \\
\hline $\mathbf{1}$ & 50 & MASC \\
$\mathbf{2}$ & 25 & FEM \\
$\mathbf{3}$ & 25 & FEM
\end{tabular}


Tabela 4 - Idade e gênero dos voluntários que foram submetidos ao exame de RMf (conclusão)

\begin{tabular}{ccc}
\hline SUJEITO & IDADE (ANOS) & GÊNERO \\
\hline $\mathbf{4}$ & 24 & FEM \\
$\mathbf{5}$ & 22 & FEM \\
$\mathbf{6}$ & 31 & FEM \\
$\mathbf{7 =}$ & 28 & MASC \\
$\mathbf{8}$ & 33 & MASC \\
$\mathbf{1 0}$ & 26 & MASC \\
$\mathbf{1 1}$ & 31 & FEM \\
$\mathbf{1 2}$ & 39 & MASC \\
$\mathbf{1 3}$ & 30 & FEM \\
$\mathbf{1 4}$ & 30 & FEM \\
$\mathbf{1 5}$ & 43 & FEM \\
$\mathbf{1 6}$ & 44 & FEM \\
$\mathbf{1 7}$ & 33 & FEM \\
$\mathbf{1 8}$ & 35 & FEM \\
$\mathbf{1 9}$ & 31 & MASC \\
$\mathbf{2 0}$ & 37 & FEM \\
$\mathbf{2 1}$ & 33 & MASC \\
$\mathbf{2 2}$ & 25 & MASC \\
$\mathbf{2 3}$ & 36 & FEM \\
$\mathbf{2 4}$ & 39 & MASC \\
$\mathbf{2 5}$ & 48 & FEM \\
\hline
\end{tabular}

Os primeiros 5 participantes constituíram a fase piloto e não foram incluídos nas análises dos dados de RMf. O estimulador luminoso apresentou defeito no funcionamento no $7^{\circ}$ caso e o exame de RM foi realizado sem a aplicação do estímulo luminoso; esse voluntário foi submetido novamente ao exame de RM após 2 meses, quando foi realizado o teste completo, com a aplicação do estímulo luminoso. $\mathrm{O} 7^{\circ}$ e o $9^{\circ}$ casos correspondem ao mesmo sujeito. $\mathrm{O} 7^{\circ}$ caso não foi incluído nas análises dos dados. O $24^{\circ}$ sujeito foi excluído das análises dos dados de RMf devido à presença de alterações encefálicas encontradas nas imagens estruturais, conforme relatado na seção 7.4.1. Foi necessária a exclusão de casos das análises das imagens funcionais por motivo de movimentação excessiva do participante ou pela presença de artefatos, gerados pelo equipamento de RM ou pelo estimulador luminoso. A tabela 5 apresenta a lista dos casos que foram incluídos e excluídos nos diferentes tipos de análise das imagens funcionais de RM. 
Tabela 5 - Sujeitos incluídos e excluídos dos diferentes tipos de análise de RMf

\begin{tabular}{|c|c|c|c|c|}
\hline SUJEITO & $\begin{array}{l}\text { ÁREAS DE } \\
\text { ATIVAÇÃO } \\
\text { PELA LUZ }\end{array}$ & $\begin{array}{c}\text { REDES NEURAIS } \\
\text { DO ESTADO DE } \\
\text { REPOUSO }\end{array}$ & $\begin{array}{c}\text { CONECTIVIDADE } \\
\text { FUNCIONAL DA } \\
\text { PINEAL }\end{array}$ & $\begin{array}{c}\text { ANÁLISE } \\
\text { ESPECTRAL }\end{array}$ \\
\hline 6 & $\begin{array}{l}\mathrm{E} \text { (cortes mais } \\
\text { baixos que nos } \\
\text { demais casos) }\end{array}$ & $\begin{array}{l}\mathrm{E} \text { (cortes mais } \\
\text { baixos que nos } \\
\text { demais casos) }\end{array}$ & $\begin{array}{l}\mathrm{E} \text { (cortes mais } \\
\text { baixos que nos } \\
\text { demais casos) }\end{array}$ & I \\
\hline 8 & $\begin{array}{l}\mathrm{E} \\
\text { (movimentação } \\
\text { excessiva) }\end{array}$ & $\begin{array}{l}\mathrm{E} \text { (movimentação } \\
\text { excessiva) }\end{array}$ & $\begin{array}{l}\text { E (movimentação } \\
\text { excessiva) }\end{array}$ & $\begin{array}{l}\text { E } \\
\text { (movimentação } \\
\text { excessiva) }\end{array}$ \\
\hline 9 & $\begin{array}{l}\text { E (artefatos na } \\
\text { sequência luz } \\
\text { não incluindo a } \\
\text { pineal) }\end{array}$ & $\begin{array}{l}\text { E (artefatos não } \\
\text { incluindo a pineal) }\end{array}$ & $\begin{array}{l}\text { E (artefatos não } \\
\text { incluindo a pineal) }\end{array}$ & I \\
\hline 10 & 1 & I & I & I \\
\hline 11 & $\begin{array}{l}\text { E (artefatos na } \\
\text { pineal e restante } \\
\text { do cérebro) }\end{array}$ & $\begin{array}{l}\text { E (artefatos na } \\
\text { pineal e restante } \\
\text { do cérebro) }\end{array}$ & $\begin{array}{l}\text { E (artefatos na } \\
\text { pineal e restante do } \\
\text { cérebro) }\end{array}$ & $\begin{array}{l}\text { E (artefatos na } \\
\text { pineal e restante } \\
\text { do cérebro) }\end{array}$ \\
\hline 12 & $\begin{array}{l}\text { E (artefatos e } \\
\text { movimentação } \\
\text { na sequência } \\
\text { luz) }\end{array}$ & 1 & 1 & $\begin{array}{l}\text { E (artefatos e } \\
\text { movimentação } \\
\text { na sequência } \\
\text { luz) }\end{array}$ \\
\hline 13 & $\begin{array}{l}\text { E (artefatos na } \\
\text { pineal e restante } \\
\text { do cérebro) }\end{array}$ & $\begin{array}{l}\text { E (artefatos na } \\
\text { pineal e restante } \\
\text { do cérebro) }\end{array}$ & $\begin{array}{l}\text { E (artefatos na } \\
\text { pineal e restante do } \\
\text { cérebro) }\end{array}$ & $\begin{array}{l}\text { E (artefatos na } \\
\text { pineal e restante } \\
\text { do cérebro) }\end{array}$ \\
\hline 14 & $\begin{array}{l}\text { E (artefatos na } \\
\text { sequência luz } \\
\text { não incluindo a } \\
\text { pineal) }\end{array}$ & 1 & 1 & 1 \\
\hline 15 & $\begin{array}{l}\text { E (artefatos na } \\
\text { sequência luz } \\
\text { não incluindo a } \\
\text { pineal) }\end{array}$ & I & I & I \\
\hline 16 & $\begin{array}{l}\text { E (artefatos na } \\
\text { sequência luz } \\
\text { não incluindo a } \\
\text { pineal) }\end{array}$ & 1 & 1 & 1 \\
\hline 17 & i & I & I & I \\
\hline 18 & I & I & I & 1 \\
\hline 19 & 1 & I & 1 & 1 \\
\hline 20 & I & I & I & 1 \\
\hline 21 & 1 & I & 1 & 1 \\
\hline 22 & $\begin{array}{l}\text { E (artefatos na } \\
\text { sequência luz } \\
\text { incluindo a } \\
\text { pineal) }\end{array}$ & I & I & I \\
\hline 23 & I & I & I & 1 \\
\hline 25 & I & I & I & 1 \\
\hline
\end{tabular}

7.4.2.1 Análise da ativação de áreas encefálicas em resposta à luz 
No mapa gerado com a análise das imagens funcionais de 8 sujeitos $(10,17,18$, 19, 20, 21, 23 e 25) adquiridas durante a aplicação do estímulo luminoso, não foi observada ativação da pineal, notando-se ativação do córtex visual bilateral, tálamo esquerdo, pré-cuneus esquerdo, giro do cíngulo posterior esquerdo e giro frontal superior bilateral (figura 19).

Figura 19 - Áreas de ativação cerebral em resposta à aplicação do estímulo luminoso

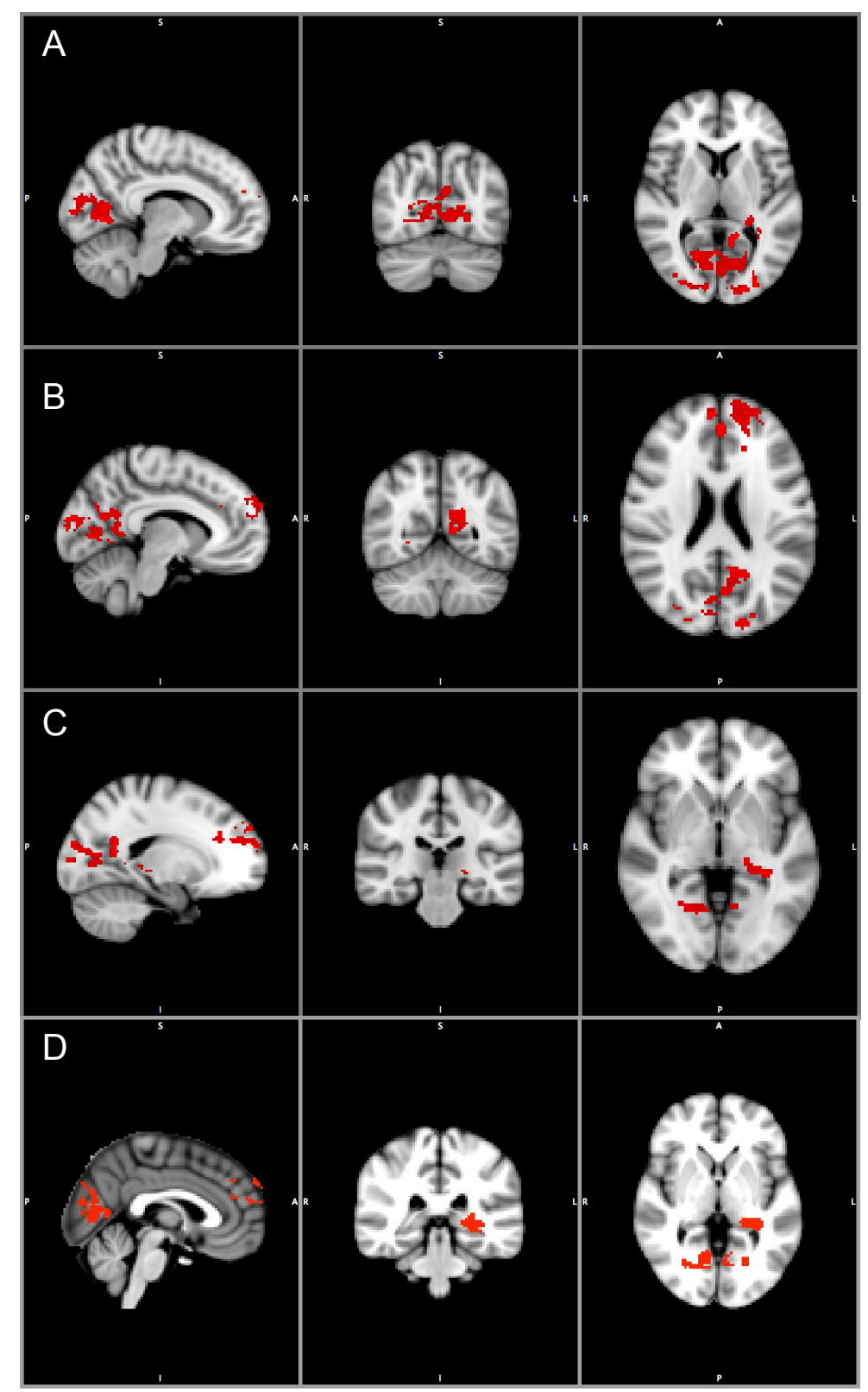

As áreas ativadas (em vermelho) foram: A) córtex visual bilateral, B) tálamo esquerdo, C) precuneus esquerdo e giro frontal superior bilateral $(N=8 ; Z$-score $>2,3 ; p<0,05)$. D) Não houve ativação da pineal. 


\subsubsection{Análise das RSN}

Foram comparadas pelo algoritmo dual regression as RSN nas condições pré e pós-estímulo luminoso de 13 sujeitos $(10,12,14,15,16,17,18,19,20,21,22,23$ e 25). Não foi encontrada diferença estatisticamente significativa entre as duas condições. Na comparação dos componentes independentes do estado de repouso, gerados na análise de grupo nas condições rspre e rspos, com as redes neurais do template foram encontradas as seguintes redes neurais: visual (área lateral), rede do estado padrão (default mode network, DMN), sensoriomotor, auditiva, controle executivo, frontoparietal esquerda na condição rspre (valor médio de $r=0,39$, variando de 0,25 a 0,59) e visual (áreas medial e lateral), DMN, sensoriomotor, auditiva, controle executivo, frontoparietal direita e frontoparietal esquerda na condição rspos (valor médio de $r=0,44$, variando de 0,27 a 0,74 ) (exemplos de RSN encontradas na análise de grupo encontram-se nos apêndices $C$ e D). As tabelas 6 e 7 mostram a rede neural do template, o número do componente independente gerado na análise de grupo do MELODIC e o valor de $r$ encontrado no teste de correlação da análise dos grupos rspre e rspos, respectivamente, para valores de $r>$ 0,25 .

Tabela 6 - Grau de correlação dos componentes independentes da análise do grupo rspre ( 13 sujeitos incluídos) com as RSN do template, para $r>0,25$

(continua)

\begin{tabular}{ccc}
\hline $\begin{array}{c}\text { REDE NEURAL } \\
\text { IDENTIFICADA }\end{array}$ & $\begin{array}{c}\text { COMPONENTE } \\
\text { INDEPENDENTE }\end{array}$ & VALOR de $\mathbf{r}$ \\
\hline Visual lateral & 11 & 0,30 \\
\hline DMN & 1 & 0,50 \\
DMN & 10 & 0,47 \\
DMN & 11 & 0,26 \\
DMN & 13 & 0,27 \\
Sensoriomotor & 4 & 0,51 \\
Auditiva & 2 & 0,55 \\
Auditiva & 11 & 0,41 \\
Controle executivo & 2 & 0,32 \\
\hline
\end{tabular}


Tabela 6 - Grau de correlação dos componentes independentes da análise do grupo rspre (13 sujeitos incluídos) com as RSN do template, para $r>0,25$

(conclusão)

\begin{tabular}{ccc}
\hline $\begin{array}{c}\text { REDE NEURAL } \\
\text { IDENTIFICADA }\end{array}$ & $\begin{array}{c}\text { COMPONENTE } \\
\text { INDEPENDENTE }\end{array}$ & VALOR de $\mathbf{r}$ \\
\hline Controle executivo & 6 & 0,25 \\
Controle executivo & 14 & 0,32 \\
Controle executivo & 18 & 0,31 \\
$\begin{array}{c}\text { Frontoparietal } \\
\text { esquerda }\end{array}$ & 8 & 0,59 \\
\hline
\end{tabular}

$\mathrm{Na} 1^{\mathrm{a}}$ coluna estão as redes neurais do template (SMITH et al., 2009). Na $2^{\mathrm{a}}$ coluna estão os números dos componentes independentes gerados na análise do grupo rspre. $\mathrm{Na} 3^{\mathrm{a}}$ coluna estão os valores de $\mathrm{r}$ encontrados no teste de correlação.

$\mathrm{DMN}=$ default mode network

Tabela 7 - Grau de correlação dos componentes independentes da análise do grupo rspos (13 sujeitos incluídos) com as RSN do template, para $r>0,25$

\begin{tabular}{ccc}
\hline $\begin{array}{c}\text { REDE NEURAL } \\
\text { IDENTIFICADA }\end{array}$ & $\begin{array}{c}\text { COMPONENTE } \\
\text { INDEPENDENTE }\end{array}$ & VALOR de r \\
\hline Visual medial & 2 & 0,63 \\
Visual lateral & 5 & 0,27 \\
DMN & 1 & 0,74 \\
Sensoriomotor & 4 & 0,51 \\
Auditiva & 3 & 0,35 \\
Auditiva & 4 & 0,40 \\
Auditiva & 12 & 0,40 \\
Controle executivo & 3 & 0,36 \\
\hline Controle executivo & 14 & 0,27 \\
\hline $\begin{array}{c}\text { Controle executivo } \\
\text { Frontoparietal } \\
\text { direita }\end{array}$ & 17 & 0,28 \\
\hline $\begin{array}{c}\text { Frontoparietal } \\
\text { esquerda }\end{array}$ & 10 & 0,57 \\
\hline
\end{tabular}

$\mathrm{Na} 1^{\mathrm{a}}$ coluna estão as redes neurais do template (SMITH et al., 2009). Na $2^{\mathrm{a}}$ coluna estão os números dos componentes independentes gerados na análise do grupo rspos. $\mathrm{Na} 3^{\mathrm{a}}$ coluna estão os valores de $\mathrm{r}$ encontrados no teste de correlação.

$\mathrm{DMN}=$ default mode network 
Não foram encontradas diferenças na análise dos grupos rspre e rspos com 13 sujeitos na inspeção visual, em relação aos resultados encontrados com o uso da ferramenta fs/cc.

Decidimos realizar este tipo de análise com subseleção incluindo, dentre os 13 participantes inicialmente avaliados, somente aqueles que apresentaram redução imediata ou tardia da concentração plasmática de melatonina associada ao estímulo luminoso, conforme descrito na seção 7.5. Foi realizada a comparação das condições rspre e rspos pelo algoritmo dual regression incluindo 5 sujeitos. Os participantes avaliados foram 10, 15, 16, 19 e 23. Não foi encontrada diferença estatisticamente significativa entre as duas condições na análise incluindo os 5 sujeitos. Na comparação dos componentes independentes do estado de repouso, gerados na análise de grupo nas condições rspre e rspos, com as redes neurais do template foram encontradas as seguintes redes neurais: visual (área medial), DMN, sensoriomotor, auditiva, controle executivo e frontoparietal direita e esquerda na condição rspre (valor médio de $r=0,42$, variando de 0,31 a 0,58 ) e visual (área medial), DMN, sensoriomotor, auditiva, controle executivo e frontoparietal direita e esquerda na condição rspos (valor médio de $r=0,36$, variando de 0,25 a 0,57) (exemplos de RSN encontradas na análise de grupo encontram-se nos apêndices $E$ e F). As tabelas 8 e 9 mostram a rede neural do template, o número do componente independente gerado na análise de grupo do MELODIC e o valor de r encontrado no teste de correlação da análise dos grupos rspre e rspos, respectivamente, para valores de $r>0,25$.

Tabela 8 - Grau de correlação dos componentes independentes da análise do grupo rspre ( 5 sujeitos incluídos) com as RSN do template, para $r>0,25$

(continua)

\begin{tabular}{ccc}
\hline $\begin{array}{c}\text { REDE NEURAL } \\
\text { IDENTIFICADA }\end{array}$ & $\begin{array}{c}\text { COMPONENTE } \\
\text { INDEPENDENTE }\end{array}$ & VALOR de $\mathbf{~}$ \\
\hline Visual medial & 1 & 0,34 \\
DMN & 1 & 0,52 \\
DMN & 10 & 0,43 \\
Sensoriomotor & 2 & 0,31 \\
Sensoriomotor & 7 & 0,39 \\
\hline
\end{tabular}


Tabela 8 - Grau de correlação dos componentes independentes da análise do grupo rspre ( 5 sujeitos incluídos) com as RSN do template, para $r>0,25$

(conclusão)

\begin{tabular}{ccc}
\hline $\begin{array}{c}\text { REDE NEURAL } \\
\text { IDENTIFICADA }\end{array}$ & $\begin{array}{c}\text { COMPONENTE } \\
\text { INDEPENDENTE }\end{array}$ & VALOR de $\mathbf{r}$ \\
\hline Auditiva & 2 & 0,58 \\
Controle executivo & 9 & 0,35 \\
$\begin{array}{c}\text { Frontoparietal } \\
\text { direita }\end{array}$ & 10 & 0,37 \\
$\begin{array}{c}\text { Frontoparietal } \\
\text { esquerda }\end{array}$ & 3 & 0,53 \\
\hline
\end{tabular}

$\mathrm{Na} 1^{\mathrm{a}}$ coluna estão as redes neurais do template (SMITH et al., 2009). Na $2^{\mathrm{a}}$ coluna estão os números dos componentes independentes gerados na análise do grupo rspre. Na $3^{\mathrm{a}}$ coluna estão os valores de $\mathrm{r}$ encontrados no teste de correlação.

$\mathrm{DMN}=$ default mode network

Tabela 9 - Grau de correlação dos componentes independentes da análise do grupo rspos (5 sujeitos incluídos) com as RSN do template, para $r>0,25$

\begin{tabular}{|c|c|c|}
\hline $\begin{array}{l}\text { REDE NEURAL } \\
\text { IDENTIFICADA }\end{array}$ & $\begin{array}{l}\text { COMPONENTE } \\
\text { INDEPENDENTE }\end{array}$ & VALOR de $r$ \\
\hline Visual medial & 2 & 0,57 \\
\hline DMN & 6 & 0,46 \\
\hline DMN & 9 & 0,29 \\
\hline DMN & 12 & 0,48 \\
\hline Sensoriomotor & 13 & 0,28 \\
\hline Auditiva & 1 & 0,41 \\
\hline Controle executivo & 1 & 0,30 \\
\hline Controle executivo & 18 & 0,25 \\
\hline $\begin{array}{c}\text { Frontoparietal } \\
\text { direita }\end{array}$ & 1 & 0,27 \\
\hline $\begin{array}{c}\text { Frontoparietal } \\
\text { direita }\end{array}$ & 5 & 0,34 \\
\hline $\begin{array}{c}\text { Frontoparietal } \\
\text { direita }\end{array}$ & 9 & 0,25 \\
\hline $\begin{array}{c}\text { Frontoparietal } \\
\text { esquerda }\end{array}$ & 5 & 0,38 \\
\hline $\begin{array}{c}\text { Frontoparietal } \\
\text { esquerda }\end{array}$ & 15 & 0,38 \\
\hline
\end{tabular}

$\mathrm{Na} 1^{\mathrm{a}}$ coluna estão as redes neurais do template (SMITH et al., 2009). Na $2^{\mathrm{a}}$ coluna estão os números dos componentes independentes gerados na análise do grupo rspos. $\mathrm{Na} 3^{\mathrm{a}}$ coluna estão os valores de r encontrados no teste de correlação.

$\mathrm{DMN}=$ default mode network 
Não foram encontradas diferenças nos grupos rspre e rspos com 5 sujeitos na inspeção visual em relação aos resultados encontrados com o uso da ferramenta fslcc.

\subsubsection{Análise da conectividade funcional da pineal}

Nesta análise foram incluídos 13 sujeitos $(10,12,14,15,16,17,18,19,20,21$, 22, 23 e 25). O grau de calcificação pineal dos sujeitos foi: $23,1 \%$ grau $1,30,7 \%$ grau 2, 23,1\% grau 3. A informação não está disponível em $23,1 \%$ dos sujeitos (indivíduos que não realizaram a TC).

Na condição rspre, a análise de grupo da correlação da série temporal do sinal BOLD na pineal com as demais áreas cerebrais, mostrou as seguintes áreas: tálamo bilateral, ínsula bilateral, giro do cíngulo e lóbulo parietal inferior bilateral (figura 20).

Figura 20 - Conectividade funcional da pineal no grupo rspre

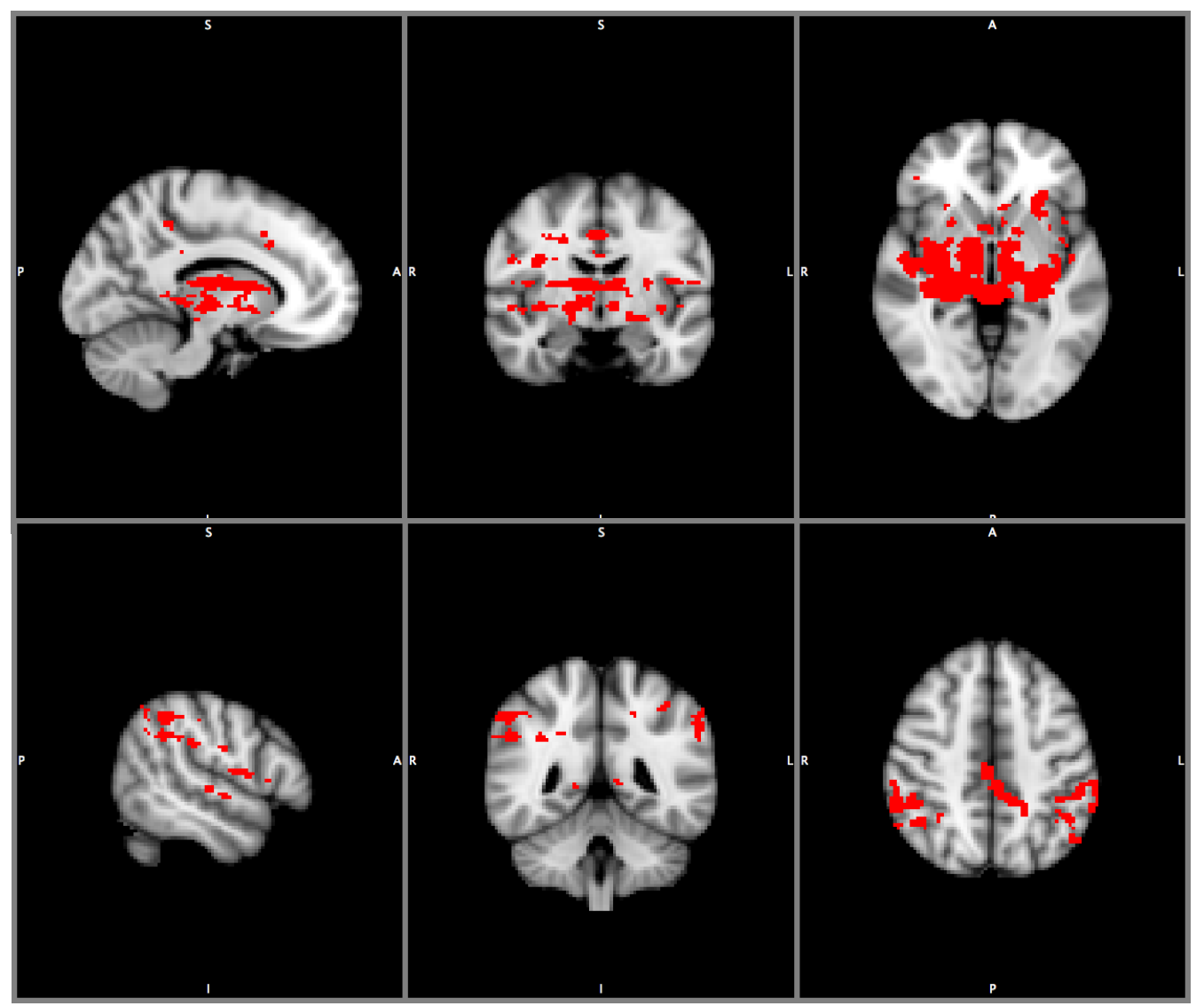

As áreas de conectividade funcional da pineal (em vermelho) evidenciadas foram: A) tálamo bilateral, ínsula bilateral, giro do cíngulo, B) lóbulo parietal inferior bilateral. 
Na condição rspos, a análise de grupo de correlação da série temporal do sinal BOLD na pineal com as demais áreas cerebrais, mostrou as seguintes áreas: tálamo bilateral, ínsula bilateral, lóbulo parietal superior direito, lóbulo parietal inferior esquerdo (figura 21).

Figura 21 - Conectividade funcional da pineal no grupo rspos

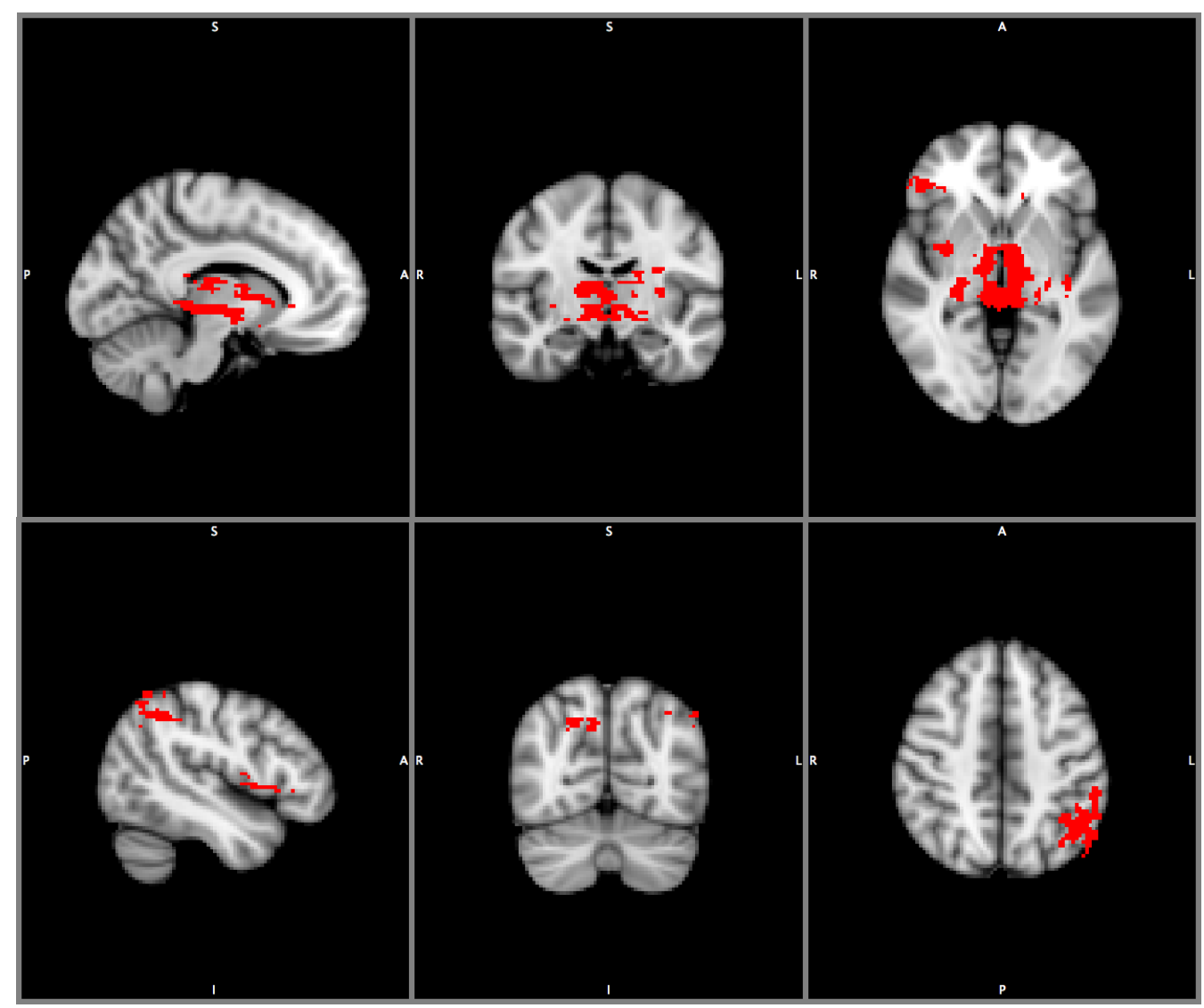

As áreas (em vermelho) de conectividade funcional da pineal evidenciadas foram: A) tálamo bilateral, ínsula bilateral, B) lóbulo parietal superior direito, lóbulo parietal inferior esquerdo.

Não foram observadas diferenças estatisticamente significativas na análise de grupo da conectividade funcional da pineal entre as condições rspre e rspos.

\subsubsection{Análise espectral da pineal}

Esta análise foi feita duas vezes, incluindo 15 sujeitos (sujeitos $6,9,10,12,14$, $15,16,17,18,19,20,21,22,23$ e 25) e incluindo 10 sujeitos (sujeitos 6, 9, 10, 17 , 
$18,19,20,21,23$ e 25).

No grupo de 15 sujeitos, o grau de calcificação pineal foi de: $20 \%$ grau $1,33,3 \%$ grau 2, 26,7\% grau 3; a informação não está disponível em $20 \%$ dos sujeitos (indivíduos que não realizaram a TC). No grupo de 10 sujeitos, o grau de calcificação pineal foi de: $10 \%$ grau 1,40\% grau 2, 30\% grau 3; a informação não está disponível em 20\% dos sujeitos (indivíduos que não realizaram a TC).

Foi realizada a comparação pareada do poder máximo da frequência de oscilação do sinal BOLD na pineal nas frequências entre 0,002 e 0,003 Hz nas condições rspre>rspos, incluindo 15 sujeitos em que as sequências funcionais puderam ser usadas na análise (sujeitos 6, 9, 10, 12, 14, 15, 16, 17, 18, 19, 20, 21, 22, 23 e 25), conforme explicado no item 7.4.2. Não foi observada diferença estatisticamente significativa na análise do poder máximo nas frequências entre 0,002 e $0,003 \mathrm{~Hz}$ do espectro do sinal BOLD na pineal nas condições rspre e rspos (figura 22).

Figura 22 - Comparação do poder máximo do espectro do sinal BOLD na pineal, nas frequências entre 0,002 e 0,003 Hz na condição rspre>rspos
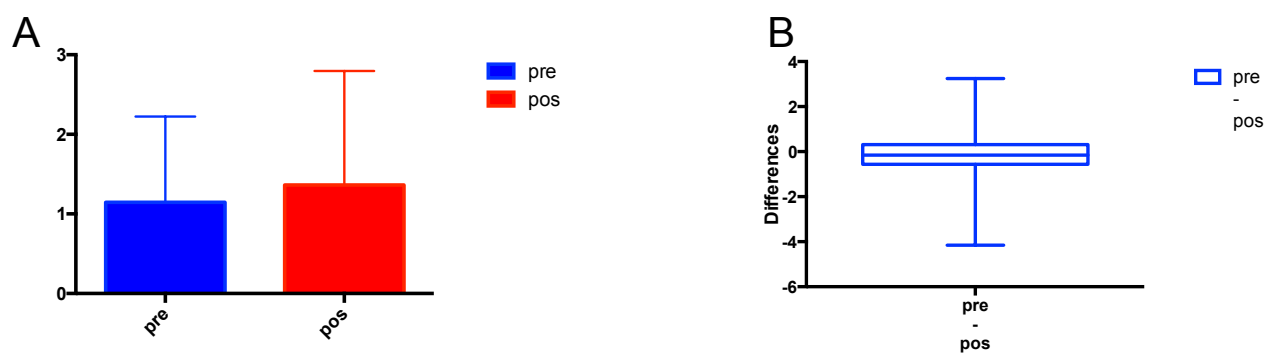

A) Em azul a média e desvio padrão do grupo rspre e em vermelho a média e desvio padrão do grupo rspos. B) Teste de Wilcoxon unicaudal (rspre $>$ rspos), $p=0,57$.

Foi calculado o poder estatístico da comparação rspre>rspos usando o programa G*Power 3, versão 3.1.9.2 (Dusseldorf, Alemanha); o cálculo mostrou que o tamanho do efeito encontrado foi de $-0,1469$ e que para atingir o poder estatístico de 0,80 , o tamanho da amostra necessária seria de 288 sujeitos, com t crítico de 1,6501 .

Foi comparado o poder máximo da frequência de oscilação do sinal BOLD na pineal nas frequências entre 0,002 e 0,003 Hz, que incluíam a frequência do estímulo luminoso aplicado (frequência do estímulo luminoso $=1 / 360 \mathrm{~Hz}=0,00277$ ), nas condições rspre, luz e rspos incluindo, dentre os 15 sujeitos inicialmente 
analisados, 10 sujeitos em que a sequência luz não apresentou artefatos na região da pineal (casos 6, 9, 10, 17, 18, 19, 20, 21, 23 e 25), conforme explicado no item 7.4.2. Não foram observadas alterações estatisticamente significativas na comparação incluindo as três condições (teste de Friedman) e as condições luz>rspos e luz>rspre (teste de Wilcoxon unicaudal, com p corrigido para comparações múltiplas) (figuras 23 a 25).

Figura 23 - Comparação do poder máximo do espectro do sinal BOLD na pineal, nas frequências entre 0,002 e 0,003 Hz nas 3 condições (rspre, luz e rspos)
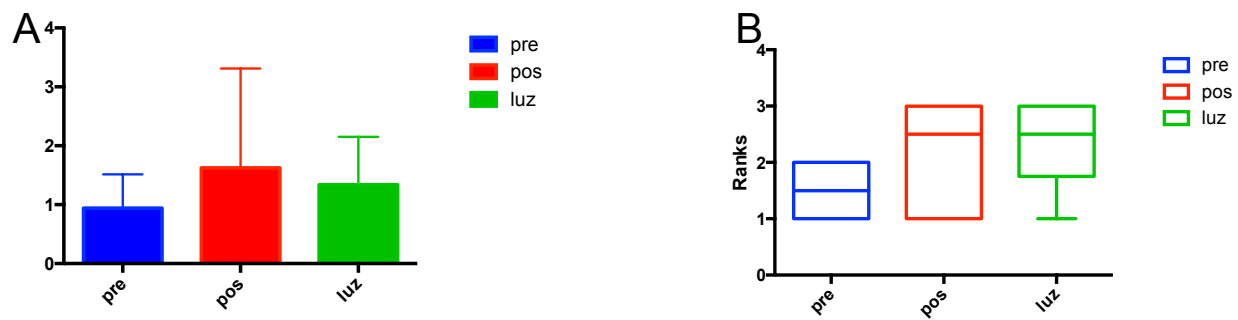

A) Em azul a média e desvio padrão do grupo rspre, em vermelho a média e desvio padrão do grupo rspos e em verde a média e desvio padrão do grupo luz. B) Teste de Friedman incluindo as 3 condições (rspre, rspos e luz) $(p=0,19)$.

Figura 24 - Comparação do poder máximo do espectro do sinal BOLD na pineal, nas frequências entre 0,002 e 0,003 Hz na condição luz>rspos

A

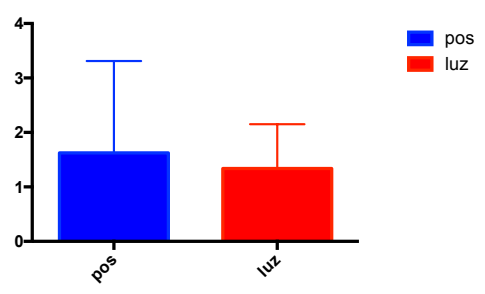

B

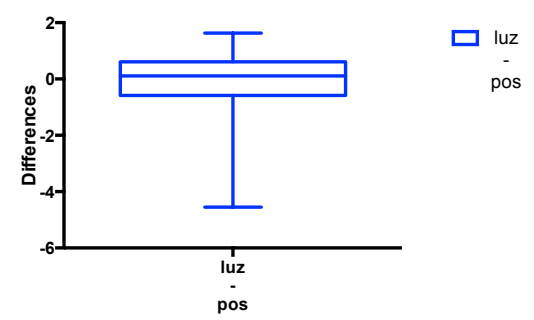

A) Em azul a média e desvio padrão do grupo rspos e em vermelho a média e desvio padrão do grupo luz. B) Teste de Wilcoxon unicaudal (luz $>$ rspos), $p=1$. 
Figura 25 - Comparação do poder máximo de oscilação do sinal BOLD na pineal, nas frequências entre 0,002 e 0,003 Hz na condição luz>rspre
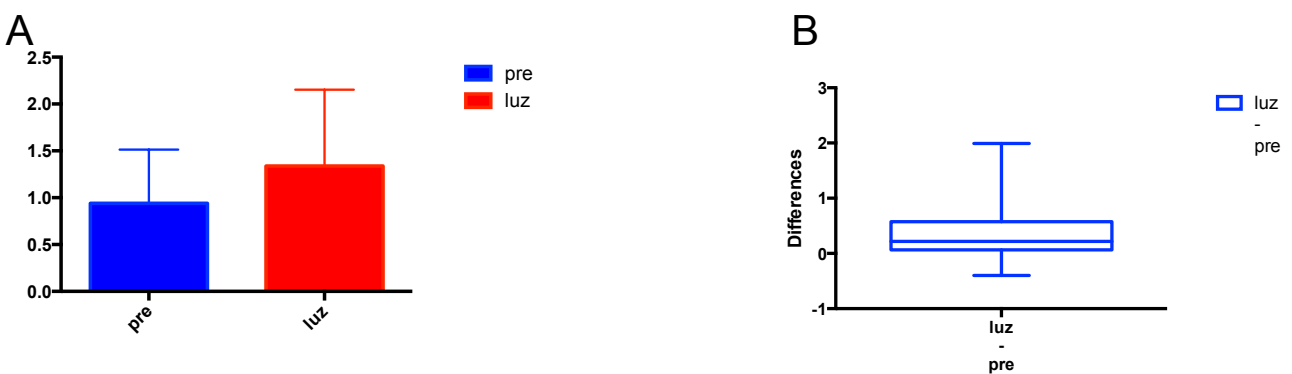

A) Em azul a média e desvio padrão do grupo rspre e em vermelho a média e desvio padrão do grupo luz. B) Teste de Wilcoxon unicaudal (luz > rspre), $p=0,06$.

Foi calculado o poder estatístico da comparação luz>rspos usando o programa G*Power 3; o cálculo mostrou que o tamanho do efeito encontrado foi de - 0,1698 e que para atingir o poder estatístico de 0,80 , o tamanho da amostra necessária seria de 216 sujeitos, com t crítico de - 1,6519.

Foi calculado o poder estatístico da comparação luz>rspre usando o programa G*Power 3; o cálculo mostrou que o tamanho do efeito encontrado foi de 0,6055 e que para atingir o poder estatístico de 0,80, o tamanho da amostra necessária seria de 19 sujeitos, com t crítico de 1,7340.

\subsection{Dosagem da melatonina plasmática}

Houve problemas técnicos na dosagem de melatonina plasmática nas amostras dos sujeitos 1 e 2, que não estão disponíveis para avaliação. Os sujeitos 7, 11 e 24 foram excluídos das análises das imagens de RMf, conforme explicado no item 7.4.2.; por esse motivo, não foi realizada a dosagem da melatonina plasmática desses sujeitos. Houve grande dificuldade de acesso venoso no voluntário 13; foram obtidas somente 3 amostras de sangue desse voluntário, a $2^{\mathrm{a}}$ amostra apresentando hemólise, que interfere na dosagem da melatonina; o sujeito 13 não foi incluído na análise dos dados sobre a dosagem de melatonina plasmática.

Os resultados mostraram que houve redução imediata na concentração plasmática de melatonina associada à aplicação do estímulo luminoso em 52,6\% dos sujeitos em que foi realizada a dosagem (sujeitos 3, 5, 6, 10, 14, 15, 16, 19, 20 e 22), redução tardia na concentração plasmática de melatonina em $15,8 \%$ dos 
sujeitos (4, 9 e 23) e redução na taxa de aumento da concentração plasmática de melatonina em 10,5\% dos sujeitos em que foi realizada a dosagem (sujeitos $17 \mathrm{e}$ 21). Em $21,1 \%$ dos sujeitos não foi observada alteração evidente na curva esperada da melatonina com a aplicação do estímulo luminoso (sujeitos 8, 12, 18 e 25). Os resultados das dosagens de melatonina plasmática encontram-se na tabela $10 \mathrm{e}$ figura 26.

Tabela 10 - Valores da dosagem de melatonina plasmática $(\mathrm{pg} / \mathrm{ml})$ nas amostras de sangue total

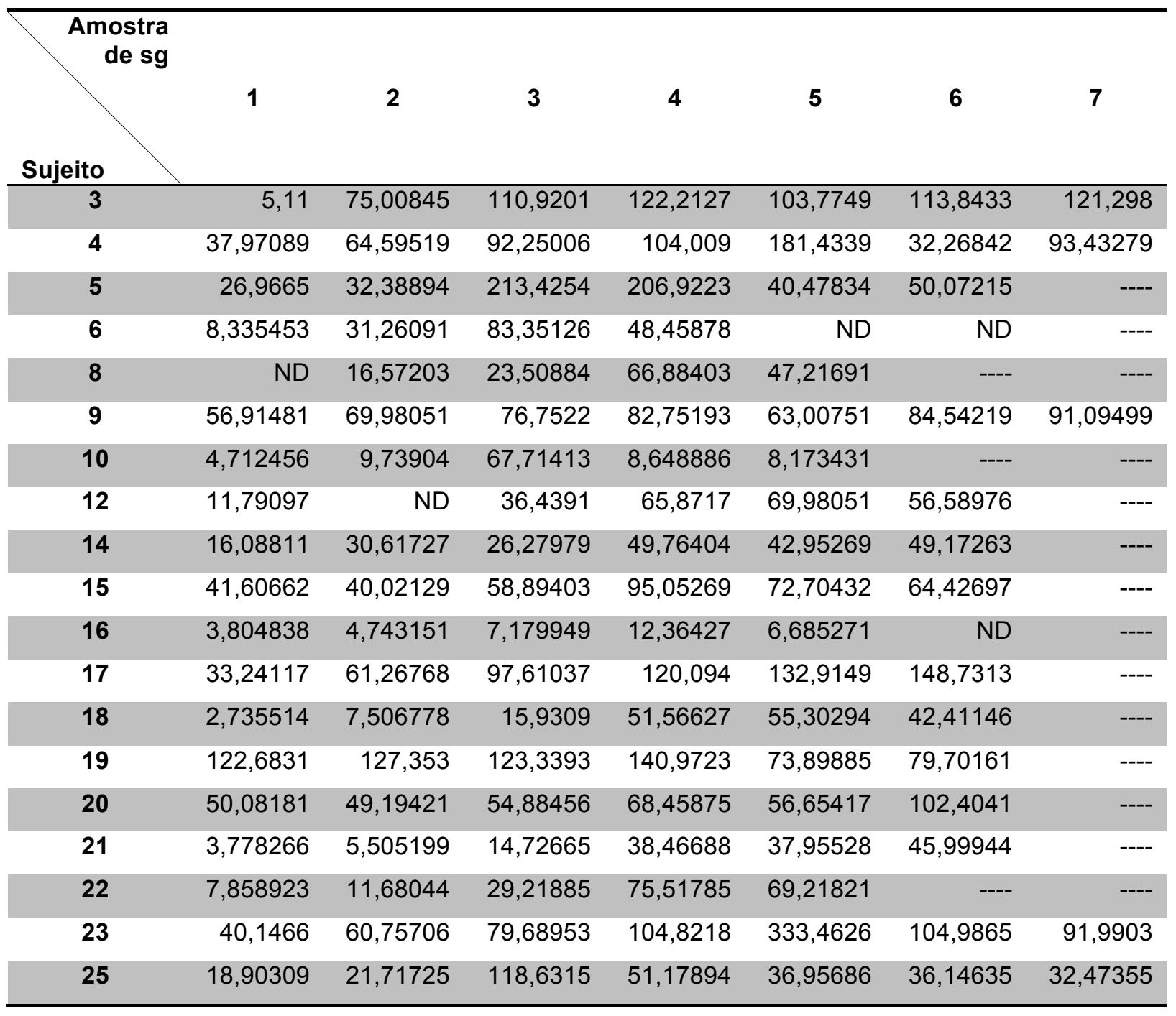

---- = amostra não coletada

ND = resultado não disponível 
Figura 26 - Gráficos das curvas de melatonina plasmática

(continua)
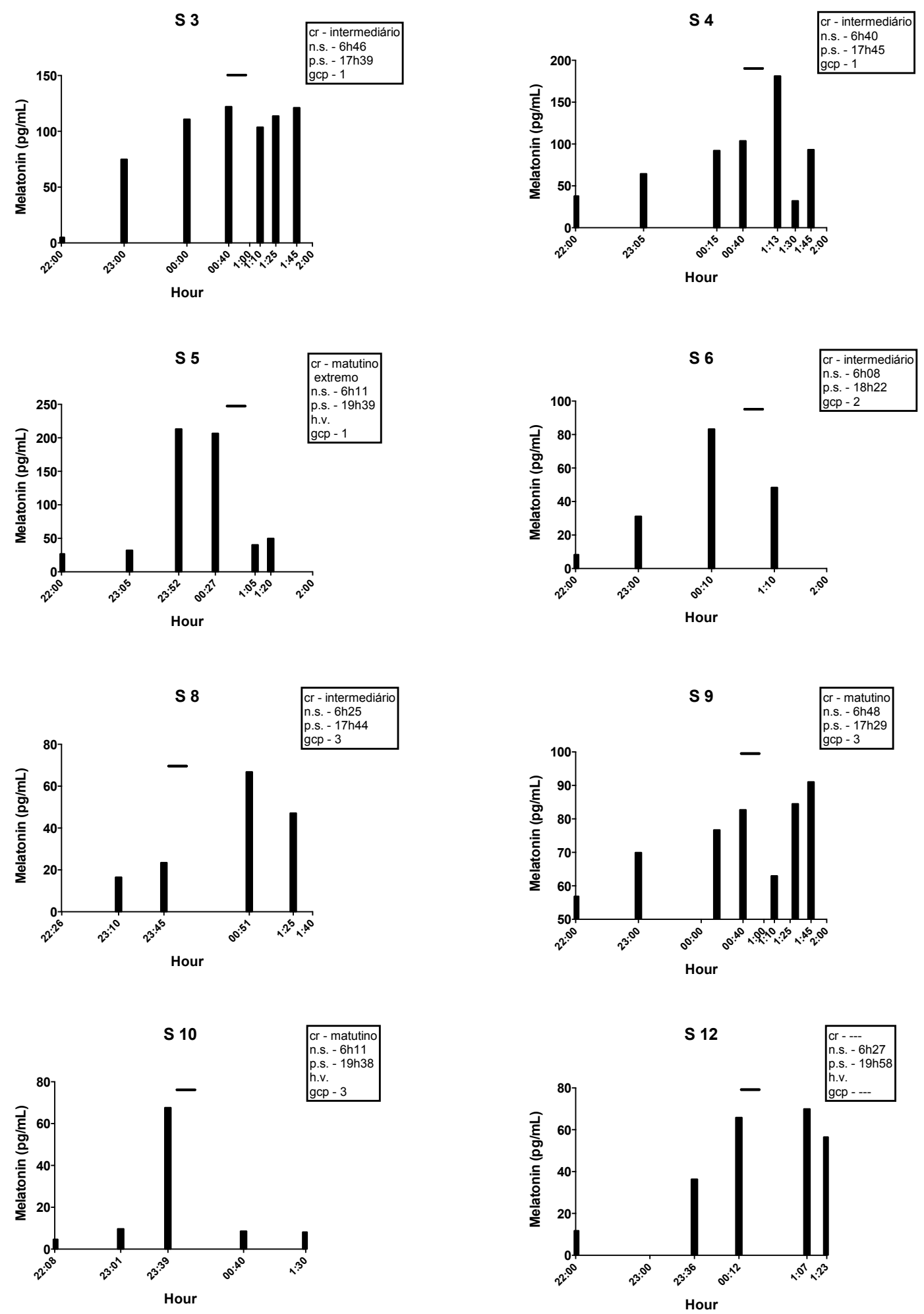
Figura 26 - Gráficos das curvas de melatonina plasmática

(continua)
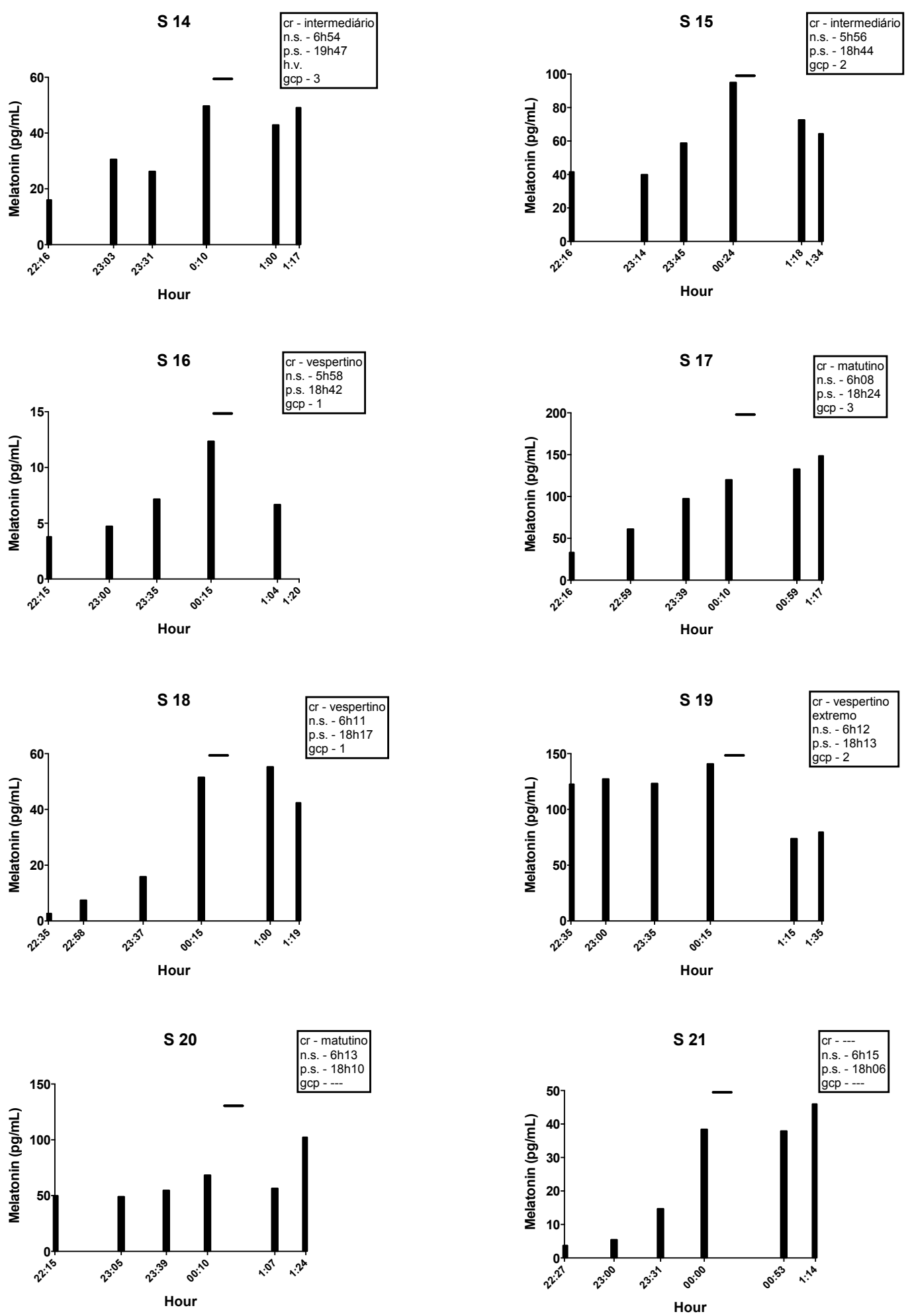
Figura 26 - Gráficos das curvas de melatonina plasmática
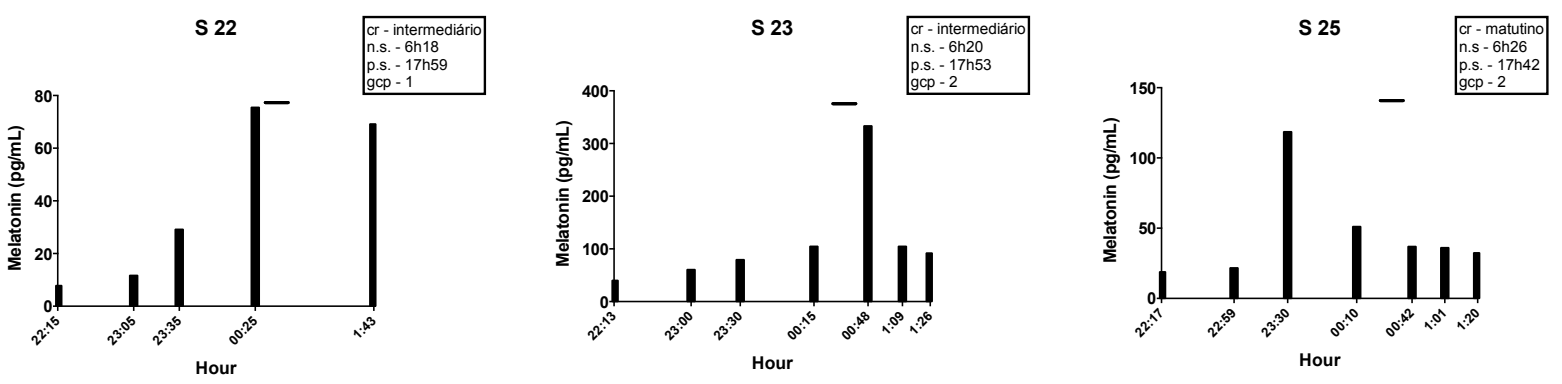

As barras pretas horizontais sobre os gráficos indicam o período da apresentação do estímulo luminoso. $\mathrm{cr}=$ cronotipo

gcp = grau de calcificação pineal $(0=$ sem calcificação; 1 = pouco; $2=$ moderada; $3=$ muito $)$

hour = horário da coleta de cada amostra de sangue

n.s. = horário do nascer do sol

p.s. = horário do pôr-do-sol

$\mathrm{S}=$ sujeito

--- = informação não disponível

A análise das RSN foi realizada duas vezes, incluindo 13 e incluindo 5 sujeitos, conforme explicado na seção 7.4.2.2. Na seleção com 13 participantes, 53,8\% apresentaram redução imediata da concentração de melatonina após a aplicação do estímulo luminoso (sujeitos 10, 14, 15, 16, 19, 20 e 22), 7,7\% apresentaram redução tardia (sujeito 23), 15,4\% apresentaram redução na taxa de aumento da concentração de melatonina (sujeitos 7 e 21) e 23,1\% não apresentaram resposta evidente (sujeitos 12, 18 e 25). Na subseleção com 5 participantes, 80\% apresentaram redução imediata da concentração da melatonina plasmática após o estímulo luminoso (sujeitos 10,15, 16 e 19) e 20\% apresentaram resposta tardia (sujeito 23). 


\section{DISCUSSÃO}

\subsection{Participantes e questionários}

O presente estudo teve o intuito de verificar se técnicas de ressonância magnética funcional podem ser utilizadas para avaliar aspectos da função da pineal em humanos.

Os participantes foram recrutados entre adultos jovens e de meia-idade saudáveis ou que apresentassem doenças crônicas não neurológicas e não descompensadas; os indivíduos foram recrutados entre estudantes de pósgraduação, médicos residentes do InRad HC FMUSP e entre familiares e conhecidos do pesquisador principal. Desta forma, a seleção de participantes limitou a amostra estudada a determinada faixa sócio-cultural da população. Porém, como trata-se de estudo de viabilidade, acreditamos que o recrutamento dos participantes em faixa limitada da população geral não foi determinante nos resultados encontrados no estudo.

O limite superior da faixa etária foi definido com base nas variações dos níveis plasmáticos de melatonina que são decorrentes do aumento da idade, para que não fossem incluídos indivíduos que apresentassem níveis plasmáticos de melatonina muito baixos; esta situação poderia dificultar a interpretação da variação do nível de melatonina em decorrência da aplicação do estímulo luminoso.

Houve predomínio dos indivíduos de cronotipo intermediário na amostra estudada, entre os participantes que responderam ao questionário para a verificação do cronotipo, com distribuição assemelhando-se à distribuição normal com assimetria deslocada para o tipo matutino. Isto difere dos achados de Benedito-Silva et al. (1998), que, estudando populações de diferentes regiões do Brasil, encontraram maior proporção de matutinos em cidades da região Norte do que em cidades das regiões Sul e Sudeste. Esses autores sugerem que hábitos sociais locais teriam significância na determinação do cronotipo, bem como, em menor grau, a latitude em que os indivíduos se encontram, explicando as diferenças encontradas em sujeitos de diferentes localidades. A diferença encontrada entre a população estudada e os dados da literatura reforça a ideia de que a amostra selecionada não foi representativa da população em geral, porém acreditamos que este fator não foi determinante nos resultados encontrados no estudo. 


\subsection{Tomografia computadorizada de crânio}

A tomografia computadorizada de crânio evidenciou calcificações pineais em todos os participantes que foram submetidos ao exame. Não houve correlação entre o grau de calcificação pineal e a idade do voluntário.

As calcificações podem ser numerosas na pineal de indivíduos idosos, porém, podem estar presentes desde a infância, sendo eventualmente observadas em crianças com 3 anos de idade (HASEGAWA et al., 1987; KERÉNYI; SARKAR, 1968 apud VíGH et al., 1998; TAPP; HUXLEY, 1972). Segundo Tapp e Huxley (1972), as calcificações podem ser encontradas em grande quantidade na pineal de jovens que acabaram de sair da fase de puberdade, não havendo relação entre o grau de calcificação pineal e a idade do indivíduo; esses autores também observaram pineais de indivíduos idosos com calcificações pineais em pequena quantidade. Os achados do presente estudo são concordantes com os dados da literatura.

É interessante ressaltar que Tapp e Huxley (1972) observaram que a presença de calcificações na pineal não estava associada à redução da celularidade do órgão, em concordância com Wurtman, Axelrod e Barchas (1964), que demonstraram que a presença de calcificações pineais não está associada à redução da atividade das enzimas envolvidas na síntese de melatonina na pineal humana.

Ao desenharmos as máscaras das pineais para extrair as séries temporais do sinal BOLD nas pineais, tivemos o cuidado de incluir somente o tecido não calcificado sempre que possível, para minimizar a interferência das calcificações nas análises dos dados. Este procedimento nem sempre foi possível nos casos em que as pineais apresentaram-se muito calcificadas (30\% dos casos). Nos sujeitos em que a pineal era muito calcificada, parte da série temporal extraída da máscara da pineal incluía informações sobre o tecido pineal funcionante e parte incluía a área de calcificação, incluindo, portanto, áreas de ausência de sinal BOLD ou ruído. Este fator (calcificação pineal) pode ter sido fonte de aumento da variabilidade encontrada nas análises da densidade espectral e conectividade funcional da pineal.

\subsection{Ressonância Magnética}

Nos diferentes tipos de análises das imagens funcionais, foi necessário realizar a exclusão de sujeitos por motivos diversos, em geral relacionados à movimentação 
excessiva ou artefatos nas imagens, gerados pelo equipamento de RM ou pelo estimulador luminoso. A redução do tamanho da amostra incluída nos diferentes tipos de análise das imagens funcionais, pode ter gerado limitações nas análises estatísticas.

\subsubsection{Análise da ativação de áreas encefálicas em resposta à luz}

A análise de grupo, realizada com a inclusão de 8 sujeitos, evidenciou as seguintes áreas de ativação em decorrência da aplicação da luz: lobo occipital bilateral, tálamo esquerdo, pré-cuneus esquerdo, giro do cíngulo posterior esquerdo e giro frontal superior bilateral. As áreas ativadas no lobo occipital localizavam-se na projeção do córtex visual no giro lingual e cúneus bilaterais. A área de ativação do tálamo localizava-se na região posterolateral do tálamo esquerdo, área que pode estar relacionada ao processamento de estímulos visuais (GAZZANIGA; IVRY; MANGUN, 2006). O pré-cúneus apresenta extensa rede de conexões com estruturas corticais e subcorticais associativas, como córtex cingulado posterior e córtex pré-frontal; é provável que sua atividade influencie essas estruturas nas etapas associativas e integrativas de informações, ao invés da participação no processamento direto de estímulos sensoriais externos (CAVANNA; TRIMBLE, 2006). O pré-cúneus tem sido associado ao processamento do imaginário visuoespacial e sua ativação pode estar associada ao direcionamento da atenção no espaço, mesmo na ausência de resposta motora explícita (CULHAM et al., 1998). Simon et al. (2002) mostraram que havia maior ativação de vóxeis situados no précúneus esquerdo do que no direito em tarefas que envolviam somente atenção. Existem evidências de que o córtex cingulado posterior desempenhe diferentes papéis, incluindo a regulação da cognição, embora ainda não exista consenso sobre suas funções (PEARSON et al., 2011); uma das hipóteses é que o córtex cingulado posterior estaria envolvido na regulação do direcionamento da atenção (LEECH; SHARP, 2014). O giro frontal superior tem sido relacionado a diferentes funções cognitivas, incluindo a atenção (LI et al., 2013). Nesse contexto, as áreas ativadas encontradas no presente estudo estão em concordância com os achados na literatura, por corresponderem a áreas relacionadas ao processamento visual. Os resultados mostram que o estímulo luminoso aplicado foi efetivo, com sensibilidade para a detecção de toda a rede visual. 
Não observamos ativação da pineal em resposta à apresentação do estímulo luminoso, tanto na análise de primeiro nível como na análise de grupo. A ausência de ativação da pineal em resposta ao estímulo luminoso pode ser decorrente de diversos fatores como: a) é possível que a presença de calcificações pineais tenha interferido com a detecção da variação do sinal BOLD na pineal; essa interferência, caso tenha ocorrido, provavelmente não foi o principal fator, uma vez que não foi observada a ativação da pineal mesmo nos casos em que havia menor quantidade de calcificações e maior extensão do tecido não calcificado na glândula; b) é possível que a resposta hemodinâmica da pineal à aplicação da luz tenha características diferentes daquelas utilizadas na sua modelagem, prejudicando a sua detecção; c) é possível que a resposta hemodinâmica da pineal à aplicação da luz ocorra em magnitude menor do que a sensibilidade mínima do equipamento de RM utilizado.

No presente estudo, aplicamos o estímulo luminoso para verificar a resposta da pineal associada ao estímulo. Foram encontradas áreas de ativação cerebral relacionadas ao processamento visual, em concordância com a literatura, o que indicou que o estímulo visual foi adequado. Entretanto, a nossa $1^{\text {a }}$ hipótese não foi verificada, não sendo observada ativação da pineal em resposta ao estímulo apresentado.

\subsubsection{Análise das RSN}

Esta análise foi realizada duas vezes, incluindo 13 sujeitos e incluindo 5 sujeitos selecionados dentre os 13 inicialmente analisados.

$\mathrm{Na}$ análise de grupo com 13 e com 5 sujeitos, as RSN encontradas foram semelhantes: visual, DMN, sensoriomotor, auditiva, controle executivo e frontoparietal. Não houve diferenças estatisticamente significativas nas redes neurais encontradas com o uso da ferramenta fslcc e por inspeção visual, entre as condições rspre e rspos nas análises com 13 e com 5 sujeitos. A análise com o algoritmo dual regression incluindo 13 sujeitos e incluindo 5 sujeitos não mostrou diferenças estatisticamente significativas entre as condições pré e pós-estímulo luminoso.

As RSN encontradas neste estudo têm sido discutidas na literatura (BECKMANN et al., 2005; BISWAL et al., 2010; DAMOISEAUX et al., 2006; SMITH et al., 2009). 
As redes neurais consistem em regiões funcionalmente conectadas, mesmo que anatomicamente separadas, que exibem variação do sinal BOLD fortemente correlacionada (ROSAZZA; MINATI, 2011). As RSN possuem componentes dinâmicos que podem apresentar variações com a experiência recente (ALBERT; ROBERTSON; MIALL, 2009; STEVENS; BUCKNER; SCHATER, 2010) e com o estado de alerta do indivíduo (HEINE et al., 2012). A seguir, descrevemos sucintamente as redes neurais encontradas na população estudada.

Redes visuais: existem pelo menos três redes distintas descritas na literatura (medial, lateral e do polo occipital), em que as áreas identificadas são predominantemente o córtex visual medial, o córtex visual lateral e córtex visual do polo occipital, respectivamente. A existência de diferentes redes visuais pode estar relacionada à dimensionalidade de decomposição em componentes independentes (número de componentes determinado para a decomposição) e ao impacto que os artefatos fisiológicos e não-fisiológicos têm sobre essa decomposição (SMITH et al., 2009).

DMN: as áreas identificadas são pré-cuneus, córtex cingulado posterior, córtex parietal lateral e córtex pré-frontal mesial. Sua atividade tem sido associada a processos mentais introspectivos e aos estados em que o indivíduo desvia a atenção de estímulos externos. Esta rede neural geralmente apresenta-se mais ativa durante o repouso e relativamente anticorrelacionada durante tarefas que requerem atenção focada (BUCKNER, 2013).

Rede sensoriomotora: as áreas identificadas são giro pré-central, giro pós-central e área motora suplementar. A atividade espontânea nesta rede neural provavelmente reflete a atividade neural que favorece tarefas motoras ativas (DE LUCA et al., 2005).

Rede auditiva: as áreas identificadas são giro temporal superior, giro de Heschl, ínsula e giro pós-central. Esta rede apresenta correspondência anatômica com áreas de ativação em resposta a tarefas auditivas, de percepção de fala (CORDES et al., 2000).

Rede do controle executivo: as áreas identificadas são giro frontal medial, giro frontal superior e córtex cingulado anterior. Muitas vezes também estão incluídas áreas parietais laterais. Esta rede está associada a tarefas que envolvem funções executivas, como processos de controle e memória de trabalho (SEELEY et al., 2007). 
Rede frontoparietal lateralizada: a rede é formada por dois componentes lateralizados, um predominantemente direito e um predominantemente esquerdo. As áreas identificadas são giro frontal inferior, giro frontal médio, pré-cuneus, giro parietal inferior e giro angular. Esta rede tem sido associada a diferentes funções, como memória, linguagem, atenção e processos visuais (ROSAZZA; MINATI, 2011).

A nossa $2^{a}$ hipótese não foi verificada. A ausência de diferenças estatisticamente significativas entre as condições rspre e rspos nas análises com 13 e com 5 sujeitos pode se dever à resposta variável na concentração de melatonina associada ao estímulo luminoso e ao tamanho pequeno da amostra. Nas análises com 13 e com 5 sujeitos, é possível que o aumento no tamanho da amostra e a inclusão apenas dos casos com redução imediata da concentração plasmática de melatonina associada ao estímulo luminoso evidenciassem diferenças estatisticamente significativas entre as condições rspre e rspos.

\subsubsection{Análise da conectividade funcional da pineal}

A análise de grupo da conectividade funcional nas condições rspre e rspos, que foi realizada com a inclusão de 13 sujeitos, evidenciou áreas cerebrais com flutuação do sinal BOLD coerentes com a flutuação do sinal BOLD na pineal. Essas áreas, que envolviam tálamo, ínsula e bordas dos sulcos intraparietais bilaterais nas duas condições, eram visualmente mais extensas na condição rspre que na rspos, porém, não houve diferença estatisticamente significativa entre as condições. Não é possível determinar se estes resultados correspondem à conectividade funcional da pineal, a artefatos ou ambos, uma vez que artefatos causados pela pulsatilidade de grandes vasos podem ter interferido, ao menos parcialmente, na análise e não foi possível usar os dados fisiológicos de frequência cardíaca como fatores de confusão. Esta dificuldade foi parcialmente superada com a utilização da série temporal da região da veia cerebral magna como regressor durante a análise dos dados.

Ainda assim, mesmo considerando-se que parte do resultado seja influenciado pela pulsatilidade de vasos, o dado é interessante, pois evidencia áreas relacionadas ao controle sono-vigília (tálamo) (MASSON et al., 2002), integração visuoespacial e processos relacionados à atenção (parietal) (GREFKES; FINK, 2005) e relacionadas a funções autonômicas (ínsula) (JONES; WARD; CRITCHLEY, 
2010), que poderiam ser influenciadas pelas informações de pinealócitos e de neurônios intrapineais.

A nossa $3^{a}$ hipótese não foi verificada. A ausência de diferença entre os grupos rspre e rspos pode ser decorrente do tamanho pequeno da população estudada. Outra possibilidade a ser considerada é que a coleta das imagens funcionais no período pós-estímulo pode ter acontecido em momento em que havia ocorrido a recuperação parcial da pineal ao seu estado antes da aplicação da luz, diminuindo as diferenças entre as duas condições. Novamente, devemos destacar a possibilidade de que a presença de calcificações pineais tenha limitado a análise da conectividade funcional da pineal.

\subsubsection{Análise espectral da pineal}

Esta análise foi realizada incluindo 15 sujeitos (comparação entre as condições rspre e rspos) e incluindo 10 sujeitos (comparação entre as condições rspre, luz e rspos). Pretendíamos verificar a mudança no poder máximo espectral do sinal BOLD na pineal antes, durante e após a aplicação da luz. Na análise espectral, a natureza periódica do estímulo aplicado determina que os componentes de variância atribuídos à resposta ao estímulo ocorram em poucas frequências no domínio espectral, que correspondem à frequência fundamental e suas harmônicas (MARCHINI; RIPLEY, 2000). Ao considerarmos a possibilidade de uma condição apresentar poder máximo maior do que na outra condição, estaríamos supondo que houve estimulação da área de interesse na condição de maior poder.

A nossa $4^{a}$ hipótese não foi verificada. Não foram observadas diferenças estatisticamente significativas na análise incluindo as três condições (rspre, luz e rspos) e nas análises incluindo duas condições (luz>rspre, luz>rspos e rspre>rspos), apesar de observamos tendência da condição luz em apresentar poder espectral máximo maior do que a condição rspre.

Ao observamos os resultados da análise de poder para estudos com mesmas características, o número para inferir que não há diferença entre as condições luz>rspre, luz>rspos e rspre>rspos é maior que o número de indivíduos utilizado em nossos experimentos. Seriam necessárias amostras de 19, 216 e 288 participantes, respectivamente, para afirmarmos que não houve diferença entre as condições. Neste caso, seria possível aumentar a amostra da condição luz>rspre, porém, 
devido ao tamanho requerido das amostras nas outras condições, o estudo tornarse-ia inviável, exceto no caso de avaliarmos somente a diferença entre as condições luz e rspre, situação em que o tamanho da amostra é bastante próximo da amostra que foi estudada. O nosso maior interesse encontrava-se na verificação de ativação na pineal em resposta a determinado estímulo adequado; portanto, esta seria uma questão bastante interessante, a ser melhor explorada em novos estudos.

\subsection{Dosagem da melatonina plasmática}

A dosagem da melatonina plasmática mostrou resposta satisfatória na maioria dos sujeitos estudados, não sendo observada resposta evidente associada à aplicação do estímulo luminoso em $21,1 \%$ dos sujeitos.

O padrão temporal da taxa de síntese de melatonina é bastante reprodutível em um dado indivíduo, quando verificado dia após dia, representando uma "digital" (fingerprint) hormonal, porém, apresenta grande variabilidade interindividual (STEHLE et al., 2011). A produção noturna de melatonina pode diferir em até 3 ordens de magnitude entre os indivíduos (LEWY et al., 2006). Lewy, Cutler e Sack, (1999) desenvolveram o conceito de dim-light melatonin onset (DLMO), que corresponde ao horário em que a produção endógena de melatonina tem início sob iluminação fraca. É utilizado como o marcador mais confiável da fase circadiana em humanos (STEHLE et al., 2011). A utilização do DLMO nesse estudo provavelmente teria auxiliado na avaliação dos casos em que a resposta ao estímulo luminoso não foi tão evidente, para a definição mais precisa sobre a intensidade da resposta. Não foi possível utilizar o DLMO no nosso estudo, pois isto iria requerer um dia adicional para a determinação do mesmo, já que as recomendações para a sua aferição eram diferentes das necessidades do experimento, como, por exemplo, manter o indivíduo em local com iluminação aproximada de 10 lux a partir das $17 \mathrm{~h}$, evitando o escuro total (LEWY et al., 2006).

Existe grande variabilidade interindividual na resposta à aplicação noturna de estímulo luminoso em relação à variação na concentração de melatonina plasmática ou na saliva (SANTHI et al., 2012). Este fato depende de vários fatores, como alterações oculares fisiológicas decorrentes da idade, características genéticas dos sujeitos ou fatores ambientais (CHELLAPPA et al., 2014; HIGUCHI et al., 2005; TURNER; MAINSTER, 2008). No nosso estudo, observamos grande variabilidade 
entre os indivíduos na intensidade da resposta ao estímulo aplicado em relação à concentração plasmática de melatonina, em concordância com a literatura. Este fato pode ter implicado na ausência de diferenças entre condições nas diversas análises dos dados de RMf.

Não foi possível utilizar os dados da dosagem da melatonina plasmática para a realização de testes de correlação nas diferentes análises efetuadas. O padrão de produção de melatonina e o DLMO de cada participante eram desconhecidos, não permitindo a estimativa da concentração esperada de melatonina de cada sujeito em cada horário, para que fosse feito o cálculo da variação da mesma. Isto somente seria possível se tivesse sido realizada outra etapa do estudo, em outra noite, quando os sujeitos permaneceriam no escuro e seriam coletadas amostras de sangue total, para a obtenção da curva de melatonina individual. Porém, isto implicaria em maiores dificuldades no recrutamento e engajamento de participantes.

\subsection{Limitações do estudo}

O número pequeno de participantes foi decorrente das características do estudo, como o fato de ser realizado à noite; manter o participante durante muitas horas engajado no estudo; submeter o sujeito à coleta de amostras de sangue; requerer disciplina do participante, uma vez que este não poderia ingerir certos alimentos e bebidas ou fumar durante muitas horas no dia da RMf; permanecer acordado, no escuro, de olhos fechados, em horário que normalmente estaria dormindo; ter que retornar ao Hospital para a realização da TC em dia diferente do exame de RMf. Além disso, a necessidade de excluir casos em decorrência de diversos fatores, como a presença de artefatos gerados pelo equipamento de RM ou pelo estimulador luminoso, contribuiu para reduzir ainda mais o tamanho da amostra. O tamanho pequeno da amostra, certamente, teve grande impacto no estudo, pois está associado à pior estimativa da variabilidade real da população.

O exame de RMf foi desenhado de forma a obtermos a maior resolução de imagem possível e sem intervalo entre as fatias. Com isso, para que não houvesse aumento no tempo de aquisição das imagens, foi necessário incluir menor número de fatias, o que impediu que fossem estudadas todas as regiões encefálicas. Portanto, não foi possível avaliar o cerebelo, hipocampo, hipotálamo e outras regiões localizadas na base do cérebro, que poderiam trazer informações 
interessantes.

A correção da análise da conectividade funcional da pineal nas diferentes condições foi prejudicada pelo fato de não conseguirmos utilizar os dados da frequência cardíaca dos participantes durante o processamento dos dados. Este problema foi parcialmente sanado, porém, tornou os resultados menos consistentes na sua interpretação.

Os dados sobre a dosagem de melatonina plasmática foram utilizados para obter a confirmação de que o estímulo luminoso foi adequado para a modificação da função da pineal, porém, sem que fosse possível a sua utilização para outras comparações e correlações, limitando a extensão das ferramentas de estudo que poderiam ter sido aplicadas.

\subsection{Perspectivas futuras}

Neste estudo, exploramos o aspecto mais conhecido sobre a função da pineal, relacionado à produção cíclica da melatonina. A ideia era observar diferentes aspectos do sinal de RMf. Apesar dos resultados negativos encontrados no estudo, consideramos de grande interesse o resultado encontrado sobre a conectividade funcional da pineal, apesar da ressalva a ser feita sobre a possibilidade da presença de artefatos nas áreas observadas. Além disso, consideramos interessante a tendência de maior poder espectral da pineal durante a aplicação do estímulo luminoso do que na condição pré-estímulo. Esses achados poderiam ser melhor avaliados em estudos futuros, com o aumento do número de participantes.

Existe, também, a possibilidade de investigarmos outros aspectos relacionados à função da pineal, utilizando como ferramentas os achados supracitados. Desde a década de 1980 tem sido investigada a possibilidade da pineal do mamífero apresentar sensibilidade a determinados campos magnéticos. Foram estudadas características da atividade elétrica de pinealócitos em animais vivos (REUSS et al., 1983; SEMM et al., 1980), bem como a produção de melatonina por pineais de mamíferos em cultura (BRENDEL et al., 2000) e por pinealócitos de mamíferos em cultura (ROSEN et al., 1998), observando-se resposta dessas células à exposição a campos magnéticos em relação ao padrão de atividade elétrica e à produção de melatonina. SCHIFFMAN et al. (1994) demonstraram que humanos submetidos ao exame convencional de RM do encéfalo em equipamento de 1,5 T, não 
apresentaram alterações nas concentrações plasmáticas noturnas de melatonina. Até o momento não fomos capazes de identificar na literatura científica estudos semelhantes utilizando equipamentos de ressonância magnética com campo de 3,0 $\mathrm{T}$.

Esta é uma questão interessante a ser explorada no futuro, partindo dos achados e das lições aprendidas no presente estudo. 


\section{CONCLUSÃO}

Foram testadas técnicas de ressonância magnética funcional (RMf) com a apresentação de estímulo com luz azul, para investigar aspectos funcionais da pineal. Não foram observadas diferenças estatisticamente significativas entre as condições pré-estímulo, durante o estímulo ou pós-estímulo. Foi identificada a conectividade funcional da pineal, que deverá ser melhor avaliada em estudo futuro. Foi observada tendência de maior poder espectral na pineal durante a aplicação do estímulo luminoso do que nas condições pré e pós-estímulo, porém, sem alcançar nível estatístico significativo.

Em relação aos objetivos específicos, podemos concluir que:

1) não houve modificação estatisticamente significativa no sinal BOLD da pineal em resposta ao estímulo aplicado;

2) não houve alteração significativa nas RSN em decorrência da apresentação do estímulo luminoso;

3) não houve alteração significativa na correlação do sinal BOLD da pineal com as demais regiões cerebrais em decorrência da apresentação do estímulo luminoso;

4) não houve alteração significativa no poder máximo do espectro de frequência do sinal BOLD na pineal em decorrência da aplicação do estímulo luminoso. 


\section{REFERÊNCIAS ${ }^{5}$}

ACKERMANN, K. et al. Characterization of human melatonin synthesis using autoptic pineal tissue. Endocrinology, v. 147, p. 3235-3242, 2006.

ACUÑA-CASTROVIEJO, D. et al. Extrapineal melatonin: sources, regulation, and potential funcitons. Cell. Mol. Life Sci., v. 71, p. 2997-3025, 2014.

AL-GHOUL, W. M.; HERMAN, M. D.; DUBOCOVICH, M. L. Melatonin receptor subtype expression in human cerebellum. Neuroreport, v. 9, p. 4063-4068, 1998.

AL-HOLOU, W. N., et al. Prevalence and natural history of pineal cysts in adults. J. Neurosurg., v. 115, p. 1106-1114, 2011.

ALBERT, N. B.; ROBERTSON, E. M.; MIALL, R. C. The resting human brain and motor learning. Curr. Biol., v. 19, p. 1023-1027, 2009.

ALLEGRA, M. et al. The chemistry of melatonin's interaction with reactive species. J. Pineal Res., v. 34, p. 1-10, 2003.

AMARAL, F. G. et al. Melatonin synthesis impairment as a new deleterious outcome of diabetes-derived hyperglycemia. J. Pineal R., v. 57, p. 67-79, 2014.

AMARO JUNIOR, E.; YAMASHITA, H. Aspectos básicos da tomografia computadorizada e ressonância magnética. Rev. Bras. Psiquiatr., v. 23, p. 2-3, 2001. Supl 1.

AMARO JUNIOR, E.; BARKER, G. J. Study design in fMRI: basic principles. Brain Cogn., v. 60, p. 220-232, 2006.

ARENDT, J. Biochemistry of the pineal. In: __. Melatonin and the Mammalian Pineal Gland. London: Chapman \& Hall, 1995a, cap. 3, p. 27-65.

The pineal in human physiology and pathology. In: Melatonin and the Mammalian Pineal Gland. London: Chapman \& Hall, 1995b, cap. 7, p. 201-246.

ATTWELL, D.; LAUGHLIN, S. B. An energy budget for signaling in the grey matter of the brain. J. Cereb. Blood Flow Metab., v. 21, p. 1133-1145, 2001.

AUER, D. P. Spontaneous low-frequency blood oxygenation level-dependent fluctuations and functional connectivity analysis of the 'resting' brain. Magn. Reson Imaging, v. 26, p. 1055-1064, 2008.

BECKMANN, C. F. et al. Investigations into resting-state connectivity using independent component analysis. Philos. Trans. R. Soc. Lond. B. Biol. Sci., v. 360, p. 1001-1013, 2005.

5 De acordo com: ASSOCIAÇÃO BRASILEIRA DE NORMAS TÉCNICAS. NBR 6023: informação e documentação: referências: elaboração. Rio de janeiro, 2002. 
BECKMANN, C. F. et al. Group comparison of resting-state FMRI data using multisubject ICA and dual regression. Neuroimage, v. 47 (S1), p. 148, 2009.

BENEDITO-SILVA, A. A. et al. A self-assessment questionnaire for the determination of morningness-evenignness types in Brazil. Prog. Clin. Biol. Res., v. 314, p. 89-98, 1990.

BENEDITO-SILVA, A. M. et al. Latitude and social habits as determinants of the distribution of morning and evening types in Brazil. Biol. Rhythm Research, v. 29, p. 591-597,1998.

BENITEZ-KING, G. Melatonin as a cytoskeletal modulator: implications for cell physiology and disease. J. Pineal Res., v. 40, p. 1-9, 2006.

BENITEZ-KING, G.; ANTON-TAY, F. Calmodulin mediates melatonina cytoskeletal effects. Experientia, v. 49, p. 635-641, 1993.

BERGIANNAKI, J. D. et al. Low and high melatonin excretors among healthy individuals. J. Pineal Res., v. 18, p. 159-164, 1995.

BERSON, D. M. Strange vision: ganglion cells as circadian photoreceptors. Trends Neurosci., v. 26, p. 314-320, 2003.

BERSON, D. M.; DUNN, F. A.; TAKAO, M. Phototransduction by retinal ganglion cells that set the circadian clock. Science, v. 295, p. 1070-1073, 2002.

BINKLEY, S. Introduction. In: _. The pineal: endocrine and nonendocrine function. New Jersey: Prentice Hall, 1988 , cap. 1, p. 1-11. (Prentice Hall Endocrinology Series).

BISWAL, B. B. et al. Functional connectivity in the motor cortex of resting human brain using echo-planar MRI. Magn. Reson. Med., v. 34, p. 537-541,1995.

BISWAL, B. B. et al. Toward discovery science of human brain function. Proc. Natl. Acad. Sci. U.S.A., v. 107, p. 4734-4739, 2010.

BOHNING, D. E. et al. BOLD-fMRI Response vs. transcranial magnetic stimulation (TMS) pulse-train length: testing for linearity. J. Magn. Reson. Imaging, v. 17, p. 279-290, 2003.

BONNEFONT-ROUSSELOT, D.; COLLIN, F. Melatonin: action as antioxidant and potential applications in human disease and aging. Toxicology, v. 278, p. 55-67, 2010.

BORJIGIN, J.; ZHANG, L. S.; CALINESCU, A. A. Circadian regulation of pineal gland rhythmicity. Mol. Cell. Endocrinol., v. 349, p. 13-19, 2012.

BRAINARD, G. C. et al. Action spectrum for melatonin regulation in humans: Evidence for a novel circadian photoreceptor. J. Neurosci., v. 21, p. 6405-6412, 2001. 
BRENDEL, $H$. et al. Direct suppressive effects of weak magnetic fields $(50 \mathrm{~Hz}$ and $16^{2 / 3} \mathrm{~Hz}$ ) on melatonin synthesis in the pineal gland of Djungarian hamsters (Phodopus sungorus). J. Pineal Res., v. 29, p. 228-233, 2000.

BUCKNER, R. L. The brain's default mode network: origins and implications for the study of psychosis. Dialogues Clin. Neurosci., v. 15, p. 351-358, 2013.

CALVO, J.; BOYA, J. Postnatal evolution of the rat pineal gland: light microscopy. J. Anat., v. 138, p. 45-53, 1984.

CALVO, J.; GONZÁLEZ-YANES, C.; MALDONADO, M. D. The role of melatonin in the cells of the innate immunity: a review. J. Pineal Res., v. 55, p. 103-120, 2013.

CARDINALI, D. P.; PÉVET, P. Basic aspects of melatonin action. Sleep Med. Rev., v. 2, p. $175-190,1998$.

CAVANNA, A. E.; TRIMBLE, M. R. The precuneus: a review of its functional anatomy and behavioural correlates. Brain, v. 129, p. 564-583, 2006.

CHELLAPPA, S. L., et al. Light modulation of human sleep depends on a polymorphism in the clock gene Period3. Behav. Brain Res., v. 271, p. 23-29, 2014.

CHEN, S. et al. Group independent component analysis reveals consistente restingstate networks across multiple sessions. Brain Res., v. 1239, p. 141-151, 2008.

CIPOLLA-NETO, J.; AFECHE, S. C. Glândula pineal. In: AIRES, M. M. Fisiologia. Rio de Janeiro: Guanabara Koogan, p. 980-990, 2008.

CIPOLLA-NETO, J. et al. Melatonin, energy metabolism, and obesity: a review. J. Pineal Res., v. 56, p. 371-381, 2014.

CORDES, D. et al. Mapping functionally related regions of brain with functional connectivity MR imaging. AJNR Am J Neuroradiol., v. 21, p. 1636-1644, 2000.

COSTA, E. J. X.; LOPES, R. H.; LAMY-FREUND, M. T. Permeability of pure lipid bilayers to melatonin. J. Pineal Res., v. 19, p. 123-126, 1995.

CULHAM, J. C. et al. Cortical fMRI activation produced by attentive tracking of moving targets. J. Neurophysiol., v. 80, p. 2657-2670, 1998.

CZEISLER, C. A., et al. Suppression of melatonin secretion in some blind patients by exposure to bright light. N. Engl. J. Med., v. 332, p. 6-11, 1995.

DACEY, D. M. et al. Melanopsin-expressing ganglion cells in primate retina signal colour and irradiance and Project to the LGN. Nature, v. 433, p. 749-754, 2005.

DAMOISEAUX, J. S. et al. Consistent resting-state networks across healthy subjects.

Proc. Natl. Acad. Sci. U.S.A., v. 103, p. 13848-13853, 2006. 
DAVIES, W. L.; FOSTER, R. G.; HANKINS, M. W. Focus on molecules: melanopsina. Exp. Eye Res., v. 97, p. 161-162, 2012.

DE LUCA, M., et al. Blood oxygenation level dependente contrast resting state networks are relevant to functional activity in the neocortical sensorimotor system. Exp. Brain Res., v. 167, p. 587-594, 2005.

DESCARTES, R. (1649) As paixões da alma. 2. ed. São Paulo: Martins Fontes São Paulo, 2005, $1^{\text {a }}$ parte, artigos 30-35, p. 48-53.

DUBOCOVICH, M. L. Melatonin receptors: are there multiple subtypes? Trends Pharmacol. Sci., v. 16, p. 50-56,1995.

DUVERNOY, H. M.; RISOLD, P. Y. The circumventricular organs: an atlas of comparative anatomy and vascularization. Brain Res. Rev., v. 56, p. 119-147, 2007.

EKMEKCIOGLU, C. Melatonin receptors in humans: biological role and clinical relevance. Biomed. Pharmacother., v. 60, p. 97-108, 2006.

EKSTRÖM, P. Central neural connections of the pineal organ and retina in the teleost Gaterosteus aculeatus. J. Comp. Neurol., v. 226, p. 321-336, 1984.

. Photoreceptors and CSF-contacting neurons in the pineal organ of a teleost fish have direct axonal connections with the brain: an HRP-electronmicroscopic study. J. Neurosci., v. 67, p. 987-995, 1987.

ERLICH, S. S.; APUZZO, M. L. J. The pineal gland: anatomy, physiology, and clinical significance. J. Neurosurg., v. 63, p. 321-341, 1985.

FALCÓN et al. Structural and functional evolution of the pineal melatonin system in vertebrates. Ann. N. Y. Acad. Sci., v. 1163, p. 101-111, 2009.

FERREIRA, Z. S. et al. Corticosterone modulates noradrenaline-induced melatonin synthesis through inhibition of nuclear factor kappa B. J. Pineal Res., v. 38, p. 182188, 2005.

FILIPPINI, N. et al. Distinct patterns of brain activity in young carriers of the APOE- $\varepsilon 4$ allele. Proc. Natl. Acad. Sci. U.S.A., v. 106, p. 7209-7214, 2009.

FOSTER, R. G. et al. A comparison of some photoreceptor characteristics in the pineal and retina. J. Comp. Physiol. A., v. 165, p. 565-572, 1989.

FRISTON, K. J. et al. Functional connectivity: the principal-component analysis of large (PET) data sets. J. Cereb. Blood Flow and Metab., v. 13, p. 5-14,1993.

FRISTON, K. J., et al. Nonlinear responses in fMRI: the balloon model, Volterra kernels, and other hemodynamics. Neuroimage, v. 12, p. 466-477, 2000.

GAMLIN, P. D. R. et al. Human and macaque pupil responses driven by melanopsina-containing retinal ganglion cells. Vision Res., v. 47, 946-954, 2007. 
GAZZANIGA, M. S.; IVRY, R. B.; MANGUN, G. R. Percepção e codificação. In: Neurociência Cognitiva: a biologia da mente. São Paulo: Artmed Editora, 2006, p. 166-210.

GERSDORFF, H. Synaptic ribbons: versatile signal transducers. Neuron, v. 29, p. 710, 2001.

GHAEMI, M. et al. Increased pineal Fdopa uptake is related to severity of Parkinson's disease - a PET study. J. Pineal Res., v. 30, p. 213-219, 2001.

GOLDMAN, H.; WURTMAN, R. J. Flow blood to the pineal body of the rat. Nature, v. 203, p. 87-88, 1964.

GONÇALVES, D. M.; STEIN, A. T.; KAPCZINSKI, F. Avaliação de desempenho do Self-Reporting Questionnaire como instrumento de rastreamento psiquiátrico: um estudo comparativo com o Structured Clinical Interview for DSM-IV-TR. Cad. Saúde Pública, v. 24, p. 380-390, 2008.

GREFKES, C.; FINK, G. R. The functional organization of the intrparietal sulcus in humans and monkeys. J. Anat., v. 207, p. 3-17, 2005.

HARDELAND, R.; PANDI-PERUMAL S. R.; CARDINALI, D. P. Melatonin. Int. J. Biochem. Cell Biol., v. 38, p. 313-316, 2006.

HARDELAND, R. et al. Melatonin - a pleiotropic, orchestrating regulator molecule. Prog. Neurobiol., v. 93, p. 350-384, 2011.

HARDING, T. W. et al. Mental disorders in primary health care: a study of their frequency and diagnosis in four developing countries. Psychol. Med., v. 10:231-241, 1980.

HARPER, D. G., et al. Dorsomedial SCN neuronal subpopulations subserve different functions in human dementia. Brain, v. 131, 1609-1617, 2008.

HASEGAWA, A.; OHTSUBO, K.; MORI, W. Pineal gland in old age; quantitative and qualitative morphological study of 168 human autopsy cases. Brain Res., v. 409, p. 343-349, 1987.

HASEGAWA, A. et al. Ultrastructural study of the human pineal gland in aged patients including a centenarian. Acta Pathol. Jpn., v. 40, p. 30-40, 1990.

HEINE, L. et al. Resting state networks and consciousness: alterations of multiple resting state network connectivity in physiological, pharmacological, and pathological consciousness states. Front. Psychol., v. 3, p. 1-12, 2012.

HEWING, M. A liquor contacting area in the pineal recess of the golden hamster (Mesocricetus auratus). Anat. Embryol. (Berl), v. 153, p. 295-304, 1978. 
HIGUCHI, S. et al. Relationship between individual difference in melatonin suppression and habitual bedtime. J. Physiol. Anthropol. Appl. Human Sci., v. 24, p. 419-423, 2005.

HORNE, J. A.; OSTBERG, O. A. A self-assessment questionnaire to determine morningness-eveningness in human circadian rhythms. Int. J. Chronobiol., v. 4, p.97-110, 1976.

HUETTEL, S.; SONG, A. W.; McCARTHY, G. Basic principles of MR signal generation. In: _. Functional Magnetic Resonance Imaging. 2nd ed. Suderland, USA: Sinauer Associates, 2008a. Cap. 3, p. 57-88.

BOLD fMRI: origins and properties. In: .Functional Magnetic Resonance Imaging. 2nd ed. Suderland, USA: Sinauer Associates, 2008b. Cap. 7, p. 193-242.

INTERNATIONAL ELECTROTECHNICAL COMMISSION. Norma IEC 62471 - CIE S 009:2002. International standard - Photobiological safety of lamps and lamp systems. Geneva, Suíça, 2006. [89 p.]

JASSER, S. A.; BLASK, D. E.; BRAINARD, G. C. Light during darkness and cancer: relationshipsin circadian photoreception and tumor biology. Cancer Causes Control, v. 17, p. 515-523, 2006.

JENKINSON, M. et al. FSL. Neurolmage, v. 62, p. 782-790, 2012.

JONES, C. L.; WARD, J.; CRITCHLEY, H. D. The neuropsychological impacto $f$ insular cortex lesions. J. Neurol. Neurosurg. Psychiatry, v. 81, p. 611-618, 2010.

JOUVET, A., et al. Structural and ultrastructural characteristics of human pineal gland, and pineal parenchymal tumors. Acta Neuropathol., v. 88, p. 334-348, 1994.

KAHILOGULLARI, G. et al. Arterial vascularization of the pineal gland. Childs Nerv. Syst., v. 29, p. 1835-41, 2013.

KAPPERS, J. A. The pineal organ: an introduction. In: WOLSTENHOLME, G. E. W.; KNIGHT, J. The pineal gland. London: J. A. Churchill, 1971, v. 1, cap. 1, p. 3-25.

. A survey of advances in pineal research. In: REITER, R. J. The Pineal Gland. I: Anatomy and Biochemistry, CRC Press, Boca Raton, Florida, USA, 1981, v. 1, cap. 1, p. 1-25.

KARASEK, M.; WINCZYK, K. Melatonin in humans. J. Physiol. Pharmacol., v. 57, supl. 5, p. 19-39, 2006.

KERÉNYI, N. A.; SARKAR, K. The postnatal transformation of the pineal gland. Acta Morphol. Hung., v. 16, p. 223-226, 1968 apud VÍGH, B. et al. Comparative histology of pineal calcification. Histol. Histopathol., v. 13, p. 851-870, 1998. 
KLEIN, D. C.; MOORE, R. Y. Pineal N-acetyltransferase and hydroxyindole-Omethyltransferase: control by the retinohypothalamic tract and the suprachiasmatic nucleus. Brain Res., v. 174, p. 245-262, 1979.

KOPIN, I. J. et al. 6-Hydroxylation, the major metabolic pathway for melatonin. Biochim. Biophys. Acta, v. 40, p. 377-378, 1960.

KORF, H. W. et al. Immunocytochemical demonstration of retinal S-antigen in the pineal organ of four mammalian species. Cell Tissue Res., v. 239, p. 81-85, 1985a.

KORF, H. W. et al. Opsin-like immunoreaction in the retinae and pineal organs of four mammalian species. Cell Tissue Res., v. 242, p. 645-648, 1985 b.

KORF, H. W. et al. Pinealocyte projections into the mammalian brain revealed with S-antigen antiserum. Science, v. 231, p. 735-737, 1986.

KORF, H. W.; SATO, T.; OKSCHE, A. Complex relationships between the pineal organ and the medial habenular nucleus-pretectal region of the mouse as revealed by S-antigen immunocytochemistry. Cell Tissue Res., v. 261, p. 493-500, 1990.

KORF, H. W. et al. Recoverin in pineal organs and retinae of various vertebrate species including man. Brain Res., v. 595, p. 57-66, 1992.

KORF, H. W. The pineal organ as a component of the biological clock. Ann. N. Y. Acad. Sci., v. 719, p. 13-42, 1994.

KORF, H. W.; SCHOMERUS, C.; STEHLE, J. H. Introduction. In: The pineal organ, its hormone melatonin and the photoneuroendocrine system. Adv Anat Embryol Cell Biol. Berlin, Heidelberg: Springer-Verlag, 1998a, v. 146, cap. 1, p. 1-8.

Phylogenetic development and gross anatomy of the pineal complex. In: The pineal organ, its hormone melatonin and the photoneuroendocrine system. Adv Anat Embryol Cell Biol. Berlin, Heidelberg: Springer-Verlag, 1998b, v. 146, cap. 2, p. 9-11.

Pineal cell biology and innervation. In: The pineal organ, its hormone melatonin and the photoneuroendocrine system. Adv Anat Embryol Cell Biol. Berlin, Heidelberg: Springer-Verlag, 1998c, v. 146, cap. 3, p. 13-44.

KURUMADO, K.; MORI, W. Synaptic ribbon in the human pinealocyte. Acta Pathol. Jpn., v. 26, n. 3, p. 381-384, 1976.

LEECH, R.; SHARP, D. J. The role of the posterior cingulate cortex in cognition and disease. Brain, v. 137(Pt 1), p. 12-32, 2014.

LERNER, A. B. et al. Isolation of melatonin, pineal factor that lightens melanocytes. J. Am. Chem. Soc., v. 80, p. 2587, 1958.

LERNER, A. B.; CASE, J. D.; HEINZELMAN, R. V. Structure of melatonin. J. Am. Chem. Soc., v. 81, p. 6084-6085, 1959. 
LEVIN, J. M. et al. Influence of baseline hematocrit and hemodilution on BOLD fMRI activation. Magn. Reson. Imaging, v. 19, p. 1055-1062, 2001.

LEWY, A. J. et al. Light suppresses melatonin secretion in humans. Science, v. 210, p. $1267-1268,1980$.

LEWY, A. J.; CUTLER, N. L.; SACK, R. L. The endogenous melatonin profile as a marker of circadian phase position. J. Biol. Rhythms, v. 14, 227-236, 1999.

LEWY, A., et al. Circadian uses of melatonin in humans. Chronobiol. Int., v. 23, p. 403-412, 2006.

LI, W. et al. Subregions of the human superior frontal gyrus and their connections. Neuroimage, v. 78, p. 46-58, 2013.

LIU, T.; BORJIGIN, J. Free-running rhythms of pineal circadian output. J. Biol. Rhythms, v. 20, p. 430-440, 2005.

LOCKLEY, S.W., et al. Relathionship between melatonin rhythms and visual loss in the blind. J. Clin. Endocrinol. Metab., v. 82, p. 3763-3770,1997.

LOCKLEY, S. W.; BRAINARD, G. C.; CZEISLER, C. A. High sensitivity of the human circadian melatonina rhythm to resetting by short wavelength light. J. Clin. Endocrinol. Metab., v. 88, p. 4502-4505, 2003.

LOGOTHETIS, N. K. et al. Neurophysiological investigation of the basis of the fMRI signal. Nature, v. 412, p. 150-157, 2001.

MACCHI, M. M.; BRUCE, J. N. Human pineal physiology and functional significance of melatonin. Front. Neuroendocrinol., v. 25, p. 177-195, 2004.

MANO, H.; FUKADA, Y. A median third eye: pineal gland retraces evolution of vertebrate photoreceptive organs. Photochem. Photobiol., v. 83, p. 11-18, 2007.

MARCHINI, J. L.; RIPLEY, B. D. A new statistical approach to detecting significant activation in functional MRI. Neuroimage, v. 12, p. 366-380, 2000.

MARONDE, E.; STEHLE, J. H. The mammalian pineal gland: known facts, unknows facets. Trends Endocrinol. Metab. , v. 18, p. 142-149, 2007.

MASSON, G. L. et al. Feedback inhibition controls spike transfer in hybrid thalamic circuits. Nature, v. 417, p. 854-858, 2002.

MATTHEWS, P. M.; JEZZARD, P. Functional magnetic resonance imaging. J. Neurol. Neurosurg. Psychiatry, v. 75, p. 6-12, 2004.

McINTYRE, I. M. et al. Human melatonin suppression by light is intensity dependente. J Pineal Res., v. 6, p. 149-156,1989. 
McMULLAN, C. J. et al. Melatonin secretion and the incidence of type 2 diabetes. JAMA., v. 309, p. 1388-1396, 2013.

McNULTY, J. A.; FOX, L. M. Pinealocyte synaptic ribbons and neuroendocrine function. Microsc. Res. Tech., v. 21, p. 175-187, 1992.

MEGUMI, H.; PANDA, S. The emerging roles of melanopsin in behavioral adaptation to light. Trends Mol. Med., v. 16, p. 435-446, 2010.

MOLLER, M.; BAERES, F. M. M. The anatomy and innervation of the mammalian pineal gland. Cell Tissue Res., v. 309, p. 139-150, 2002.

MOORE, R. Y. Neural control of the pineal gland. Behav. Brain Res., v. 73, p. 125130, 1996.

NADAKAVUKAREN, M. J.; BUCANA, C.D. Cone-like structure in the pineal gland of the hamster. J. Submicrosc. Cytol., v. 12, p. 691-693, 1980.

NORRIS, D. G. Principles of magnetic resonance assessment of brain function. J. Magn. Reson. Imaging, v. 23, p. 794-807, 2006.

OKSCHE, A. Survey of the development and comparative morphology of the pineal organ. Prog. Brain Res., v. 10, p. 3-29, 1965.

PANDI-PERUMAL, S. R. et al. Melatonin: nature's most versatile biological signal? FEBS J., v. 273, p. 2813-2838, 2006.

PAULING, L.; CORYELL, C. D. The magnetic properties and structure of hemoglobina, oxyhemoglobin and carbonmonoyhemoglobin. Proc. Natl. Acad. Sci. U.S.A., v. 22, p. 201-216, 1936.

PAUL, P. et al. Characterization of $2-\left[{ }^{125} \mid\right]$ iodomelatonin binding sites in Syrian hamster peripheral organs. J. Pharmacol. Exp. Ther., v. 290, p. 334-340, 1999.

PEARSON, J. M. et al. Posterior cingulate cortex: adapting behaviour to a changing world. Trends Cogn. Sci., v. 15, p. 143-151, 2011.

PHANSUWAN-PUJITO, P.; MOLLER, M.; GOVITRAPONG, P. Cholinergic innervation and function in the mammalian pineal gland. Microsc. Res. Tech., v. 46, p. 281-295, 1999.

QUAY, W. B. Circadian and estrous rhythms in pineal melatonin and 5-hydroindole3-indole acetic acid. Proc. Soc. Exp. Biol. Med., v. 115, p. 710-714, 1964.

RAICHLE, M. E.; MINTUN, M. A. Brain work and brain imaging. Annu. Rev. Neurosci., v. 29, p. 449-476, 2006.

RAICHLE, M. E. A brief history of human brain mapping. Trends in Neurosci., v. 32, p.118-126, 2008. 
. Two views of brain function. Trends Cogn. Sci., v. 14, p. 180-190, 2010.

RAMSEY, N. F.; HOOGDUIN, H.; JANSMA, J. M. Functional MRI experiments: acquisition, analysis and interpretation of data. Eur. Neuropsychopharmacol., v. 12, p. 517-526, 2002.

REA, M. et al. A model of phototransduction by the human circadian system. Brain Res. Brain Res. Rev., v. 50, p. 213-228, 2005.

REITER, R. J. et al. Circadian mechanisms in the regulation of melatonin synthesis: disruption with light at night and the pathophysiological consequences. J. Exp. Integr. Med., v. 1, p. 13-22, 2011.

REITER, R. J. et al. Melatonin and stable circadian rhythms optimize maternal, placental and fetal physiology. Hum. Reprod. Update, v. 20, p. 293-307, 2014.

REUSS, S. T. et al. Different types of magnetically sensitive cells in the rat pineal gland. Neurosci. Lett., v. 40, p. 23-26, 1983.

REUSS, S. T. Pineal ribbon synapses: regulated by the gland's central innervation. Neuro Endocrinol. Lett., v. 31, p. 761-765, 2010.

ROSAZZA, C.; MINATI, L. Resting-state brain networks: literature review and clinical applications. Neurol. Sci., v. 32, p. 773-785, 2011.

ROSEN, L. et al. A $0.5 \mathrm{G}, 60 \mathrm{~Hz}$ magnetic field suppresses melatonin production in pinealocytes. Bioelectromagnetics, v. 19, p. 123-127, 1998.

SANCHEZ-BARCELO, E. J. et al. Melatonin-estrogen interactions in breast cancer. J. Pineal Res., v. 38, p. 217-222, 2005.

SANTHI, N., et al. The spectral composition of evening light and individual differences in the suppression of melatonin and delay of sleep in humans. $\mathbf{J}$ Pineal Res., v. 53, p. 47-59, 2012.

SAVASKAN, E. et al. Reduced hippocampal $\mathrm{MT}_{2}$ melatonin receptor expression. In Alzheimer disease. J. Pineal Res., v. 38, p. 10-16, 2005.

SCHOMERUS, C.; RUTH, P.; KORF, H. W. Photoreceptor-specific proteins in the mammalian pineal organ: immunocytochemical data and function considerations. Acta Neurobiol. Exp., v. 54 (Suppl.), p. 9-17, 1994.

SCHIFFMAN, J. S. et al. Effect of MR imaging on the normal human pineal body: measurement of plasma melatonin levels. J. Magn. Reson. Imaging, v. 4, p. 7-11, 1994.

SEELEY, W. W., et al. Dissociable intrinsic connectivity networks for salience processing and executive control. J. Neurosci., v. 27, p. 2349-2356, 2007. 
SELMAOUI, B.; TOUITOU, Y. Reproducibility of the circadian rhythms of serum cortisol and melatonin in healthy subjects: a study of three different 24-h cycles over six weeks. Life Sci., v. 73, p. 3339-3349, 2003.

SEMM, P. et al. Effects of an Earth-strength magnetic field on electrical activity of pineal cells. Nature, v. 288, p. 607-608, 1980.

SEXTON, T.; BUHR, E.; GELDER, R. N. V. Melanopsin and mechanisms of nonvisual ocular photoreception. J. Biol. Chem., v. 287, p. 1649-1656, 2012.

SHEHZAD, Z. et al. The resting brain: unscontrained yet reliable. Cereb. Cortex, v. 19, p. 2209-2229, 2009.

SHIDA, C. S.; CASTRUCCI, A. M. L.; LAMY-FREUND, M. T. High Melatonin solubility in aqueous medium. J. Pineal Res., v. 16, p. 198-201, 1994.

SIMON, O. et al. Topographical layout of hand, eye, calculation, and languagerelated áreas in the human parietal lobe. Neuron, v. 33, p. 475-487, 2002.

SKENE, D. J., et al. Effects of light on human circadian rhythms. Reprod. Nutr. Dev., v. 39, p. 295-304, 1999.

SKENE, D. J.; ARENDT, J. Circadian rhythm sleep disorders in the blind and their treatment with melatonin. Sleep Med., v. 8, p. 651-655, 2007.

SMIRNOV, A. N. Nuclear melatonin receptors. Biochemistry (Mosc.), v. 66, p. 1926, 2001.

SMITH, S. M. et al. Advances in functional and structural MR image analysis and implementation as FSL. Neuroimage, v. 23(S1), p. 208-19, 2004.

SMITH, S. M. et al. Correspondence of the brain's functional architecture during activation and rest. Proc. Natl. Acad. Sci. U.S.A., v. 106, p. 13040-13045, 2009.

STEHLE, J. H. et al. A survey of molecular details in the human pineal gland in the light of phylogeny, structure, function and chronobiological diseases. J. Pineal Res., v. 51, p. 17-43, 2011.

STEVENS, W. D.; BUCKNER, R. L.; SCHATER, D. L. Correlated low-frequency BOLD fluctuations in the resting human brain are modulated by recente experience in category-preferencial visual regions. Cereb. Cortex, v. 20, p. 1997-2006, 2010.

TAPP, E.; HUXLEY, M. The histological appearance of the human pineal gland from puberty to old age. J. Pathol., v. 108, p. 137-144, 1972.

THAPAN, K.; ARENDT, J.; SKENE, D. J. An action spectrum for melatonina suppression: evidence for a novel non-rod, non-cone photoreceptor system in humans. J. Physiol., v. 535, p. 261-267, 2001. 
TORDJMAN, S. et al. Advances in the research of melatonin in autism spectrum disorders: literature review and new perspectives. Int. J. Mol. Sci., v. 14, p. 2050820542, 2013.

TRICOIRE, $\mathrm{H}$. et al. Melatonin enters the cerebrospinal fluid through the pineal recess. Endocrinology, v. 143, p. 84-90, 2002.

TSANG, A. H.; BARCLAY, J. L.; OSTER, H. Interactions between endocrine and circadian systems. J. Mol. Endocrinol., v. 52, p. R1-16, 2014.

TU, D. C., et al. Physiologic diversity and development of intrinsically photosensitive retinal ganglion cells. Neuron, v. 48, p. 987-999, 2005.

TURATI, A. O. Análise do perfil diário e dos mecanismos de síntese da melatonina pineal em ratos diabéticos por estreptozotocina tratados com insulina. 2013. Dissertação (Mestrado em Fisiologia Humana) - Instituto de Ciências Biomédicas, Universidade de São Paulo, São Paulo, 2013. [83p.]

UCKO, D. A. Química para as ciências da saúde: uma introdução à química geral, orgânica e biológica. São Paulo: Editora Manole, 2. ed., 1992. [646p.]

UZ, T. et al. The regional and cellular expression profile of the melatonin receptor $\mathrm{MT}_{1}$ in the central dopaminergic system. Brain Res. Mol. Brain Res., v. 136, p. 4553, 2005.

VíGH, B. et al. Comparative histology of pineal calcification. Histol. Histopathol., v. 13, p. 851-870, 1998.

VÍGH, B.; VÍGH-TEICHMANN, I. Light- and electron-microscopic demonstration of immunoreactive opsin in the pinealocytes of various vertebrates. Cell Tissue Res., v. 221, p. 451-463, 1981.

. Comparative neurohistology and immunocytochemistry of the pineal complex with special reference to CSF-contacting neuronal structures. Pineal Res. Rev., v. 6, p. 1-65, 1988.

Cytochemistry of CSF-contacting neurons and pinealocytes. Prog. Brain Res., v. 91, p. 299-306, 1992.

- Development of the photoreceptor outer segment-like cilia of the CSFcontacting pinealocytes of the ferret (Putorius furo). Arch. Histol. Cytol., v. 56, n. 5, p. 485-493, 1993.

VÍGH-TEICHMANN, I. et al. GABA-immunoreactive intrinsic and GABAimmunonegative secondary neurons in the cat pineal organ. J. Pineal Res., v. 10, p. 18-29, 1991.

VILLRINGER, A. Physiological changes during brain activation. In: MOONEN, C. T. W.; BANDETTINI, P. A. Functional MRI. New York: Springer, 2000, p. 3-13. 
VOLLRATH, L.; OKSCHE, A. Handbuch der Mikroskopischen Anatomie des Menschen, VI/7, Berlin: Springer-Verlag, p. 12-20, 1981a.

. Handbuch der Mikroskopischen Anatomie des Menschen, VI/7, Berlin: Springer-Verlag, p. 65-66, 1981b.

- Handbuch der Mikroskopischen Anatomie des Menschen, VI/7, Berlin: Springer-Verlag, p. 177-186, 1981c.

- Handbuch der Mikroskopischen Anatomie des Menschen, VI/7, Berlin: Springer-Verlag, p. 186-193, 1981 d.

. Handbuch der Mikroskopischen Anatomie des Menschen, VI/7, Berlin: Springer-Verlag, p. 216-223, 1981 e.

VOLLRATH, L. Functional anatomy of the human pineal gland. In: REITER, R.J. The Pineal Gland. New York: Raven Press, 1984, p. 285-322.

One millisecond of light suffices to suppress nighttime pineal melatonin synthesis in rats. Neurosci. Lett., v. 98, p. 297-298, 1989.

WEAVER, D. R.; REPPERT, S. M. The Mel1a melatonin receptor gene is expressed in human suprachiasmatic nuclei. Neuroreport, v. 8, p. 109-112, 1996.

WEISSKOFF, R. M. Basic theoretical models of BOLD signal change. In: MOONEN, C. T. W.; BANDETTINI, P. A. Functional MRI. New York: Springer, 2000, p. 115123.

WESTBROOK, C.; KAUT, C. Princípios básicos. In:__. Ressonância magnética prática. 2. ed. Tradução de Fernando Diniz Mundim. Revisão técnica de Andrea Ginelli Nardi. Rio de Janeiro: Guanabara Koogan, 2000. Cap. 1, p. 1-11.

WITT-ENDERBY, P. A. et al. Melatonin receptors and their regulation: biochemical and structural mechanisms. Life Sci., v. 72, p. 2183-2198, 2003.

WOOLRICH, M. W. et al. Bayesian analysis of neuroimaging data in FSL. Neuroimage, v. 45, p. S173-186, 2009.

WORLD HEALTH ORGANIZATION. Mental health: new understanding, new hope. Geneva: World Health Organization, 2001. [178 p.]

WU, Y. H. et al. Distribution of $\mathrm{MT}_{1}$ melatonin receptor immunoreactivity in the human hypothalamus and pituitary gland: colocatization of $\mathrm{MT}_{1}$ with vasopressin, oxytocin, and corticotropin-releasing hormone. J. Comp. Neurol., v. 499, p. 897-910, 2006.

WURTMAN, R. J.; AXELROD, J.; BARCHAS, J. D. Age and enzime activity in human pineal. J. Clin. Endocrinol. Metab., v. 24, p. 299-301, 1964. 
ZEITZER, J. M. et al. Sensitivity of the human circadian pacemaker to nocturnal light: melatonina phase resetting and suppression. J. Physiol., v. 526, p. 695-702, 2000. 
APÊNDICE A - Consentimento informado

INSTITUTO DE CIÊNCIAS BIOMÉDICAS DA UNIVERSIDADE DE SÃO PAULO (ICB)/HOSPITAL DAS CLÍNICAS DA FACULDADE DE MEDICINA DA UNIVERSIDADE DE SÃO PAULO (HCFMUSP)

DADOS DE IDENTIFICAÇÃO DO SUJEITO DA PESQUISA:

NOME:

DOCUMENTO DE IDENTIDADE N ${ }^{\circ}$ : SEXO :.$M \square F \square$ DATA NASCIMENTO: I ..l ENDEREÇO:

$\mathrm{N}^{\mathrm{O}}$ : APTO: BAIRRO

CIDADE: CEP:

TELEFONE (S): ).

\section{DADOS SOBRE A PESQUISA}

1. TÍTULO DO PROTOCOLO DE PESQUISA AVALIAÇÃO DA PINEAL HUMANA IN VIVO PELA RESSONÂNCIA MAGNÉTICA FUNCIONAL.

2. PESQUISADOR: Claudia de Queiroz Accioly Constantinides

CARGO/FUNÇÃO: Médica Radiologista, pós-graduanda em Ciências (Neurofisiologia) pelo Instituto de Ciências Biomédicas da USP.

INSCRIÇÃO CONSELHO REGIONAL de MEDICINA № 62285

UNIDADE DO HCFMUSP: Instituto de Radiologia

3. AVALIAÇÃO DO RISCO DA PESQUISA: RISCO MÍNIMO

4. DURAÇÃO DA PESQUISA: 4 anos.

INSTITUTO DE CIÊNCIAS BIOMÉDICAS DA UNIVERSIDADE DE SÃO PAULO (ICB)/HOSPITAL DAS CLÍNICAS DA FACULDADE DE MEDICINA DA UNIVERSIDADE DE SÃO PAULO (HCFMUSP) 
1 - Essas informações estão sendo fornecidas para sua participação voluntária neste estudo, que visa o desenvolvimento de um método para avaliação da função da pineal em seres humanos. 2 - Será realizado o exame de Ressonância Magnética (RM) funcional do crânio sem o uso de contraste endovenoso (este exame é uma forma especial de Ressonância Magnética cerebral, onde será feito o estudo de alguma função do cérebro; por isso é chamado de "funcional"). No dia do exame de RM, antes, durante e após este exame serão colhidas amostras de sangue (por punção periférica de veia do antebraço) para a dosagem de um hormônio que é produzido pela pineal, a melatonina, além de outras substâncias que podem interferir com o sinal da RM funcional (RMf), como a hemoglobina, ou com a produção da melatonina, como TGO, TGP, FA e y-GT (exames para avaliar a função do fígado) e cortisol. A coleta das amostras de sangue prosseguirá até $1 \mathrm{~h} 30 \mathrm{~min}$ após o término do exame de RMf. Os exames de RM serão realizados das $00 \mathrm{~h}$ até $01 \mathrm{~h}$, pois é neste momento do dia em que ocorre uma grande produção do hormônio melatonina pela pineal, ou seja, é um momento em que a pineal está muito ativa. Porém, como o início da produção da melatonina ocorre por volta das 20/21h, será necessário que você chegue ao setor de Ressonância Magnética do HC-FMUSP às $21 \mathrm{~h} 30$, para que sejam feitos os preparativos para o exame e para que tenham início as coletas de amostras de sangue. No mês ou meses que antecedem o exame de RM funcional, será necessário que você realize uma tomografia computadorizada (TC) do crânio sem contraste endovenoso (a duração deste exame é de no máximo de 15 minutos), para termos certeza de que a sua pineal é pouco ou não é calcificada (se a pineal for calcificada, não significa que ela tem algum problema; isto é o seu padrão normal). Se a sua pineal for muito calcificada não será possível a sua participação neste estudo, porque a calcificação na pineal dificulta a análise da mesma na RM. No dia que antecede o exame e no dia do exame de RM você não poderá ingerir café, chá, bebidas alcoólicas e nem poderá fumar, pois estas substâncias interferem com a produção de melatonina (bloqueiam ou reduzem muito a produção deste hormônio). 3 - Cada exame de RM terá duração aproximada de 1 hora. Durante o exame você não poderá se mexer e poderá haver desconforto devido ao ruído do aparelho de $\mathrm{RM}$, o que normalmente é minimizado com o uso de tampões nos ouvidos. Como o 
aparelho de RM é em forma de túnel, você não poderá participar do estudo se sofrer de claustrofobia (aversão ao confinamento ou a lugares fechados). 4 - Trata-se de estudo para testar a possibilidade de avaliarmos a função da pineal humana in vivo. Existem muitos estudos mostrando a correlação entre alterações da função pineal com certas doenças. Hoje em dia, é bastante limitado o estudo da função da pineal humana, sendo necessário o uso de material de autópsia, limitando muito a compreensão sobre este órgão. Por isso, é de grande importância para a compressão de certas doenças e para o tratamento adequado das mesmas, que seja desenvolvido um método para o estudo da função pineal no indivíduo vivo, que dê informações adicionais para serem avaliadas em conjunto com a dosagem da melatonina no sangue. 5 - Em qualquer etapa do estudo você terá acesso aos profissionais responsáveis pela pesquisa para esclarecimento de eventuais dúvidas. O principal investigador é a Dra Claudia de Queiroz Accioly Constantinides, que pode ser encontrada no endereço comercial Av. Antonio Joaquim de Moura Andrade, 265, Vila Nova Conceição, São Paulo, SP, telefone (11) 3050-0602.

6 - É garantida a liberdade da retirada do consentimento a qualquer momento e deixar de participar do estudo. 7 - Direito de confidencialidade - As informações obtidas serão analisadas em conjunto com as de outros voluntários, não sendo divulgada a identificação de nenhum participante. 8 - Direito de ser mantido atualizado sobre os resultados parciais das pesquisas, quando em estudos abertos, ou de resultados que sejam do conhecimento dos pesquisadores.

9 - Despesas e compensações: não há despesas pessoais para o participante em qualquer fase do estudo, incluindo exames. Também não há compensação financeira relacionada à sua participação. Se existir qualquer despesa adicional, ela será absorvida pelo orçamento da pesquisa. 10 - Compromisso do pesquisador de utilizar os dados e o material coletado somente para esta pesquisa.

Acredito ter sido suficientemente informado a respeito das informações que li ou que foram lidas para mim, descrevendo o estudo "AVALIAÇÃO DA PINEAL HUMANA IN VIVO PELA RESSONÂNCIA MAGNÉTICA FUNCIONAL". 
Eu discuti com a Dra ${ }^{a}$. Claudia de Queiroz Accioly Constantinides sobre a minha decisão em participar nesse estudo. Ficaram claros para mim quais são os propósitos do estudo, os procedimentos a serem realizados, seus desconfortos e riscos, as garantias de confidencialidade e de esclarecimentos permanentes. Ficou claro também que minha participação é isenta de despesas e que tenho garantia do acesso a tratamento hospitalar quando necessário. Concordo voluntariamente em participar deste estudo e poderei retirar o meu consentimento a qualquer momento, antes ou durante o mesmo, sem penalidades ou prejuízo ou perda de qualquer benefício que eu possa ter adquirido, ou no meu atendimento neste Serviço.

Assinatura do paciente/representante legal

Data $1 \quad 1$

Assinatura da testemunha

Data $1 /$

para casos de pacientes menores de 18 anos, analfabetos, semi-analfabetos ou portadores de deficiência auditiva ou visual.

(Somente para o responsável do projeto)

Declaro que obtive de forma apropriada e voluntária o Consentimento Livre e Esclarecido deste paciente ou representante legal para a participação neste estudo. 11 
APÊNDICE B - Questionário geral de saúde

Nome:

Idade:

Peso:

Data:

Sofre de alguma doença? ( )Sim ( )Não

Qual(is)?

Está em tratamento médico atualmente? ( )Sim ( )Não

Faz uso de alguma medicação? ( )Sim ( )Não

Qual(is)?

Já esteve internado(a)? ( )Sim ( )Não

Relacionar o motivo e data:-

Já foi operado(a)? ( )Sim ( )Não

Relacionar as cirurgias e datas:

Está grávida? ( )Sim ( )Não

Sofre ou já sofreu de alguma das seguintes doenças?

Problemas cardíacos? ( )Sim ( )Não

Pressão alta? ( )Sim ( )Não

Problemas renais? ( )Sim ( )Não

Problemas gástricos e intestinais? ( )Sim ( )Não

Problemas hepáticos? ( )Sim ( )Não 
Problemas respiratórios? ( )Sim ( )Não

Problemas articulares, reumatismo ou doenças autoimunes? ( )Sim ( )Não

Diabetes? ( )Sim ( )Não

Problemas de tireoide? ( )Sim ( )Não

Dificuldades para dormir? ( )Sim ( )Não

Problemas psiquiátricos? ( )Sim ( )Não

Problemas neurológicos? ( )Sim ( )Não

Caso tenha respondido positivamente a alguma das questões acima, relacione as doenças e datas:

RM:

Tem claustrofobia (medo exagerado de permanecer em locais fechados)? ( )Sim ( )Não

Usa marcapasso? ( )Sim ( )Não

Possui algum clip metálico interno no corpo ou algum tipo de prótese (ouvido, dentes, etc.)? ( )Sim ( )Não

Local:

Já sofreu algum ferimento com faca, serra, farpas metálicas ou arma de fogo?

( )Sim ( )Não

Local:

Hábitos:

É fumante? ( )Sim ( )Não

Qual a quantidade de bebida alcoólica que você ingere em média por semana?

Relacione o tipo de bebida e o número de doses: 
Você trabalha em turnos ou é plantonista? ( )Sim ( )Não

Caso responda afirmativamente, descreva a sua agenda de trabalho:

As informações contidas neste questionário são confidenciais. 
APÊNDICE C - Exemplos de RSN da análise de grupo da condição rspre com 13 sujeitos

\begin{tabular}{|c|c|c|c|c|c|c|c|c|c|c|c|c|}
\hline 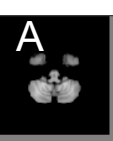 & $\omega$ & $\infty$ & 8 & 3 & 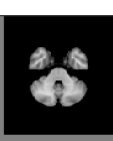 & 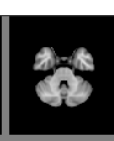 & \% & 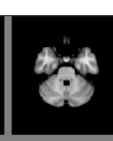 & 粮 & 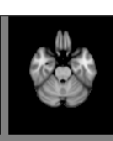 & 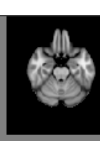 & des \\
\hline 4 & 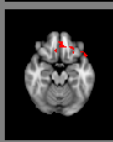 & 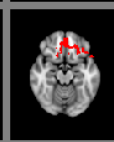 & 数 & 6 & 63 & 9 & 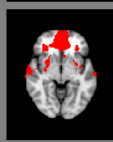 & 3 & 0 & $\%$ & 4 & \\
\hline F & 4 & 6 & 致 & (⿻丷木大 & 4 & (4) & (4) & 积 & 程 & 4 & 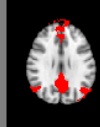 & \\
\hline$d$ & 4 & 1 & 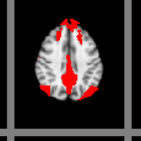 & 4 & (u) & (u) & 8 & 諒 & 4 & 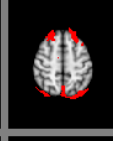 & (t) & \\
\hline 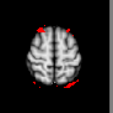 & 楼 & 楼 & 耧 & 昸 & 鈢 & 鍦 & 薪 & 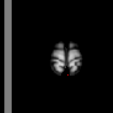 & . & 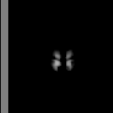 & & \\
\hline 30 & 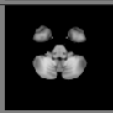 & $\$$ & 8 & 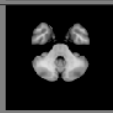 & 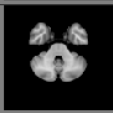 & 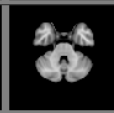 & as & 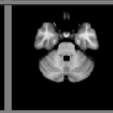 & 20 & 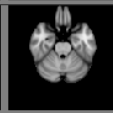 & 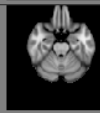 & \\
\hline 1 & (e) & $\Leftrightarrow$ & 6 & 8 & 0 & 8 & (3) & (3) & 6 & 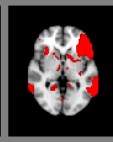 & F & \\
\hline 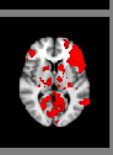 & 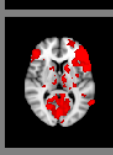 & 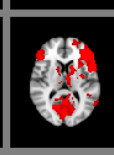 & 到 & M & 喽 & 裹 & H & 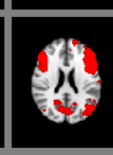 & 13 & 3 & 18 & \\
\hline 3 & (3) & 4 & 3 & 4 & 18 & 13 & 18 & 6 & 4 & 16 & (1) & \\
\hline tis & 鄅 & 4 & 塻 & 辚 & 橉 & 䊤 & 莗 & 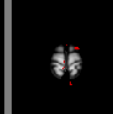 & $w$ & $"$ & & \\
\hline
\end{tabular}

A - DMN; B - rede frontoparietal esquerda e DMN 
APÊNDICE D - Exemplos de RSN da análise de grupo da condição rspos com 13 sujeitos

\begin{tabular}{|c|c|c|c|c|c|c|c|c|c|c|c|c|}
\hline & $\therefore$ & 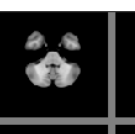 & sis & $\Leftrightarrow$ & \& & 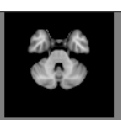 & कs & so & \multicolumn{2}{|c|}{ 徒 } & * & \\
\hline 4 & & B. & 9 & $y$ & 6 & 97 & 次 & 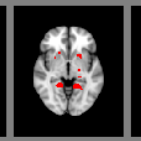 & 3 & 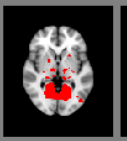 & 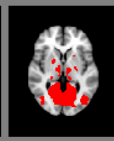 & \\
\hline & 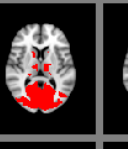 & 稅 & W & 枹 & 镂 & 新 & 新 & 1 & 維 & 4 & 14 & \\
\hline & 6 & 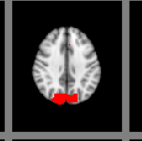 & 4 & (1) & (1) & 1 & (1) & 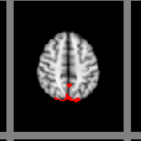 & 秘 & IS & 毁 & \\
\hline & & & & & & & & & & & & \\
\hline & $\Phi$ & $\infty$ & s & \& & 8 & 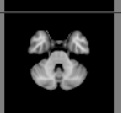 & 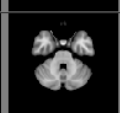 & 8 & 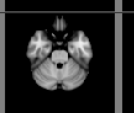 & 4 & $\Leftrightarrow$ & \\
\hline & 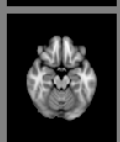 & \% & 8 & 4 & 6 & 6 & 3 & 6 & W & 4 & 模 & \\
\hline & 4 & 1 & 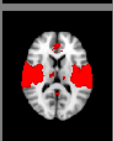 & 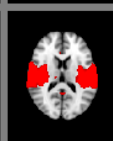 & 锞 & 璘 & 器 & 急 & 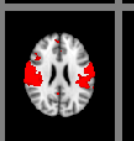 & W & 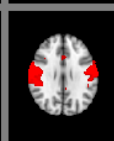 & \\
\hline & at & 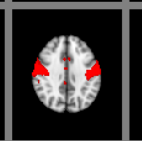 & 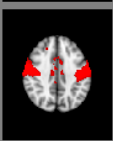 & W & W & 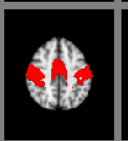 & 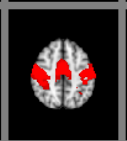 & 3 & X & 3 & & \\
\hline & & & & & & & & & & & & \\
\hline
\end{tabular}

A - rede visual medial; $\mathrm{B}$ - rede auditiva. 
APÊNDICE E - Exemplos de RSN da análise de grupo da condição rspre com 5 sujeitos

\begin{tabular}{|c|c|c|c|c|c|c|c|c|c|c|c|c|}
\hline 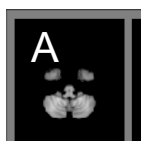 & 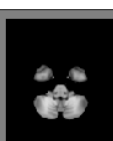 & 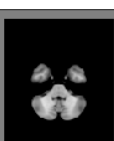 & s & \& & $\Leftrightarrow$ & * & 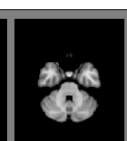 & 极 & *3. & 4 & 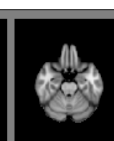 & 4 \\
\hline 5 & (4) & (4) & 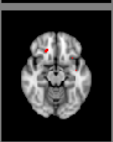 & 8 & 5 & 19 & 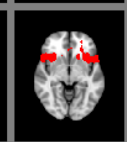 & 4 & \% & \% & 4 & \\
\hline 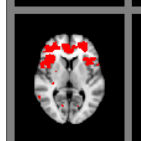 & 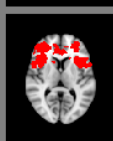 & 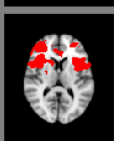 & 鈢 & 䫶 & 繁 & 新 & (3) & 称 & 穏 & 雤 & A & 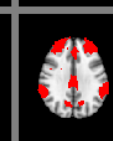 \\
\hline 1 & 13 & 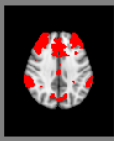 & M & 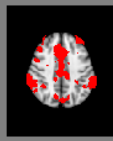 & 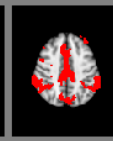 & (1) & (n) & H & 4 & 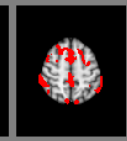 & 雅 & \\
\hline$\sqrt{3}$ & S & 制 & 物 & 䑤 & 能 & 氙 & 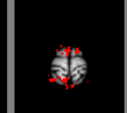 & $\hat{B}$ & $*$ & $" *$ & & \\
\hline 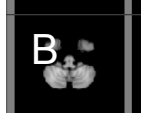 & $\Leftrightarrow$ & 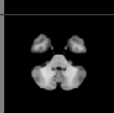 & s & 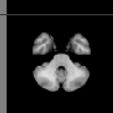 & $\%$ & 8 & sis & s: & 象 & 4 & 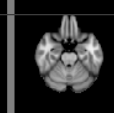 & 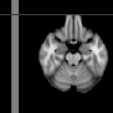 \\
\hline ) & (u) & ty & 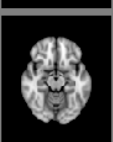 & 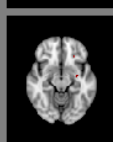 & 4 & (at & 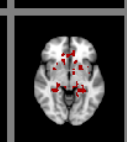 & 4 & 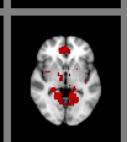 & $\%$ & 3 & $*$ \\
\hline $\mathcal{O}$ & 4 & 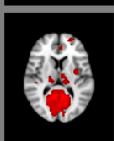 & 6 & 紊 & 6 & S & 数 & 数 & 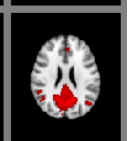 & A & 1 & 1 \\
\hline$y$ & 13 & 13 & 4 & 11 & A & A & it & 绩 & (1) & 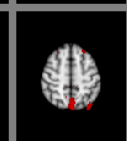 & 龂 & \\
\hline & 楼 & 楼 & 傃 & 鈢 & 跣 & 瞵 & 8 & i & $*$ & & & \\
\hline
\end{tabular}

A - rede do controle executivo; B - DMN. 
APÊNDICE F - Exemplos de RSN da análise de grupo da condição rspos com 5 sujeitos

\begin{tabular}{|c|c|c|c|c|c|c|c|c|c|c|c|c|}
\hline & $\therefore$ & 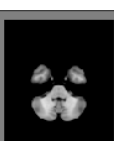 & $\infty$ & is & $\$$ & 30 & 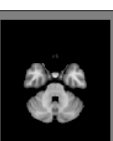 & 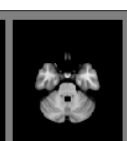 & 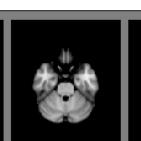 & * & 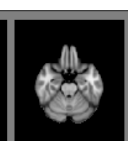 & \\
\hline 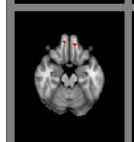 & 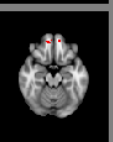 & (4) & 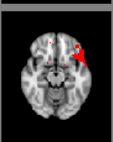 & 8 & 6 & 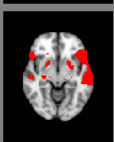 & 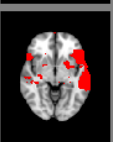 & 3 & 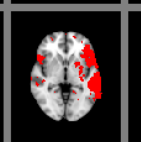 & $\%$ & 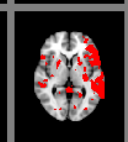 & \\
\hline 林 & 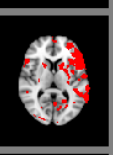 & 嘫 & 新 & 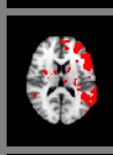 & 秝 & * & 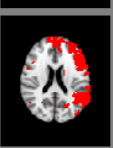 & a & a & 炡 & 4 & 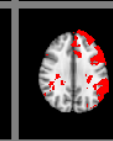 \\
\hline 柆 & 4 & (4) & $M$ & (4) & 保 & 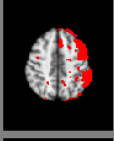 & $\Delta$ & 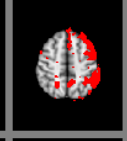 & 9 & 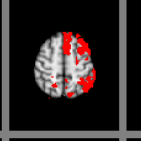 & M & \\
\hline 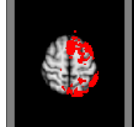 & 4 & 4 & 5 & tit & & & & & $\ddot{*}$ & & & \\
\hline 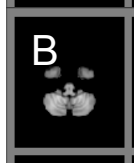 & 8 & $\infty$ & s & 8 & $\infty$ & 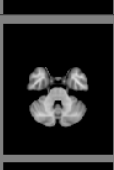 & 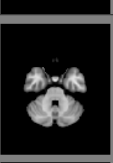 & 8 & 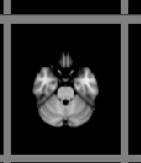 & 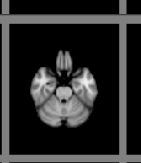 & 4 & \\
\hline$y$ & 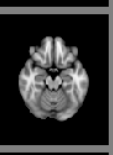 & 数 & 3 & 3 & 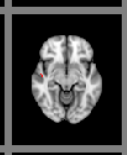 & 4 & 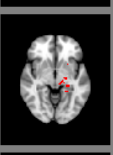 & 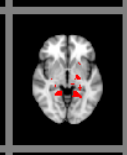 & 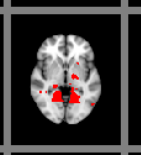 & 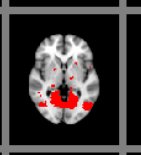 & 4 & \\
\hline 4 & 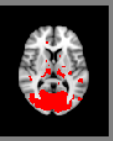 & 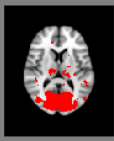 & 魏 & 新 & 㰫 & 䧼 & 稀 & 落 & 趋 & 新 & N & \\
\hline & 13 & 15 & 4 & 的 & $1 \%$ & 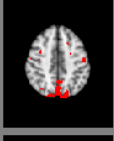 & (1) & (1) & (4) & 1 & 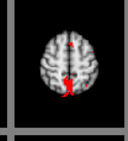 & \\
\hline & 楼 & & & & & & & & & & & \\
\hline
\end{tabular}

A - rede frontoparietal esquerda; B - rede visual medial. 
ANEXO A - SRQ-20

Nome:

Data:

\section{INSTRUÇÕES}

Estas questões relacionam-se a certas dores e problemas que podem ter the incomodado nos últimos 30 dias. Se você acha que a questão se aplica a você e você teve o problema descrito nos últimos 30 dias, responda SIM. Por outro lado, se a questão não se aplica a você e você não teve o problema nos últimos 30 dias, responda NÃO.

Se você está em dúvida sobre como responder a alguma pergunta, por favor, dê a melhor resposta que você puder.

As informações que você irá fornecer neste questionário são de caráter confidencial.

\begin{tabular}{|c|c|c|}
\hline \multirow{2}{*}{1 - Você tem dores de cabeça frequentes? } & SIM & NÃO \\
\hline & & \\
\hline 2 - Você tem falta de apetite? & & \\
\hline 3 - Dorme mal? & & \\
\hline 4 - Assusta-se com facilidade? & & \\
\hline $5-$ Tem tremores nas mãos? & & \\
\hline 6 - Sente-se nervoso (a), tenso (a) ou preocupado (a)? & & \\
\hline 7 - Tem má digestão? & & \\
\hline 8 - Tem dificuldade de pensar com clareza? & & \\
\hline 9 - Tem se sentido triste ultimamente? & & \\
\hline 10 - Tem chorado mais do que costume? & & \\
\hline $\begin{array}{l}11 \text { - Encontra dificuldades para realizar com satisfação suas atividades } \\
\text { diárias? }\end{array}$ & & \\
\hline 12 - Tem dificuldades para tomar decisões? & & \\
\hline $\begin{array}{l}13 \text { - Tem dificuldades no serviço - seu trabalho é penoso, causa-lhe } \\
\text { sofrimento? }\end{array}$ & & \\
\hline 14 - É incapaz de desempenhar um papel útil em sua vida? & & \\
\hline 15 - Tem perdido o interesse pelas coisas? & & \\
\hline 16 - Você se sente uma pessoa inútil, sem préstimo? & & \\
\hline 17 - Tem tido idéia de acabar com a vida? & & \\
\hline 18 - Sente-se cansado o tempo todo? & & \\
\hline 19 - Você se cansa com facilidade? & & \\
\hline 20 - Tem sensações desagradáveis no estômago? & & \\
\hline
\end{tabular}


ANEXO B - Questionário sobre cronotipo

\section{Instruções}

1. Leia com atenção cada questão antes de responder.

2. Responda todas as questões.

3. Responda as questões em ordem numérica.

4. Cada questão deve ser respondida independentemente das outras; não volte atrás e nem corrija suas respostas anteriores.

5. Para cada questão coloque apenas uma resposta (x); algumas questões têm uma escala, nestes casos coloque $\mathrm{o}(\mathrm{x})$ no ponto apropriado da escala.

6. Responda cada questão com toda honestidade possível. Suas respostas e os resultados são confidenciais.

\section{Questões}

1. Considerando apenas seu bem-estar pessoal e com liberdade total de planejar seu dia, a que horas você levantaria?

$\begin{array}{lllllllllllll}01 & 02 & 03 & 04 & 05 & 06 & 07 & 08 & 09 & 10 & 11 & 12 & 13\end{array}$

$\begin{array}{lllllllllll}14 & 15 & 16 & 17 & 18 & 19 & 20 & 21 & 22 & 23 & 24\end{array}$

2. Considerando apenas seu bem-estar pessoal e com liberdade total de planejar sua noite, a que horas você se deitaria?

$\begin{array}{lllllllllllll}01 & 02 & 03 & 04 & 05 & 06 & 07 & 08 & 09 & 10 & 11 & 12 & 13 \\ 14 & 15 & 16 & 17 & 18 & 19 & 20 & 21 & 22 & 23 & 24 & & \end{array}$

3. Até que ponto você depende do despertador para acordar de manhã?

Nada dependente

Não muito dependente

Razoavelmente dependente

Muito dependente

4. Você acha fácil acordar de manhã?

Nada fácil

Não muito fácil

Razoavelmente fácil

Muito fácil

5. Você se sente alerta durante a primeira meia hora depois de acordar?

Nada alerta 
Não muito alerta

Razoavelmente alerta

Muito alerta

6. Como é seu apetite durante a primeira meia hora depois de acordar?

Muito ruim

Não muito ruim

Razoavelmente ruim

Muito bom

7. Durante a primeira meia hora depois de acordar você se sente cansado?

Muito cansado

Não muito cansado

Razoavelmente em forma

Em plena forma

8. Se você não tem compromisso no dia seguinte e comparando com sua hora habitual, a que horas você gostaria de ir deitar?

Nunca mais tarde

Menos que uma hora mais tarde

Entre uma e duas horas mais tarde

Mais do que duas horas mais tarde

9. Você decidiu fazer exercícios físicos. Um amigo sugeriu o horário das $07 \mathrm{~h}$ às $08 \mathrm{~h}$ da manhã, duas vezes por semana. Considerando apenas seu bem-estar pessoal, o que você acha de fazer exercícios nesse horário?

Estaria em boa forma

Estaria razoavelmente em forma

Acharia isso difícil

Acharia isso muito difícil

10. A que horas da noite você se sente cansado e com vontade de dormir?

$\begin{array}{lllllllll}20 & 21 & 22 & 23 & 24 & 00 & 01 & 02 & 03\end{array}$

11. Você quer estar no máximo de sua forma para fazer um teste que dura duas horas e que você sabe que é mentalmente cansativo. Considerando apenas o seu bem-estar pessoal, qual desses horários você escolheria para fazer esse teste?

Das $08 \mathrm{~h}$ às $10 \mathrm{~h}$ 
Das $11 \mathrm{~h}$ às $13 \mathrm{~h}$

Das $15 \mathrm{~h}$ às $17 \mathrm{~h}$

Das $19 \mathrm{~h}$ às $21 \mathrm{~h}$

12. Se você fosse deitar às $23 \mathrm{~h}$, em que nível de cansaço você se sentiria?

Nada cansado

Um pouco cansado

Razoavelmente cansado

Muito cansado

13. Por alguma razão você foi dormir várias horas mais tarde do que é seu costume. Se no dia seguinte você não tivesse hora certa para acordar, o que aconteceria com você?

Acordaria na hora normal, sem sono

Acordaria na hora normal, com sono

Acordaria na hora normal e dormiria novamente

Acordaria mais tarde do que seu costume

14. Se você tivesse que ficar acordado das $04 \mathrm{~h}$ às $06 \mathrm{~h}$ para realizar uma tarefa e não tivesse compromissos no dia seguinte, o que você faria?

Só dormiria depois de fazer a tarefa

Tiraria uma soneca antes da tarefa e dormiria depois

Dormiria bastante antes e tiraria uma soneca depois

Só dormiria antes de fazer a tarefa

15. Se você tiver que fazer duas horas de exercício físico pesado e considerando apenas o seu bem-estar pessoal, qual desses horários você escolheria?

Das $08 \mathrm{~h}$ às $10 \mathrm{~h}$

Das $11 \mathrm{~h}$ às $13 \mathrm{~h}$

Das $15 \mathrm{~h}$ às $17 \mathrm{~h}$

Das $19 \mathrm{~h}$ às $21 \mathrm{~h}$

16. Você decidiu fazer exercícios físicos. Um amigo sugeriu o horário das $22 \mathrm{~h}$ às $23 \mathrm{~h}$, duas vezes por semana. Considerando apenas seu bem-estar pessoal, o que você acha de fazer exercícios nesse horário?

Estaria em boa forma

Estaria razoavelmente em forma

Acharia isso difícil 
Acharia isso muito difícil

17. Suponha que você possa escolher seu próprio horário de trabalho e que você deva trabalhar cinco horas seguidas por dia. Imagine que seja um serviço interessante e que você ganhe por produção. Qual horário você escolheria para trabalhar? (marque a hora do início e a hora do fim)

$\begin{array}{lllllllllllll}01 & 02 & 03 & 04 & 05 & 06 & 07 & 08 & 09 & 10 & 11 & 12 & 13 \\ 14 & 15 & 16 & 17 & 18 & 19 & 20 & 21 & 22 & 23 & 24 & & \end{array}$

18. A que hora do dia você atinge seu melhor momento de bem-estar?

$\begin{array}{lllllllllllll}01 & 02 & 03 & 04 & 05 & 06 & 07 & 08 & 09 & 10 & 11 & 12 & 13\end{array}$

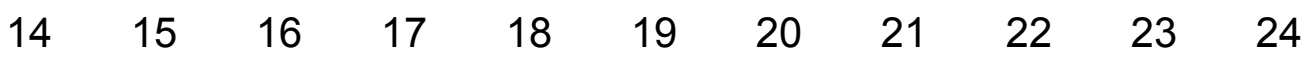

19. Fala-se em pessoas matutinas e vespertinas (as primeiras gostam de acordar cedo e dormir cedo, as segundas de acordar tarde e dormir tarde). Com qual desses tipos você se identifica?

Tipo matutino

Mais matutino que vespertino

Mais vespertino que matutino

Tipo vespertino 
ANEXO C $-1^{\circ}$ Relatório sobre o estimulador luminoso

\section{RELATÓRIO}

Teste do estimulador com LEDs azuis para usar na Resonancia Magnetica

\section{Equipamentos usados:}

- Konica Minolta CS-1000, espectroradiometer (S/N: 18011001)

- Konica Minolta CS-100, chromameter (S/N: 40724024) - portável

Datas dos testes: 19/12/2011 e 24/01/2012

\section{Lugares dos testes:}

- Laboratório da Fotometria do Instituto da Eletrotécnica e Energia da Universidade de São Paulo

- Sala de Resonancia Magnetica, Hospital das Clínicas, USP

\section{Setup}

10 LEDs (LXML-PB01-0030) com comprimento de onda do pico $475 \mathrm{~nm}$ foram colocadas em dois colunas de cinco peças em uma placa eletrónica. Dois difusores dos tipos 3029 (primeiro) e 3026 (segundo) foram colocados em frente dos LEDs para homogenizar a distirbuição da emissão. (Figura 1.)

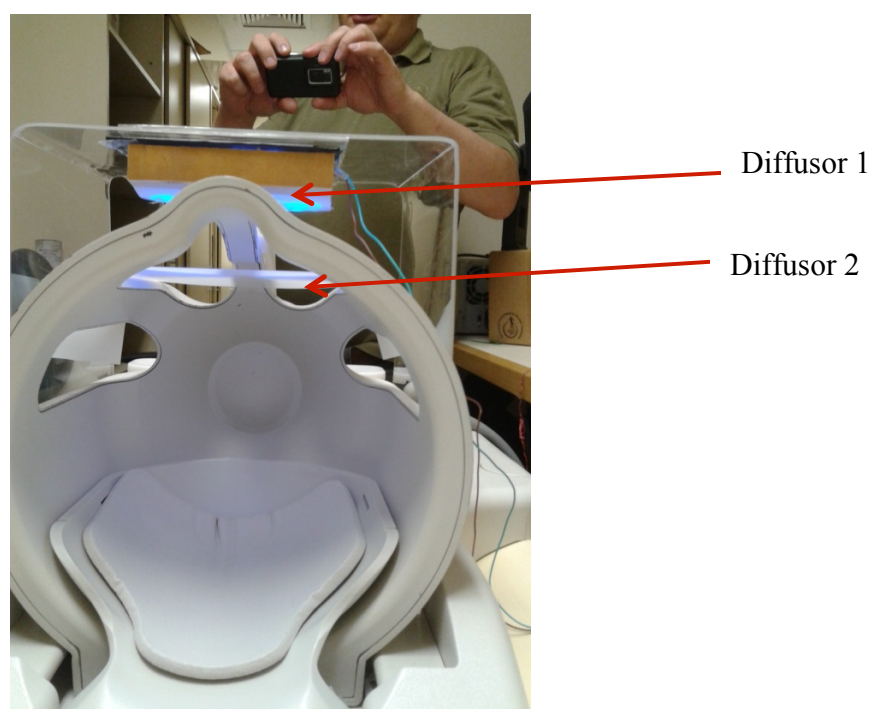

Figura 1 - Montagem do estimulador em cima da bobina 
O setup foi medido fora da bobina com o espetroradiometer no Laboratório da Fotometria da IEE-USP. Os resultados espectrais são mostrados na Figura 2.

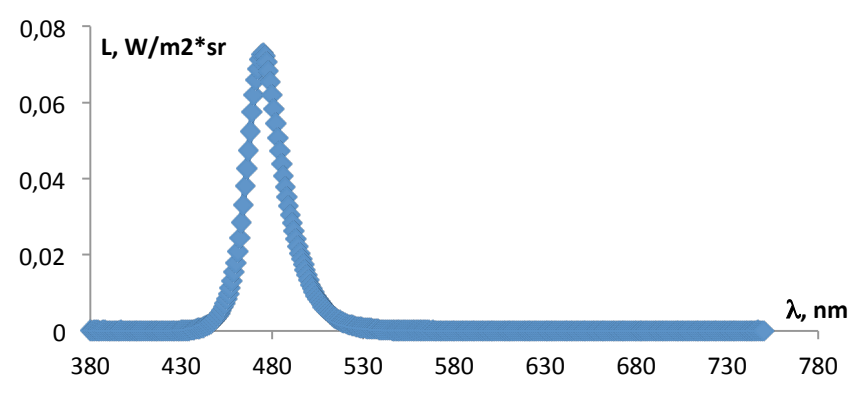

Figura 2 - Radiancia espectral do estimulador

Os resultados espectrais foram usados para calcular o perigo para a retina (Retinal blue light hazard) baseado na norma IEC 62471- CIE S 009:2002 Photobiological safety of lamps and lamp systems. Para fontes usados menos durante menos que $10^{4}$ secundos o valor da exposição chegou até $1719 \mathrm{~J} /\left(\mathrm{m}^{2} \cdot \mathrm{sr}\right)$ calculado com 30 minutos de duração do estímulo. $\mathrm{O}$ limiar desse valor seguindo a norma seria $10^{6} \mathrm{~J} /\left(\mathrm{m}^{2} \cdot \mathrm{sr}\right)$.

O efeito dentro do campo EM foi verificado medindo a reflexão da iluminação de uma montagem branca em 45 graus colocado dentro da bobina. $O$ valor desse (approx. $6.5 \mathrm{~cd} / \mathrm{m}^{2}$ ) foi repetido dentro e fora do campo EM significando que o campo não tinha efeito de curto prazo no estimulador.

$\mathrm{O}$ valor da luminancia medida direto no estimulador perpendicular ao difusor foi maximo $56.2 \mathrm{~cd} / \mathrm{m}^{2}$ (valor corrigido pela calibração do chroma meter).

São Paulo, 28/02/2012

Dr. Balázs Vince Nagy 


\title{
ANEXO D - $2^{\circ}$ Relatório sobre o estimulador luminoso
}

\section{RELATÓRIO NO.2}

Teste do estimulador com LEDs azuis para usar na Resonancia Magnetica

\author{
Equipamentos usados: \\ - Konica Minolta CS-100, chromameter (S/N: 40724024) - portável
}

Data do teste: $19 / 07 / 2012$

Lugar dos teste:

- Hospital das Clínicas, USP

Setup

10 LEDs (LXML-PB01-0030) com comprimento de onda do pico $475 \mathrm{~nm}$ foram colocadas em duas colunas de cinco peças em uma placa eletrónica. Dois difusores dos tipos 3029 (primeiro) e 3026 (segundo) foram colocados em frente dos LEDs para homogenizar a distirbuição da emissão.

$\mathrm{O}$ valor da luminancia medida direto no estimulador perpendicular ao difusor foi maximo em 10 puntos (usando os valores picos em cima de cada LED) tinham uma media de 494.3 \pm 99.8 $\mathrm{cd} / \mathrm{m}^{2}$ (valor corrigido pela calibração do chroma meter). Temos que notar que o valora da luminancia possui efeitos da posição dos lentes e da qualidade e alignamento dos difusores.

Usando os dados espectrais calculamos o perigo para a retina (Retinal blue light hazard) baseado na norma IEC 62471- CIE S 009:2002 Photobiological safety of lamps and lamp systems. Para fontes usados menos durante menos que $10^{4}$ secundos o valor da exposição chegou até $3934 \mathrm{~J} /\left(\mathrm{m}^{2} \cdot \mathrm{sr}\right)$ calculado com 30 minutos de duração do estímulo. O limiar desse valor seguindo a norma seria $10^{6} \mathrm{~J} /\left(\mathrm{m}^{2} \cdot \mathrm{sr}\right)$.

São Paulo, 20/07/2012

Dr. Balázs Vince Nagy 


\section{ANEXO E - $3^{\circ}$ Relatório sobre o estimulador luminoso}

\section{RELATÓRIO NO.3}

\section{Teste do estimulador com LEDs azuis para usar na Resonancia Magnetica}

\section{Equipamentos usados:}

- Konica Minolta CS-100, chromameter (S/N: 40724024) - portável

Data do teste: $13 / 03 / 2013$

\section{Lugar dos teste:}

- Instituto da Psicologia, USP

\section{Setup}

10 LEDs com comprimento de onda do pico $475 \mathrm{~nm}$ foram colocadas em duas colunas de cinco peças em uma placa eletrônica. Dois difusores dos tipos 3029 (primeiro) e 3026 (segundo) foram colocados em frente dos LEDs para homogeneizar a distribuição da emissão.

O valor da luminância medida direto no estimulador perpendicular ao difusor foi máximo em 10 pontos (usando os valores picos em cima de cada LED) tinham a valor máxima de 126 $\mathrm{cd} / \mathrm{m}^{2}$ (valor corrigido pela calibração do chromameter). Temos que notar que o valora da luminância possui efeitos da posição dos lentes e da qualidade e alinhamento dos difusores.

Usando os dados espectrais calculamos o perigo para a retina (Retinal blue light hazard) baseado na norma IEC 62471- CIE S 009:2002 Photobiological safety of lamps and lamp systems. Para fontes usados durante menos que $10^{4}$ segundos o valor da exposição chegou até $1003 \mathrm{~J} /\left(\mathrm{m}^{2} \cdot \mathrm{sr}\right)$ calculado com 30 minutos de duração do estímulo. O limiar desse valor seguindo a norma seria $10^{6} \mathrm{~J} /\left(\mathrm{m}^{2} \cdot \mathrm{sr}\right)$. 
ANEXO $\mathrm{F}-4^{\circ}$ Relatório sobre o estimulador luminoso

RELATÓRIO NO.4

Teste do estimulador com LEDs azuis para usar na Resonancia Magnetica

\section{Equipamentos usados:}

- Konica Minolta CS-100A, chromameter (S/N: 40724024) - portável

Data do teste: $12 / 06 / 2013$

\section{Lugar dos teste:}

- Instituto da Psicologia, USP

\section{Setup e Resultados}

16 LEDs com comprimento de onda do pico $465 \mathrm{~nm}$ foram colocadas em duas colunas de oito peças em uma placa eletrônica. Dois difusores dos tipos 3029 (primeiro) e 3026 (segundo) foram colocados em frente dos LEDs para homogeneizar a distribuição da emissão.

O valor da luminância medida direto no estimulador perpendicular ao difusor foi máximo em 16 pontos (usando os valores picos em cima de cada LED) tinham a valor máxima de $332 \mathrm{~cd} / \mathrm{m}^{2}$ (valor corrigido pela calibração do chromameter).

Usando os dados espectrais simuladas pelas medidas dos LEDs de pico de comprimento de onda igual calculamos o perigo para a retina (Retinal blue light hazard) baseado na norma IEC 62471- CIE S 009:2002 Photobiological safety of lamps and lamp systems. Para fontes usados durante menos que $10^{4}$ segundos o valor da exposição chegou até $5639 \mathrm{~J} /\left(\mathrm{m}^{2} \cdot \mathrm{sr}\right)$ calculado com 30 minutos de duração do estímulo. O limiar desse valor seguindo a norma seria $10^{6} \mathrm{~J} /\left(\mathrm{m}^{2} \cdot \mathrm{sr}\right)$.

São Paulo, 23/12/2013

Dr. Balázs Vince Nagy 